Florida International University FIU Digital Commons

FIU Electronic Theses and Dissertations

University Graduate School

$3-7-2017$

\title{
The Interactions of Relationships, Interest, and Self- Efficacy in Undergraduate Physics
}

Remy Dou

Florida International University, rdou002@fiu.edu

DOI: $10.25148 /$ etd.FIDC001742

Follow this and additional works at: https://digitalcommons.fiu.edu/etd

Part of the Curriculum and Instruction Commons, Longitudinal Data Analysis and Time Series Commons, Multivariate Analysis Commons, Other Physics Commons, $\underline{\text { Science and Mathematics }}$ Education Commons, and the Secondary Education Commons

\section{Recommended Citation}

Dou, Remy, "The Interactions of Relationships, Interest, and Self-Efficacy in Undergraduate Physics" (2017). FIU Electronic Theses and Dissertations. 3228.

https://digitalcommons.fiu.edu/etd/3228

This work is brought to you for free and open access by the University Graduate School at FIU Digital Commons. It has been accepted for inclusion in FIU Electronic Theses and Dissertations by an authorized administrator of FIU Digital Commons. For more information, please contact dcc@fiu.edu. 
FLORIDA INTERNATIONAL UNIVERSITY

Miami, Florida

THE INTERACTIONS OF RELATIONSHIPS, INTEREST, AND SELF-EFFICACY IN UNDERGRADUATE PHYSICS

A dissertation submitted in partial fulfillment of the requirements for the degree of DOCTOR OF PHILOSOPHY

in

CURRICULUM AND INSTRUCTION

by

Remy Dou 
To: Dean Michael R. Heithaus

College of Arts, Sciences and Education

This dissertation, written by Remy Dou, and entitled The Interactions of Relationships, Interest, and Self-Efficacy in Undergraduate Physics, having been approved in respect to style and intellectual content, is referred to you for judgment.

We have read this dissertation and recommend that it be approved.

Zahra Hazari

Haiying Long

Laird Kramer

Eric Brewe, Major Professor

Date of Defense: March 7, 2017

The dissertation of Remy Dou is approved.

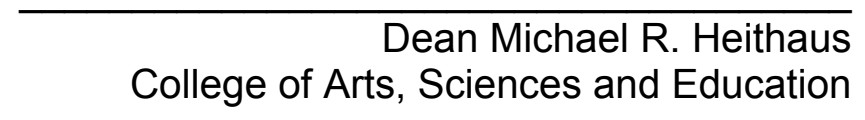

College of Arts, Sciences and Education

Andrés G. Gil
$\begin{array}{r}\text { Vice President for Research and Economic Development } \\ \text { and Dean of the University Graduate School }\end{array}$

Florida International University, 2017 


\section{DEDICATION}

I dedicate this dissertation to my mother, Odalys Dou Del Toro. She steered me away from the many harmful paths I could have followed. She fed me, protected me, and believed in me. She bore my childhood and teenage burdens when others did not. She gave up everything to make sure her three sons had everything. 


\section{ACKNOWLEDGMENTS}

This voyage started over four years ago on the banks of Hope and Trepidation. Had I not sensed the peace of God like a warm ocean breeze promising adventures and success, I would never have set sail. For one, I knew the livelihood of my then five-year-old First Mate was at stake. Who knew what the sea would bring? Who knew what perils, both financial and emotional, we would encounter? But I felt God's assurance that something wonderful lay on the other side of the ocean, so my son and I embarked without looking back to shore.

Fortunately, we never traveled alone. Our family and friends helped us raise the anchor and take up the ropes-specifically my mom, to whom this dissertation is dedicated, my brother and chief counselor, Remy A. Dou, my aunts Leticia and Aimee, my cousin, Maria Karla, my spiritual mentor, Vance Ablott, and his wife, Betsy, my guardian angel, Valentine Kass, and my best friends, Sherwin, Sirac, and Tyler. The help, support, guidance, receptiveness, and prayers of these beautiful people sustained us on this journey.

Along the way I met others who led me past my intellectual comfort zone. They shaped me into the researcher (i.e., adventurer) I am today. First and foremost in this line of people is Eric Brewe, my advisor. Everything about how I approach research and researchers, I learned from him. He reminds me that it is important to be a person of integrity, that others should be treated with respect, and that research should be practical. I hope to have the same heart he has toward his graduate students for the ones I may one day have the pleasure of mentoring. On this note, I cannot go on without acknowledging the other 
members of my committee: Zahra Hazari, Haiying Long, and Laird Kramer. They champion me every week. They brag about me, advise me, encourage me, and make me believe that I am as capable as they say I am. I could not imagine a more human committee.

I hope that the culture of collaboration that exists among the graduate students and postdocs of the STEM Institute continues for years to come. My interactions with these amazing individuals, some of whom have gone on to other destinations, spawned many moments of laughter, friendship, learning, and personal growth that will stay with me forever. These people know exactly who they are, and I hope that our paths cross many more times either in STEM education research or in life.

Halfway through this voyage I met the person who eventually became coCaptain of the ship: Jeannette Coto Dou. We realized our winds blew in the same direction, joined forces, and charted a course together. The duo my son and I were a part of became a trio. For a long time now the weight I carry has felt a lot lighter thanks to my wife. Her unselfishness and positivity reflects one of our family mottos: "There are far, far better things ahead than any we leave behind."

Finally, I want to acknowledge the funders that made this voyage possible: Florida International University, its School of Education, the College of Arts, Sciences, \& Education, the STEM Transformation Institute, the National Science Foundation, and the scholarship sponsors that ensured me smooth sailing. These organizations and people have not only changed the field of STEM education, they have changed lives. 
Of course, there are dozens of others who have also contributed to me and to this work, big and small, directly and indirectly. May this short section be a memorial of gratitude to those not explicitly mentioned. 


\section{ABSTRACT OF THE DISSERTATION \\ THE INTERACTIONS OF RELATIONSHIPS, INTEREST, AND SELF-EFFICACY \\ IN UNDERGRADUATE PHYSICS}

by

Remy Dou

Florida International University, 2017

Miami, Florida

Professor Eric Brewe, Major Professor

This collected papers dissertation explores students' academic interactions in an active learning, introductory physics settings as they relate to the development of physics self-efficacy and interest. The motivation for this work extends from the national call to increase participation of students in the pursuit of science, technology, engineering, and mathematics (STEM) careers. Self-efficacy and interest are factors that play prominent roles in popular, evidence-based, career theories, including the Social cognitive career theory (SCCT) and the identity framework. Understanding how these constructs develop in light of the most pervasive characteristic of the active learning introductory physics classroom (i.e., peer-to-peer interactions) has implications on how students learn in a variety of introductory STEM classrooms and settings structured after constructivist and sociocultural learning theories.

I collected data related to students' in-class interactions using the tools of social network analysis (SNA). Social network analysis has recently been shown to be an effective and useful way to examine the structure of student 
relationships that develop in and out of STEM classrooms. This set of studies furthers the implementation of SNA as a tool to examine self-efficacy and interest formation in the active learning physics classroom. Here I represent a variety of statistical applications of SNA, including bootstrapped linear regression (Chapter 2), structural equation modeling (Chapter 3), and hierarchical linear modeling for longitudinal analyses (Chapter 4).

Self-efficacy data were collected using the Sources of Self-Efficacy for Science Courses - Physics survey (SOSESC-P), and interest data were collected using the physics identity survey. Data for these studies came from the Modeling Instruction sections of Introductory Physics with Calculus offered at Florida International University in the fall of 2014 and 2015. Analyses support the idea that students' perceptions of one another impact the development of their social network centrality, which in turn affects their self-efficacy building experiences and their overall self-efficacy. It was shown that unlike career theories that emphasize causal relationships between the development of selfefficacy and the subsequent growth of student interest, in this context student interest takes precedence before the development of student self-efficacy. This outcome also has various implications for career theories. 


\section{TABLE OF CONTENTS}

CHAPTER

PAGE

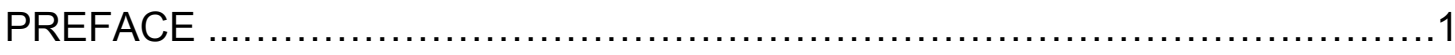

CHAPTER 1 INTRODUCTION ................................................. 4

1.1. Advancing the Current State of Knowledge in the Field ................4

1.2. Self-Efficacy in Career Decision-Making: Overview .......................5

1.2.1. Undergraduate Physics Self-Efficacy ........................ 7

1.2.2. Self-Efficacy and Interest in Career Decision-Making .........9

1.2.3. Academic Social Interactions and Self-Efficacy

Development ...............................................

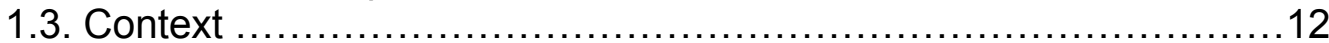

1.3.1. Florida International University ..........................12

1.3.2. Modeling Instruction Introductory Physics ..................12

1.4. Chapter Descriptions: Overview of Three Studies .....................14

1.4.1. Chapter 2: Examining Changes in Students' Physics Self-

Efficacy Through a Social Networks Lens ...................14

1.4.2. Chapter 3: The Development of Interest, Self-Efficacy, and Student Networks in Undergraduate Physics Courses .......18

1.4.3. Chapter 4: Development of Student Centrality in a Highly Interactive Introductory Physics Classroom ......................22

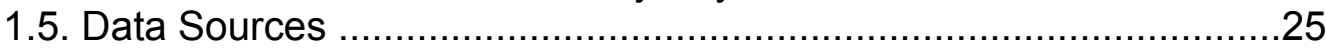

1.6. Brief Dissemination Plan for This Research Including Potential

Scholarly Journals to Publish the Research ................................26

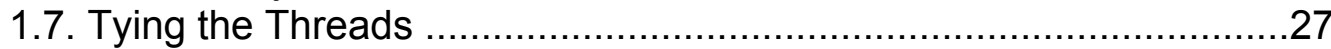

1.8. A Few Words About My Personal Motivation ..................................28

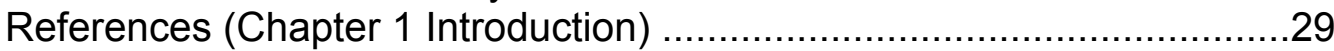

CHAPTER 2 BEYOND PERFORMANCE METRICS: EXAMINING A DROP

IN STUDENTS' PHYSICS SELF-EFFICACY THROUGH A

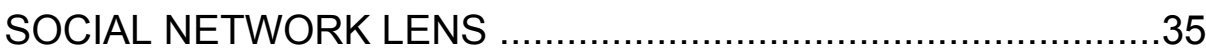

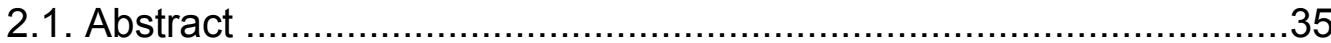

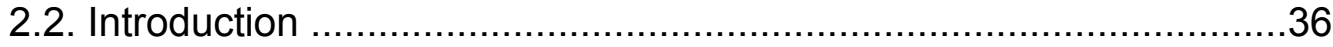

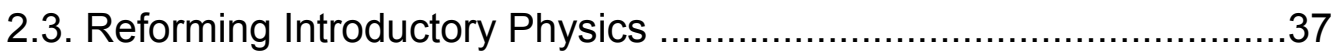

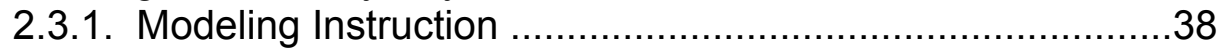

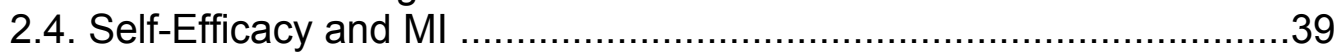

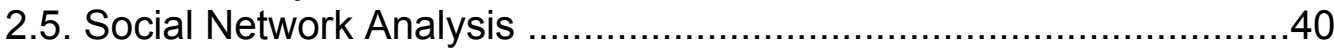

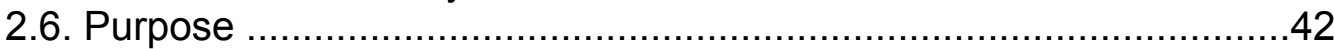

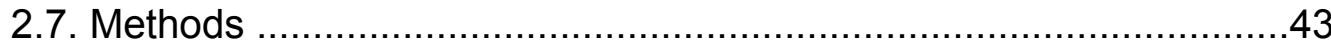

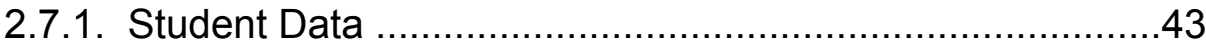

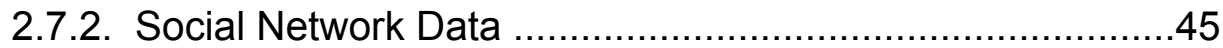

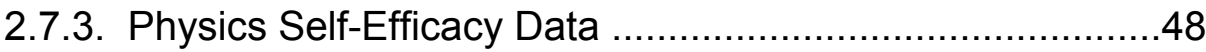

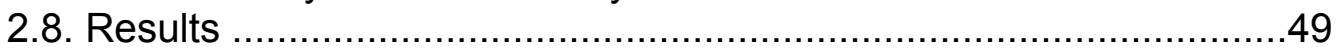


2.8.1. Diagnosing Changes in Self-Efficacy ..............................49

2.8.2. Measuring Social Interactions ......................................51

2.8.3. Bootstrapped Linear Regressions ...................................53

2.8.4. Examining Other Relevant Variables ………...................55

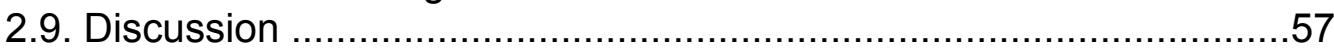

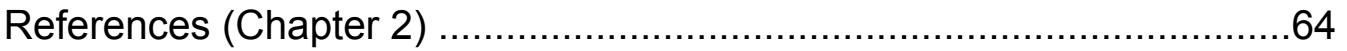

CHAPTER 3 THE RISKS WE TAKE: UNDERSTANDING THE DEVELOPMENT OF INTEREST, SELF-EFFICACY, AND STUDENT NETWORKS IN REFORMED UNDERGRADUATE

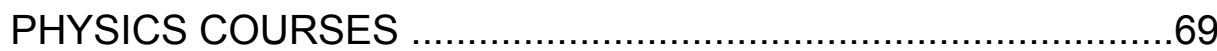

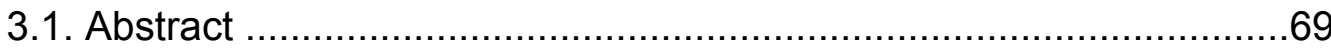

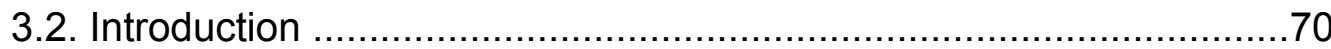

3.3. Overlaps in Career Theories: SCCT and Identity ..........................72

3.4. Self-Efficacy and Interest ....................................................... 76

3.5. Self-Efficacy in the Active learning Physics Classroom ....................77

3.5.1. The Modeling Instruction Curriculum ...............................78

3.6. The Role of Student Interactions in Physics Self-Efficacy Formation

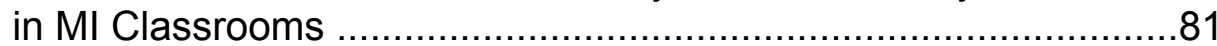

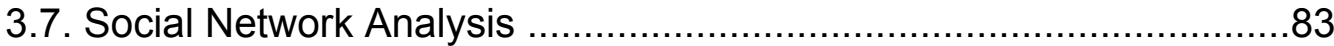

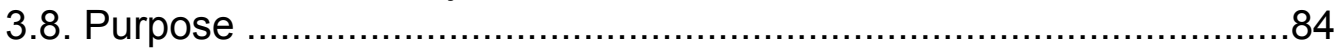

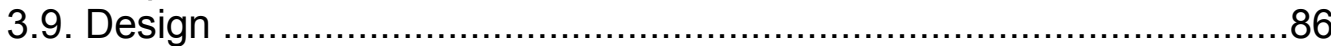

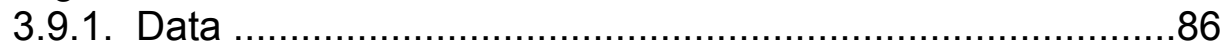

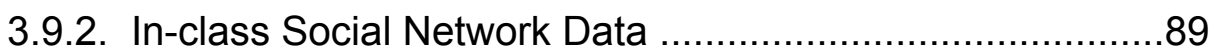

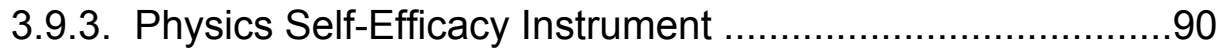

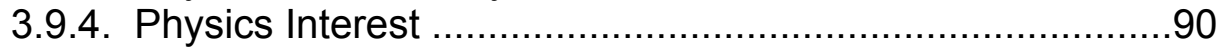

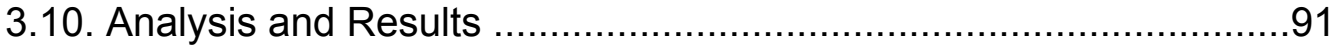

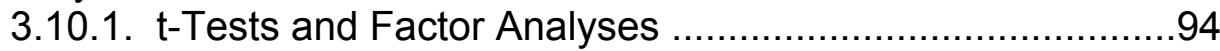

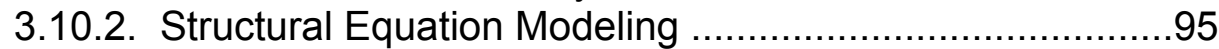

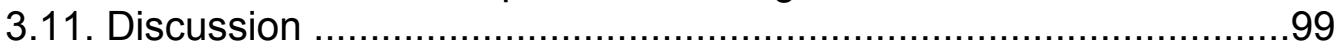

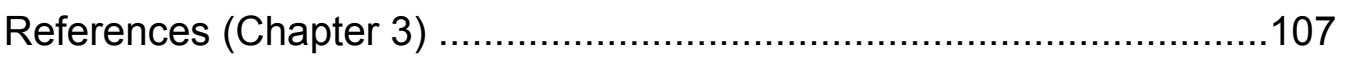

CHAPTER 4 LONGITUDINAL ANALYSIS OF STUDENTS' SOCIAL POSITIONING IN AN ACTIVE LEARNING INTRODUCTORY PHYSICS CLASSROOM …......................................................115

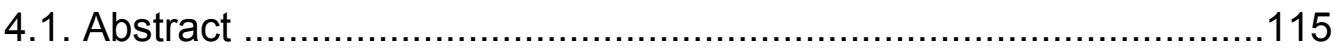

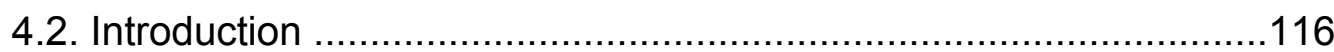

4.3. Social Network Development as a Factor of Classroom Success ..117

4.4. Centrality and Social Capital ................................................... 118

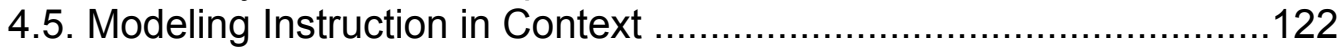

4.6. Examining Students' Centrality Development ..............................125

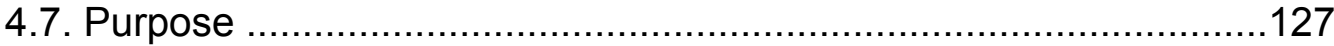

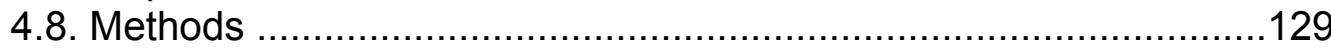

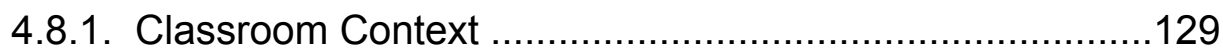

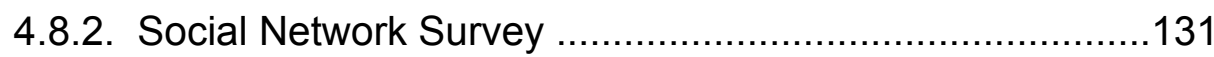


4.8.3. Calculating inDegree and outDegree

132

4.8.4. Using HLM in Longitudinal Data Analysis ......................134

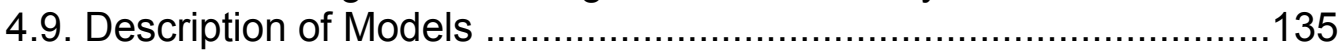

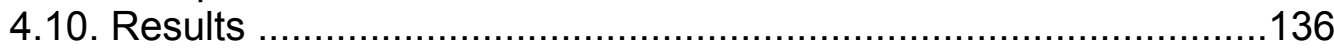

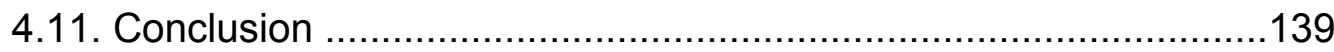

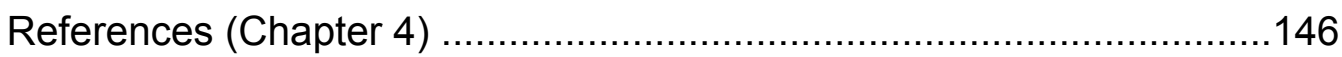

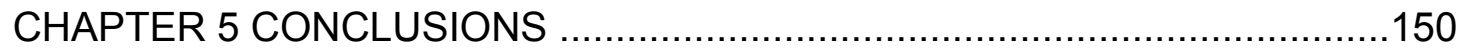

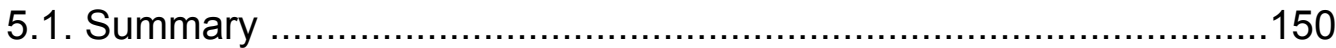

5.2. Future Directions in Active Learning Frameworks: Learning as

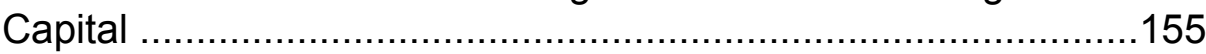

5.3. Directions for Future Work .......................................................158

5.4. Implications of This Research For the Teaching Enterprise ...........159

5.7. Final Remarks: Focusing on Active Learning Environments ...........161

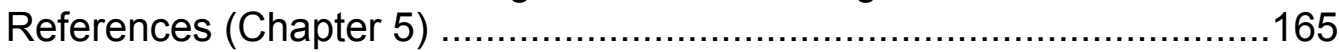

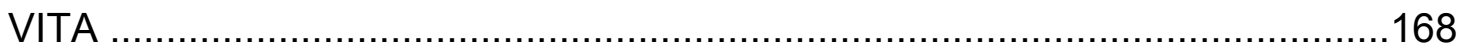




\section{LIST OF TABLES}

TABLE

PAGE

1. Changes in the Sources of Self-Efficacy Scores ........................................51

2. Models Using Network Variables Predicting Post-Self-Efficacy Scores ...... 56

3. Gender-based comparisons of network centrality ....................................57

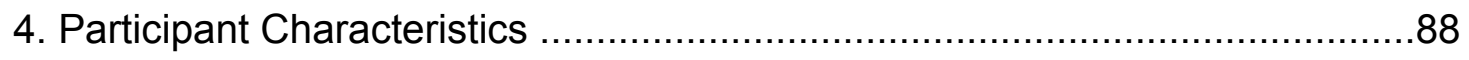

5. Summary of student responses to surveys ….......................................... 


\section{LIST OF FIGURES}

FIGURE

PAGE

1. Model of Self-Efficacy Development in Active-Learning Environments ..........15

2. Cross-sectional Mediated Model of Self-Efficacy, Interest, and Centrality .....20

3. Longitudinal Mediated Model of Self-Efficacy, Interest, and Centrality ..........21

4. Contrasting Academic Interactions Between Students in Physics Courses ...23

5. Sociogram of students in the Fall $2014 \mathrm{Ml}$ course survey, first ....................24

6. Sociogram of students in the Fall $2014 \mathrm{Ml}$ course survey, second ................24

7. Sociogram of students in the Fall $2014 \mathrm{MI}$ course survey, third ....................24

8. Sociogram of students in the Fall $2014 \mathrm{Ml}$ course survey, fourth ..................24

9. Model of Self-Efficacy Development in Active-Learning Environments ..........43

10. Combined student network in the Ml course for Fall $2014 \ldots \ldots \ldots \ldots \ldots \ldots \ldots \ldots \ldots . . .53$

11. Model of SCCT adapted from Lent et al. (2003) ......................................73

12. Model of the identity framework adapted from Godwin et al. (2016) ............74

13. General Model of Interactions of Self-Efficacy, Interest, \& Centrality ............86

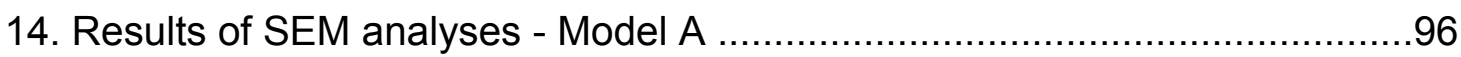

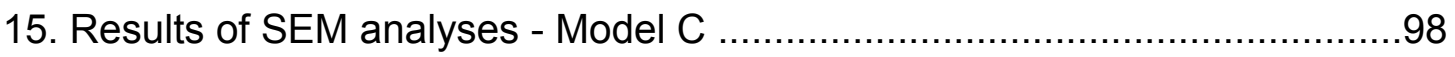

16. Comparison of Three Models ……….....................................................101

17. Example Network to Illustrate InDegree and OutDegree ........................133

18. Pattern of quadratic growth of inDegree centrality.................................137

19. Pattern of quadratic growth of outDegree centrality …...........................138 


\section{PREFACE}

The implementation of active learning environments across science, technology, engineering, and mathematics (STEM) fields has garnered attention from education researchers across the country. Their work has revealed with strong significance the advantage of active learning strategies over traditional, lecture-based pedagogies (Freeman et al., 2014). Active learning STEM courses yield positive outcomes in students' conceptual understanding and exam scores. These benefits have been posited as part of the solution to our country's shortage of STEM majors and professionals (National Research Council [NRC], 2010). The shortage of STEM professionals is particularly pertinent to the field of physics where fewer women, African Americans, and Hispanics graduate than what is commensurate with their population sizes (NRC, 2013). Yet, much of the research in STEM education centers on academic performance (e.g., exam scores, course grades, concept inventory evaluations), which explains only a portion of the variance in career decision-making around STEM. Constructs, like self-efficacy and interest, have been shown to be robust and highly predictive in the formation of students' career pathways (Hazari, Sonnert, Sadler, \& Shanahan, 2010; Lent, Brown, \& Hackett, 1994).

In the chapters below I describe my dissertation research, which aims to increase our understanding of student self-efficacy and interest formation in active learning introductory physics courses taught using the Modeling Instruction (MI) curriculum. Active learning courses by definition place more emphasis on peer-to-peer interactions than do traditional pedagogies (e.g., lecture-based 
teaching). The prevalence of these interactions leads to the formation of larger and more intricate social networks than those found in lecture-based courses (Brewe, Kramer, \& O'Brien, 2010). Specifically, the work presented here is part of an examination of how in-class student networks, quantified using social network analysis (SNA), relate to undergraduate students' physics self-efficacy and interest formation in light of demographic characteristics, such as gender and race/ethnicity, as well as major.

Employing a "collected papers" dissertation format, I describe three connected studies and their outcomes:

Chapter 2 - an examination of the change in student self-efficacy and the sources of self-efficacy, and the utility of centrality (i.e., position in a social network) to predict the variance in these changes;

Chapter 3 - an examination of student centrality and its contribution to the development of physics self-efficacy and interest using structural equation modeling; and

Chapter 4 - a longitudinal exploration of student centrality development.

Chapter 1 sets up an introduction and short description of each study, and Chapter 5 showcases points of overlap between the studies, as well as the implications these have on teaching practices and career theories. Dissemination of this work will contribute to our understanding of how academic interactions in active learning courses shape the factors that promote student retention and 
persistence in STEM. Ultimately, I will use the products of this dissertation and

expertise acquired to promote positive changes in local and federal policy related

to STEM education.

References (Preface)

Brewe, E., Kramer, L. H., \& O'Brien, G. E. (2010). Changing participation through formation of student learning communities. AIP Conference Proceedings, 1289, 85-88. http://doi.org/10.1063/1.3515255

Freeman, S., Eddy, S. L., McDonough, M., Smith, M. K., Okoroafor, N., Jordt, H., \& Wenderoth, M. P. (2014). Active learning increases student performance in science, engineering, and mathematics. Proceedings of the National Academy of Sciences of the United States of America, 111(23), 8410-5. doi:10.1073/pnas.1319030111

Hazari, Z., Sonnert, G., Sadler, P. M., \& Shanahan, M.-C. (2010). Connecting high school physics experiences, outcome expectations, physics identity, and physics career choice: A gender study. Journal of Research in Science Teaching, 47(8), 978-1003. doi:10.1002/tea.20363

Lent, R. W., Brown, S. D., \& Hackett, G. (1994). Toward a unifying social cognitive theory of career and academic interest, choice, and performance. Journal of Vocational Behavior, 45, 79-122.

National Research Council. (2010). Rising above the gathering storm: Revisited. Washington, DC: National Academies Press.

National Research Council. (2013). Adapting to a changing world: Challenges and opportunities in undergraduate physics education. Washington, DC: National Academies Press. 


\section{CHAPTER 1}

\section{INTRODUCTION}

\subsection{Advancing the Current State of Knowledge in the Field}

For the United States, the rate of students seeking and completing STEM degrees lags behind that which would keep this nation competitive in the global economy; the trend strongly resonates in the context of our growing minority populations (National Research Council [NRC], 2010; President's Council of Advisors on Science and Technology [PCAST], 2010). As a result, the implementation of active learning STEM courses has garnered attention from education researchers across the country. Specifically in the arena of physics education, a variety of active learning approaches have led to the reformation of introductory physics courses in colleges and universities. These include Investigative Science Learning Environments (ISLE), Student-Centered Activities for Large Enrollment University Physics (SCALE-UP), Workshop Physics, Tutorials in Introductory Physics, and Modeling Instruction (MI) among others. To various degrees, they have exhibited positive impacts on student learning (Brewe, 2010; Etkina \& Van Heuvelen, 2007; Finkelstein \& Pollock, 2005; Laws, 1997; Robert et al., 2000). Yet, success in physics education, particularly in the realm of career persistence, involves more than just improving learning gains; it requires exploring changes in affective constructs that complement academic performance (NRC, 2012, 2013; PCAST, 2010).

Affective constructs, such as self-efficacy, identity, and interest, are often positively correlated with student outcomes such as academic performance 
(NRC, 2012; Schunk, 2012). Yet, more relevant to career research, these constructs play major roles in students' decision-making process when choosing a profession (Bandura, Barbaranelli, Caprara, \& Pastorelli, 2001; Hazari, Sonnert, Sadler, \& Shanahan, 2010; Lent, Brown, \& Hackett, 1994; Wang, 2013). The constructs' predictive power holds true across global cultures, postulating that self-concepts and personal values matter more in determining whether students foresee themselves in science careers than do performance outcomes (Kjaernsli \& Lie, 2011). Considering the dearth of individuals from underrepresented communities pursuing physical science degrees in comparison to other STEM majors, attention should be paid to these often-overlooked factors (NRC, 2011; National Science Board [NSB], 2014). While focusing on the impact of active learning curricula on academic performance provides valuable support in favor of these types of pedagogies, their possible effect on affective constructs may help researchers better understand why students persist (or do not persist) in a major.

\subsection{Self-Efficacy in Career Decision-Making: Overview}

Of the constructs related to both performance attainment and career choice, self-efficacy plays a unique, well-tested, and meaningfully influential role (Bandura et al., 2001; Dou \& Gibbs, 2013; Hill, Corbett, \& Rose, 2010; Larkin, Lent, \& Brown, 1986; Lent at al., 1994; NRC, 2012; Wang, 2013; Zeldin, Britner, \& Pajares, 2008; Zeldin \& Pajares, 2000). Even while controlling for prior academic attainment, aptitude, and career interest, self-efficacy continues to significantly predict career choices (Lent, Brown, \& Larkin, 1987; Lent, Lopez, \& 
Bieschke, 1993). When comparing self-efficacy to career-choice theories that link students to a vocation depending on their personalities, self-efficacy has greater predictive power for career-choice than personality-based theories (Brown, Lent, \& Larkin, 1989). Students with high self-efficacy regarding tasks related to a field of study will more likely develop interests in, set goals toward, and make positive decisions about careers in that field (Lent et al., 1994); indeed, other factors play a similar role, but few hold the predictive power that self-efficacy does (Larkin et al., 1986; Pajares \& Urdan, 2006).

Bandura (1997) describes self-efficacy as the beliefs individuals have about their capability to complete domain-specific tasks and the outcomes they believe may result from their efforts. He proposed four types of experiences (i.e., sources) contribute to a person's self-efficacy beliefs: mastery experiences, vicarious learning, verbal persuasion, and physiological states (Bandura, 1977). Students' self-efficacy on physics related tasks is influenced by (a) students' past performance on similar tasks (i.e., mastery experiences), (b) observations of peers to whom they relate succeeding or failing at those tasks (i.e., vicarious learning), (c) direct encouragement or discouragement from peers, instructors, and others (i.e., verbal/social persuasion), and (d) the emotional and physiological states of each student at the moment one assesses their selfefficacy or when students think about completing the task in question (i.e., physiological states). Anxiety, depression, or excitations are examples of physiological states that can contribute to students' self-efficacy. 


\subsubsection{Undergraduate Physics Self-Efficacy}

Research studies have reported correlations between self-efficacy and final grade in introductory physics courses, as well as the likelihood of passing the class (Brewe et al., 2010; Fencl \& Scheel, 2005; Lynch, 2010). The same can be said about other introductory courses in STEM fields, including chemistry, biology, and computer science (Askar \& Davenport, 2009; Larose, Ratelle, Guay, Senecal, \& Harvey, 2006; Smist 1993). Not only does physics self-efficacy impact academic performance, but it has also been shown to have a direct correlation with student affect, like motivation in physics courses (Lynch, 2010).

Gender trends have also been reported, some of which are seen not only in self-efficacy as a whole, but also in the sources of self-efficacy. A study of 281 first-year college students who belonged to the same physics cohort revealed that female students reported lower self-efficacy beliefs than their male counterparts (Lindstrom \& Sharma, 2011). Moreover, in this same study, male students who had not taken any high school physics courses had higher selfefficacy than all other groups of students, indicating a gendered overconfidence. Larose et al. (2006) performed a longitudinal study where females who experienced increases in their self-efficacy during and after high school were more likely to report stability in their STEM-related vocational choices. This stability applied even after controlling for high school achievement and socioeconomic status. On the other hand, a decline in self-efficacy had the opposite effect for female students and no effect on male students. In general, men report mastery experiences as the basis for their persistence and ongoing 
achievement (Zeldin, Britner, \& Pajares, 2008). Women in similar contexts, as noted earlier, seem to rely on vicarious learning and verbal persuasion experiences as part of the foundation of their professional success (Zeldin \& Pajares, 2000).

Previous studies on MI have explicitly explored students' self-efficacy (Sawtelle et al., 2012; Sawtelle, Brewe, \& Kramer, 2012). A study by Sawtelle et al. (2012) showed that respondents taking one of several 30-student MI courses at a public research university, regardless of gender, did not exhibit a statistically significant change in overall self-efficacy. When disaggregated by the sources of self-efficacy, the results did reveal an increase for women on the VP subscale. On the other hand, the same study revealed that both male and female students in lecture-based introductory physics courses exhibited a drop in self-efficacy. The drop was observed across all four sources of self-efficacy. These findings align somewhat with findings by Fencl and Scheel (2004) who showed that Calculus-based Physics I courses that employ a mixture of reformed pedagogical approaches, in particular student collaborations, have a stronger positive impact on students' self-efficacy than traditionally taught courses. The positive effect is enhanced for physics majors. Another study by Sawtelle, Brewe, and Kramer (2012) employed logistic regression analysis to show that mastery experiences predict the rate at which male students pass or fail introductory physics, while female students' success depends more on vicarious learning than the other sources of self-efficacy. 


\subsubsection{Self-Efficacy and Interest in Career Decision-Making}

The relationship between interest and self-efficacy has been thoroughly examined in a variety of settings (Bandura, 1993, 1997; Schunk, 2012). More importantly, both of these constructs have been shown to predict career decisionmaking behavior more so than academic achievement (Bandura, 2001). Prominent career theories confirm this. Lent et al.'s (1994) Social cognitive career theory (SCCT) focuses on the mediating role that self-efficacy and vocational outcome expectations play between learning experiences and interest. The SCCT posits that learning experiences contribute to changes in students' self-efficacy and vocational outcome expectations, which in turn, influence students' interests, eventually having effect on students' goals and goal accomplishments. Taking a more identity-based approach, Hazari et al. (2010) have made the case that "performance competence," a construct that shares similarities with self-efficacy, influence students' interest in a particular field, which can then contribute to students' identification with that field. This fieldspecific identity has been shown to predict career choices of physicists and engineers (Hazari et al., 2010; Cass, Hazari, Cribbs, Sadler, \& Sonnert, 2011).

\subsubsection{Academic Social Interactions and Self-Efficacy Development}

Although individuals regulate their self-efficacy internally (Schunk, 2012), some of the experiences that contribute to self-efficacy development result from social behavior. Development of efficacy beliefs, to an extent, relies on social interactions in social settings, both of which are the hallmark of various reformed physics curricula. The basis for this begins with how theory defines vicarious 
learning and verbal persuasion-two of the four established sources of selfefficacy. Vicarious learning and verbal persuasion experiences imply environments where social interactions exist.

Vicarious learning $(\mathrm{VL})$ requires that an individual in question observes another person succeeding or failing at a given task. For this to occur, two or more persons must find themselves in the same space, within reasonable distance to observe one another's performance. While one may argue that this need not occur in physical proximity (e.g., watching videos of someone performing the task), the bulk of formal education environments primarily allow for in-person vicarious learning experiences ${ }^{1}$.

The presence of peers does more than create VL opportunities, it also nurtures threatening or affirming contexts that result in changes to students' overall self-efficacy. These contexts hold particular sway in circumstances where individuals rate their performance by comparing their progress to that of those around them. In the case where a person observes others surpassing his or her performance, that individual has a higher likelihood of feeling less confident about his or her ability to perform the task at hand (Bandura, 1993). Educational settings often place students in situations where they find themselves explicitly or implicitly ranked among their peers according to their academic success. The ranking need not occur publicly or blatantly, but may be perceived by students nevertheless (e.g., a teacher drawing smiley faces on just a subset of graded exams).

\footnotetext{
${ }^{1}$ The context of online education may limit such experiences and render this statement less valid.
} 
Social interactions are also required in circumstances where individuals receive verbal feedback on performance, which may strengthen or undermine their self-efficacy. In general, classroom structures provide a forum for these kinds of verbal persuasion (VP) experiences to take place. Students often receive verbal recognition about their progress from teachers, peers, and on occasion, administrators. On a similar note, the type of emphasis placed on these performance evaluation matters (Schunk, 1983). Feedback that accentuates shortcoming contributes more to the breakdown of efficacy beliefs than feedback that focuses on amount of progress (Dweck, 1975).

Some studies reveal that the socially oriented sources of self-efficacy (i.e., $\mathrm{VL}$ and VP) play a more significant role in the development and sustaining of the efficacy beliefs of women who work in STEM professions (Hill, Corbett, \& St. Rose, 2010). For example, Zeldin and Pajares (2000) interviewed 15 women working in STEM fields where underrepresentation of women persists, which included engineering and computer science. The researchers asked them about their self-beliefs and career history, specifically probing for information about their mathematics efficacy beliefs because of the highly mathematical nature of their professions. The participants reported experiences in line with VL and VP as playing a critical role in their career decision-making process and their persistence in their respective fields. These VL and VP experiences often included the presence of role models and encouragement from teachers. 


\subsection{Context}

\subsubsection{Florida International University}

The three studies presented here took place at Florida International University (FIU). Florida International University is Miami's public, urban research university, which boasts a unique population. The institution educates over 56,000 students, making it one of the largest public universities in the country. Over $60 \%$ of FIU's students identify themselves as "Hispanic," while $13 \%$ identify themselves as "Black," another $12 \%$ as "White," and $13 \%$ as "Other" (State University System of Florida, 2014). FIU is classified as a Hispanic Serving Institution (HSI), offering critically important services to the members of its community, who are primarily Hispanic. Considering recent national calls for a greater number of STEM majors, many of which include an emphasis on recruiting from underrepresented groups (NRC, 2011; PCAST, 2010), it is relevant that no other university awards more STEM bachelor's degrees to underrepresented minorities than FIU (Office of Governmental Relations, 2014).

\subsubsection{Modeling Instruction Introductory Physics}

Of the existing, reformed instructional approaches directed at introductory university physics curricula (with Calculus), the current research focuses on Modeling Instruction (MI), which differs significantly from the more common, lecture-based introductory-course format. The MI introductory physics courses (referred to as "Ml" from here on out) tend to support low student-instructor ratios, short or non-existent lectures, high numbers of solicited student-student and student-instructor interactions, and classroom settings designed to promote 
small group formation and collaborative learning. Students explore physical phenomena and solve classroom assignments in small groups, use various representations to summarize their conclusions on a white board, and come together during a "Board Meeting" to share and evaluate group solutions. Board Meetings—a characteristic feature of $\mathrm{Ml}$-reflect the highly social nature of learning that takes place (Brewe, 2008).

The originators of Ml developed the approach to promote student engagement for the purpose of mediating the construction of physics knowledge (Hestenes, 1987). The curriculum highlights the dialectical process where individuals reconcile their naïve ideas with concepts presented in the curriculum, which in this case occurs via experimentation and argumentation-the latter better described as social exchanges of ideas. Further development of MI by Desbien (2002), as well as Brewe (2008), cemented the inherently social nature of knowledge construction espoused by this physics teaching method. Grouping students, encouraging them to develop physics models together, and then having them relate group results to a larger classroom setting provides participants with opportunities to create knowledge and shared meanings/interpretations via verbal exchanges. This relationship between the building of knowledge and discussion is summarized in a common motto of the MI process: learning and social interactions are not mutually exclusive (Bruun and Brewe, 2013). Additionally, learning occurs within a physics context. Students in this active learning environment employ a variety of physics-relevant tools, including language, to develop representations of physics concepts. 


\title{
1.4. Chapter Descriptions: Overview of Three Studies
}

\subsubsection{Chapter 2: Examining Changes in Students' Physics Self-}

\author{
Efficacy Through a Social Networks Lens ${ }^{2}$
}

\section{Key Research Questions}

1. Do students in Ml courses experience statistically significant changes in physics self-efficacy as measured by pre- and post- scores on a selfefficacy in physics instrument (i.e., Sources of Self-Efficacy in Science Courses - Physics)?

2. Do students in the Ml course experience statistically significant changes in physics self-efficacy scores when disaggregated by the four sources of self-efficacy?

3. How are social interactions as measured by student network centrality in the MI classroom associated with changes in students' self-efficacy?

4. Do other variables historically associated with student success in physics, such as gender, major, and race/ethnicity, contribute to the variance in students' post- self-efficacy scores when controlling for pre- scores?

My first study aimed to more carefully examine both changes in students' self-efficacy in a larger MI course, as well as tested the belief that the prevalent social interactions that occur in these courses have a notable relationship with self-efficacy development. The approach did not compare MI to lecture-based sections, but rather offered a more introspective look at the affective outcomes of MI as an active learning curriculum. Using self-efficacy theory as a guide, I suggested that individual students come into class with certain internal expectations about their performance in the $\mathrm{Ml}$ course. These expectations may

\footnotetext{
2 This study was published in Physics Education Research-Physical Review. While I performed the preponderance of the work, the following co-authors of the published study provided much input: my major professor, Eric Brewe, a committee member, Laird Kramer, the course instructor, Geoff Potvin, an FIU postdoc, Justyna P. Zwolak, and an FIU graduate student, Eric Williams.
} 
differ according to each source of self-efficacy. For example, a student may have high expectation of receiving praise from others (i.e., VP) but lower expectations of learning from peers (i.e., VL). Classroom experiences will influence students' expectations along the four sources of self-efficacy (see Figure 1). I paid particular attention to VP and VL because the social nature of the MI curriculum led me to hypothesize heightened prevalence for these events. I expected these types of experiences influence overall student self-efficacy at the end of the semester.

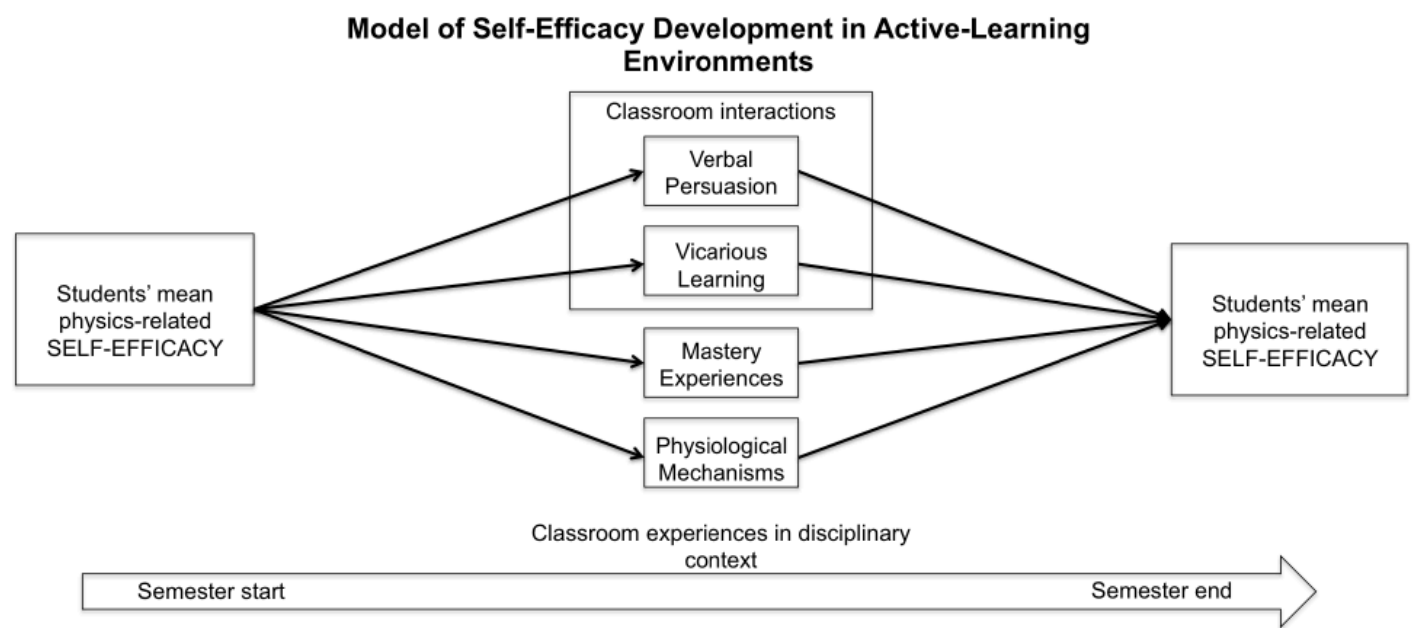

Figure 1. Model of Self-Efficacy Development in Active-Learning Environments.

Given the increases of student conceptual understanding in MI courses, the social nature of self-efficacy development, and the highly interactive structure of MI courses, I hypothesized that students would exhibit a positive shift in their efficacy beliefs related to physics and the MI classroom even when controlling for variables associated with self-efficacy development. Furthermore, I used students' in-class social networks as a proximal measure of types and 
abundance of potential VL and VP-related experiences that may play a role in mediating self- efficacy shifts.

I examined data collected from MI Introductory Physics I with Calculus courses taught in large-capacity classrooms. Participant demographic data were collected form the university system, which records a variety of variables, including student-reported gender and ethnicity at the time of matriculation. Preand post- student self-efficacy and sources of self-efficacy scores was measured using the 33-item, Sources of Self-Efficacy in Science Courses - Physics (SOSESC-P) survey. I chose this survey for a variety of reasons, including its specific designation for physics classroom settings given that self-efficacy measures require task-relevant items in order to align with the construct's definition (Pajares, 1997). The survey has been shown to correlate well with the Self-Efficacy for Academic Milestones Strength scale-a positively recognized and validated instrument (Pajares, 1997). Some of the statements on the survey include the following: "I am capable of receiving good grades on assignments in this class" (mastery experience) and "I will get positive feedback about my ability to recall physics ideas" (verbal persuasion). Students use a 5-point Likert scale to express agreement or disagreement with these. The use of the SOSESC-P also supported continuity with past studies performed at FIU that employed the same instrument.

To measure relevant social interactions I administered a social network survey during the first week of class and subsequently approximately once a month until the end of the semester for a total of 5 administrations. The 
development of this short survey took place under the guidance of the PER group at FIU, building off a previously used survey (Brewe, Kramer, and Sawtelle, 2012). Of the open-ended questions appearing on this survey, only the first was relevant to this study: "Name the individual(s) (first and last name) you had a meaningful classroom interaction with today, even if you were not the main person speaking or contributing. (You may include names of students outside of the group you usually work with)." The survey provided a note to participants stating, "classroom interaction includes but is not limited to people you worked with to solve physics problems and people that you watched or listened to while solving physics problems." Blank space was also provided so that participants could list as few or as many individuals they wish to. The latest version of the survey also presented participants with an alphabetical list of classmates in order to facilitate identification. Responses to this survey were used to calculate student centrality (i.e., relational position in a classroom social network).

Several analyses were run and models tested on the data collected from these surveys. Pre- and post- scores on the SOSESC-P as a whole and on each of its four subsections were compared using dependent samples $t$-tests with alpha threshold adjustments according to Bonferroni correction methods in order to avoid Type I error. Similarly, independent sample $t$-tests were used to compare male students' mean scores on the SOSESC-P, both pre- and post-, to female students' pre- and post- scores. Multiple imputation procedures were implemented prior to these analyses to account for missing data. 
Bootstrapped linear regressions ${ }^{3}$ tested the ability of students' network centrality measures to predict students' post-SOSESC-P scores while controlling for pre- scores. Similar analyses tested whether these centrality measures are predictive of students' post- scores on subsections of the SOSESC-P. I tested three separate centrality measures: inDegree, outDegree, and PageRank. I chose to examine these three measures of centrality primarily because they limit the analysis of the relationship between self-efficacy and social interactions to students who had direct interactions with one another. They also follow with the uses and recommendations of past research (Brewe, Kramer, and Sawtelle, 2012; Forsman, Moll, and Linder, 2014; Grunspan, Wiggins, and Goodreau, 2014; Thomas, 2000), and they are generally understood by researchers outside the field of social network analysis (SNA).

\subsubsection{Chapter 3: The Development of Interest, Self-Efficacy, and}

\section{Student Networks in Undergraduate Physics Courses ${ }^{4}$}

\section{Key Research Questions}

1. Do classroom interactions as measured by social network centrality directly influence students' physics interest in Ml courses?

2. Do classroom interactions as measured by social network centrality indirectly influence students' physics interest via their physics self-efficacy in Ml courses?

\footnotetext{
${ }^{3}$ Social networks often fail to meet assumptions of independence. For this reason measures of centrality can result in non-normal distributions. Bootstrapped linear regressions do not require assumptions about the distribution, hence my use of this technique to account for any dependency in data retrieved from the social network.

${ }^{4}$ This study is under review for publication in the Journal of Research in Science Teaching. Like the previous study, while I performed the majority of the work, the paper includes co-authors who provided meaningful input: Eric Brewe, Zahra Hazari, Justyna P. Zwolak, and Geoff Potvin.
} 
3. Do reciprocal relationships exist between physics self-efficacy and physics interest in an active-learning introductory physics course?

Building off the previous study, this paper was designed to situate the contribution of centrality in the larger context of self-efficacy and interest formation. As these two constructs have been shown to play a major role in persons' career decision-making process (Hazari et al., 2010; Lent et al., 1994), I sought to illuminate how the quantity and quality of peer-to-peer interactions prominent in active learning curricula influence their change. I drew data for this analysis from the same surveys administered and described in the previous section (i.e., 1.4.1.). The SOSESC-P provided information about students' preand post- self-efficacy as a whole and the sources of self-efficacy. The social network survey provided information on student centrality.

Students' interest in physics and physics related content at the beginning and end of the class was collected using the Physics Identity Development (PID) survey (Potvin and Hazari, 2013). This questionnaire captures a series of variables related to students' sense of identity as a physics person, their performance competence, their general science interest, and their physics interest. I was only concerned with students' responses to the question about interest in specific topics related to physics (i.e., mechanics, optics/waves, electromagnetism, relativity/modern physics, history and people in physics, current topics in physics). Indication of interest was demarcated on a seven-point anchored Likert scale ranging from "No Interest" to "Very Interested". 
I tested two major models (i.e., A and B) using structural equation modeling (SEM). The models tested centrality measures' contribution to physics self-efficacy and physics interest. Specifically they examined whether we can know with some degree of certainty that the contribution of centrality to physics interest occurs directly, is mediated by self-efficacy, both, or none of the above. Both Model A and B take a somewhat longitudinal approach to examining directionality between these constructs with model A highlighting the influence of self-efficacy on interest formation, and model B the reverse (see Chapter 3).

Previously, I tested preliminary mediated models using pilot data as precursors to the final SEM models (see Figure $2 \& 3$ ).

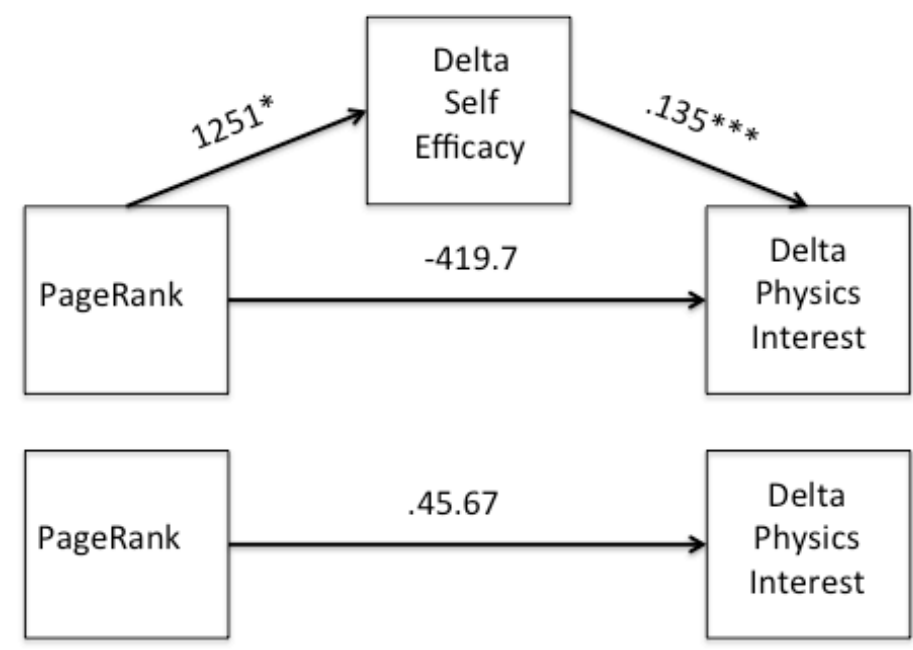

Figure 2. Cross-sectional Mediated Model of Self-Efficacy, Interest, and Centrality. This mediated model served as a pilot for a cross-sectional examination of the relationship between PageRank, self-efficacy, and interest. PageRank is a particular measure of students' position in a classroom social network. Here we find that PageRank contributes to the change in students' physics interest indirectly via the change in students' self-efficacy. 

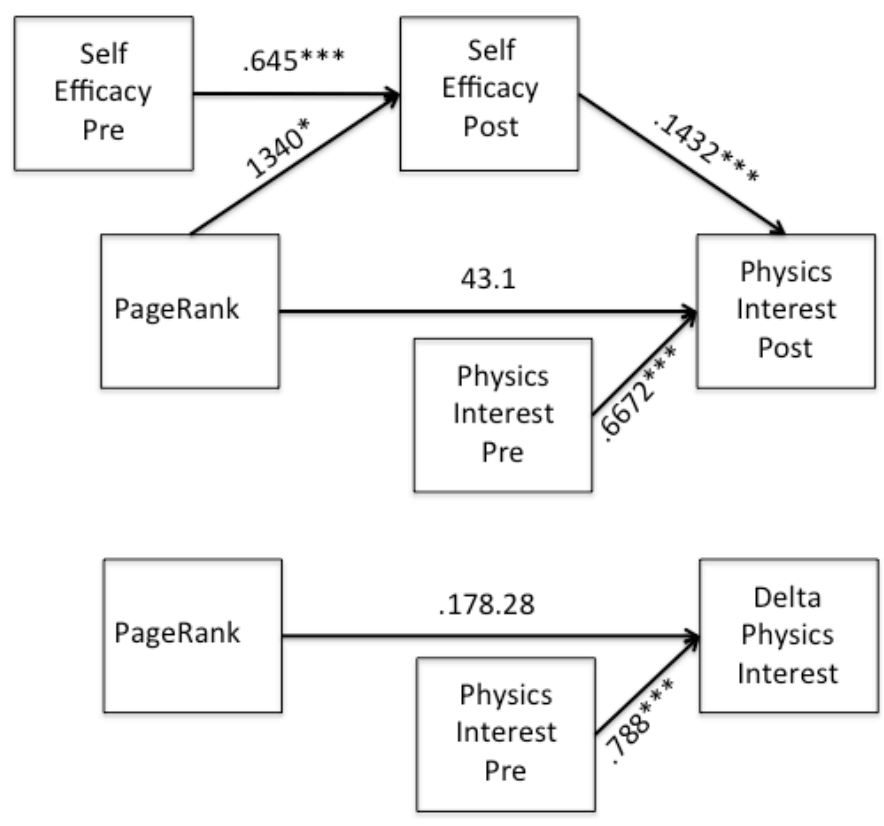

Figure 3. Longitudinal Mediated Model of Self-Efficacy, Interest, and Centrality. This mediated model served as a pilot for a longitudinal examination of the relationship between PageRank, self-efficacy, and interest. Note how both mediated models above indicate that PageRank centrality likely plays an indirect role in physics interest formation via physics self-efficacy.

Although the complexity of Models A and B are not quite captured in the mediated models depicted above, these served as blueprints for the final SEM models, which offered a greater degree of rigor and robustness with regard to outcomes. Two of the variables included in these figures were tested as latent variables resulting from student responses to two surveys (i.e., SOSESC-P, PID). After factor analysis, the majority of the items on the SOSESC-P were included, while only the six items on the PID relevant to this paper were included. The centrality variable (i.e., PageRank) was not treated as a latent variable. 


\subsubsection{Chapter 4: Development of Student Centrality in a Highly}

Interactive Introductory Physics Classroom

\section{Key Research Questions}

1. Does student centrality as measured by inDegree and outDegree exhibit linear growth over time?

2. Does student centrality exhibit quadratic growth over time?

3. Does student gender play a significant role in students' centrality and its development over time?

After establishing how centrality relates to student self-efficacy and interest in physics, this study focused more on the development of student centrality itself. A recent comparison of introductory physics students at FIU by Dou and Brewe (2014) revealed a stark contrast between the academic social networks formed by students in Modeling Instruction courses, versus students in lecture-based courses. Figure 4 captures this dichotomy. The MI students (i.e., yellow nodes) formed tight classroom-related networks with multiple connections to peers. Students in the lecture-based sections (i.e., blue nodes) tended to work on their own or with one other partner. Furthermore, although both groups reported working with people outside of the student community (e.g., family members, coworkers) to learn physics, MI students reported a greater number of these kinds of interactions. 


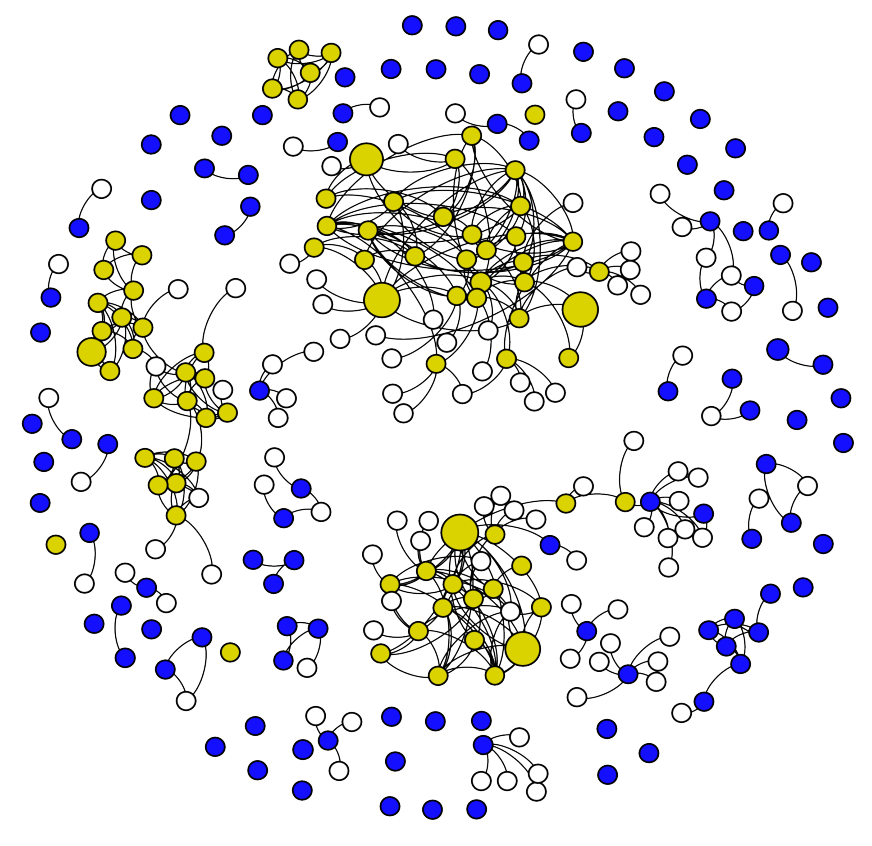

MI students

Lecture students

Non-Student

Figure 4. Contrasting Academic Interactions Between Students in Physics Courses. The network diagram to the left depicts the abundance of classroom related interactions that $\mathrm{MI}$ students in the fall of $\mathbf{2 0 0 9}$ reported having with the purpose of learning physics. Node size represents students' PageRank centrality.

Despite its contributions, the study did not describe the development of student networks in $\mathrm{Ml}$, rather capturing its final configuration at the end of a semester-long course. Pilot data from the Fall $2014 \mathrm{Ml}$ course showed that the social dynamics of the classroom are not static (see Figure $5-8$ ). They change over each survey administration despite the relative consistency of the curriculum and pedagogical environment. By taking a longitudinal approach that focuses on students in MI classrooms, I sought to understand the development of classroom networks according to the type of interactions (i.e., centrality) they carry out. 


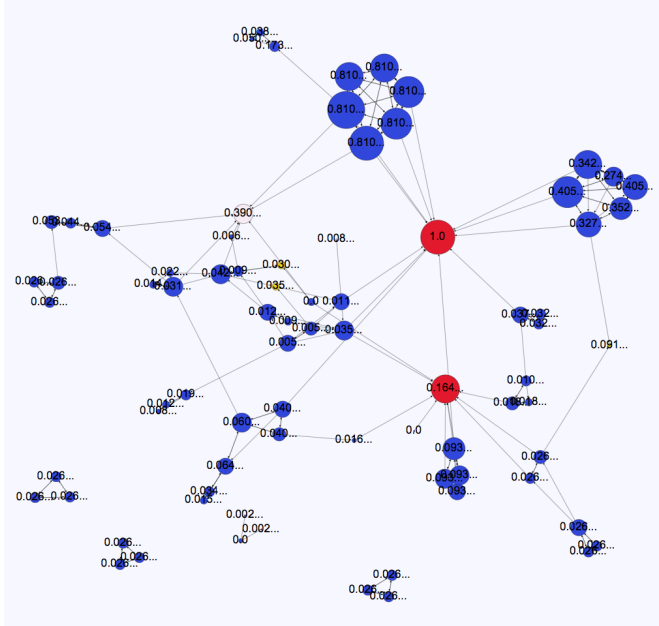

Figure 5. Sociogram of students in the Fall $2014 \mathrm{MI}$ course from the first survey administration. Node size and figures repre-sent PageRank.

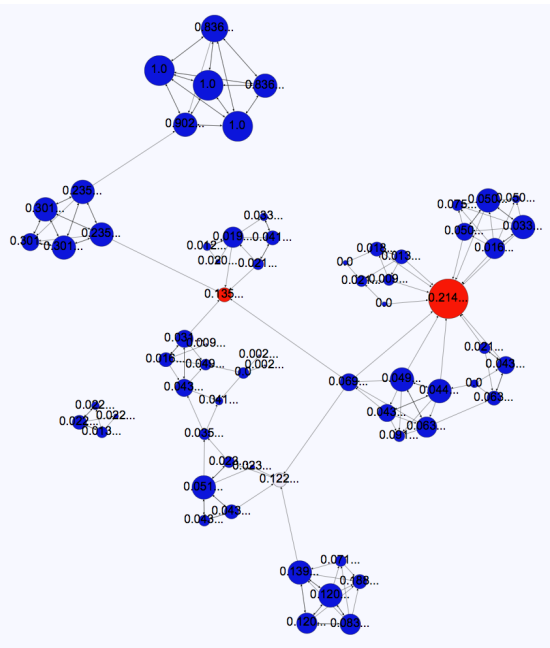

Figure 7. Sociogram of students in the Fall $2014 \mathrm{MI}$ course from the third survey administration.

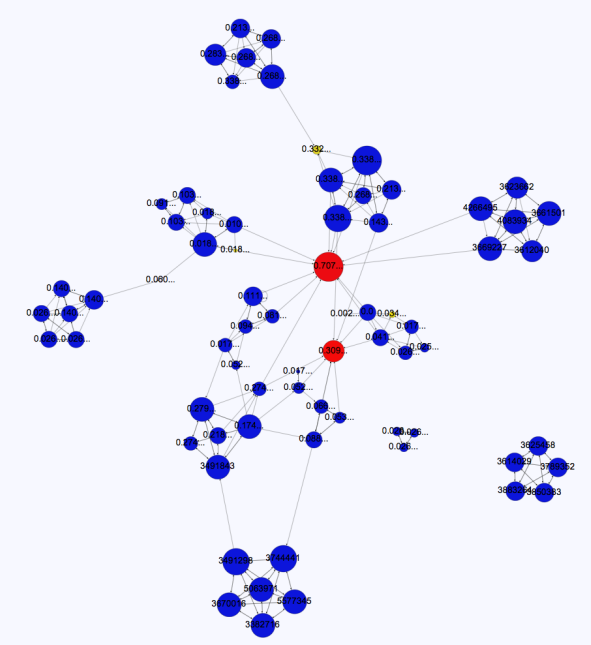

Figure 6. Sociogram of students in the Fall $2014 \mathrm{Ml}$ course from the second survey administration.

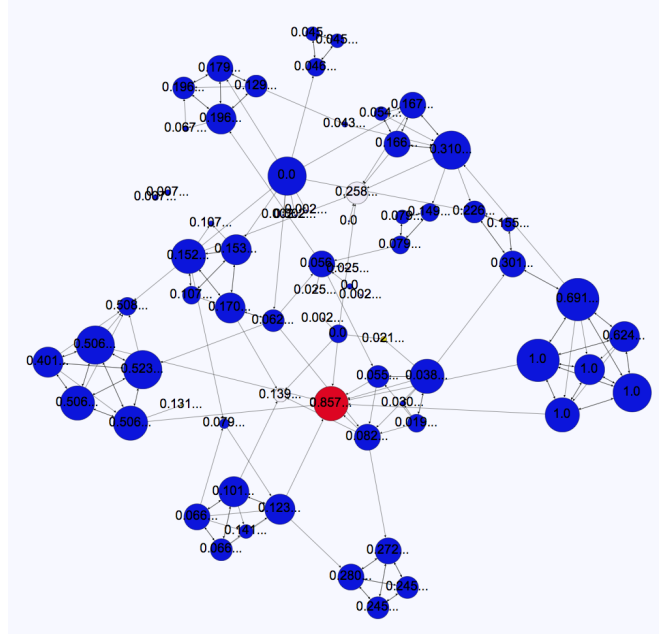

Figure 8. Sociogram of students in the Fall $2014 \mathrm{Ml}$ course from the fourth survey administration.

How students' behavior alters over the course of a semester when

seeking out peers or how students' centrality changes reveals subtle nuances about when students in large active learning physics courses (approx. 70-person) interact with one another and in what ways. I interpreted these results in light of past studies (i.e., Chapter 2 and 3 ) that aimed to identify links between network 
measures and physics self-efficacy, as well as physics interest. The progress of student interactions in the class aligned with past work that suggests that the "quality" of the individuals with whom an interaction takes place may matter more than the quantity of such engagements (Siciliano, 2016).

In order to answer these research questions, I ran several longitudinal growth models using HLM 6-a program designed specifically for running hierarchical models ${ }^{5}$. In my models, student-level data formed my level-2 variables (e.g., gender), and student centrality at the time of each survey administration was nested within student data as a level-1 variable. Unconditional models with only student centrality as an outcome allowed me to get a baseline reading of lower and higher level variance. One general model tested inDegree as an outcome, and another tested outDegree as an outcome. Additional models included "time" as a predictor of linear and quadratic trends for each respective outcome variable. I reported on the models that offer the best fit for each outcome variable.

\subsection{Data Sources}

Pilot data collection efforts began as far back as the fall semester of 2013 through the efforts of the Physics Education Research (PER) group at FIU. Under the guidance of my major professor and committee, I included these data along with additional data collected later particularly during the Fall 2014 and Fall 2015 semesters.

\footnotetext{
${ }^{5}$ Given that repeated measures data, as exists in cases where multiple data points are collected from the same individuals, fail to meet assumptions of independence, I must use techniques, like hierarchical linear modeling that account for both between and within student variance.
} 


\subsection{Brief Dissemination Plan for This Research Including Potential Scholarly Journals to Publish the Research}

Several conferences and scholarly journals stand out as likely avenues through which to disseminate this research. The PER community, as a whole, would strongly resonate with this kind of research and therefore they would value publications and presentations in spaces relevant to their community. In particular, the Physical Review - Physics Education Research open-access journal housed within the American Physical Society bears tremendous weight in the field. Here I submitted and published my first study (i.e., Chapter 2, see Footnote 2), introducing the connection between centrality and self-efficacy to a community familiar with self-efficacy studies (Dou et al., 2016). Relatedly, presentations and conference proceedings from the annual Physics Education Research Conference (PERC) have and would facilitate the spread of my work to this target audience. Other aspects of my research, such as establishing the place of centrality in broader career-related frameworks (i.e., Chapter 3), may find a larger audience in far-reaching science education research outlets, such as the Journal for Research in Science Teaching (JRST). The community of researchers that participate in this meeting and journal has tremendous interest in science education research, and often overlaps with the community of researchers that participate in PERC. The study described in Chapter 3 is currently under review by JRST reviewers (Dou, Brewe, Potvin, Zwolak, and Hazari, Under review). Last but not least, the study highlighted in Chapter 4 will be submitted to the International Journal of Science Education. 
Finally, my personal experience in STEM education policy at the local and federal levels prepares me to disseminate my work beyond academic outlets. These additional outlets may include working with science and education organizations, as well as governmental agencies/institutions and STEM education NGOs, to promote directed social integration of students seeking to enter STEM fields. Dissemination of the results at FIU will lead to the success of its diverse students pursuing STEM degrees, while impact at other institutions around the country will also be pursued through dissemination within the policymaking community.

\subsection{Tying the Threads}

The collection of these studies is at its heart an exploration of the social interactions that take place in active learning courses. While I focus on the environment created by the MI curriculum, these works set the stage for an exploration of active learning pedagogies that has yet to take place in earnest. Given the momentous spread of these kinds of teaching strategies-a proliferation that will likely not slow down-education researchers must keep an open eye for unseen factors resulting from an increase in classroom interactions. Understanding these may help to further our goals of maximizing the motivation of students from all backgrounds to pursue STEM fields.

More specifically, I hope to forge a strong link between social network analysis and self-efficacy theory (i.e., Chapter 2). By extending this to interest (i.e., Chapter 3), I further situate the advantages of examining classroom interactions as factors that contribute to highly influential career decision-making 
constructs. If these links exist, then understanding how student centrality develops (i.e., Chapter 4) may offer clues that will help curriculum writers maximize positive outcomes in students' self-efficacy and domain interests. Finally, in light of the population at FIU, I hope these three studies will unravel some of the nuanced social experiences of students from underrepresented communities in physics that may contribute to their affective development.

\subsection{A Few Words About My Personal Motivation}

Ultimately, I hope the expertise I have developed will create a stronger platform on which I may continue contributing to STEM education research, as well as STEM education policy at the local, state, and federal levels. My prior experience at the National Science Foundation, serving as an Einstein Fellow, solidified in me a conviction that leaders and practitioners whose ideas are grounded in research can make a positive impact on the state of our nation's education system. I envision my work, in collaboration with the work of other experts and policy-makers, influencing students' motivational attributes related to STEM career pursuit. This may occur through changes in instruction, policy, and institutional culture. With research-supported guidance, programs and interventions can be designed to promote factors that influence retention and persistence in STEM, particularly for underrepresented populations. I have valuable experience as a member of a minority group ${ }^{6}$, the necessary science background, motivation, and understanding of STEM education policy to make significant, long-term contributions toward this objective.

\footnotetext{
${ }^{6}$ I identify as Hispanic.
} 
Along these lines, I hope my efforts also result in opportunities to contribute to research and education through faculty appointments. Helping to develop and work with teams of STEM education researchers, as well as teaching courses related to methodology and STEM pedagogy, will fulfill in me a desire to make an impact on the communities of practice I belong to. My background in policy and policy-making broadens my horizons to include the pursuit of administrative roles at the higher education level where small changes have the capacity of producing large effects. Administrative and faculty positions also bear the potential of opening doors to contribute to STEM education policymaking on a larger scale (i.e., state and federal).

References (Chapter 1 Introduction)

Askar, P., and Davenport, D. (2009). An investigation of factors related to selfefficacy for Java programming among engineering students. The Turkish Online Journal of Educational Technology, 8(1). Retrieved from http://eric.ed.gov/?id=ED503900

Bandura, A., Barbaranelli, C., Caprara, G. V, and Pastorelli, C. (2001). Selfefficacy beliefs as shapers of children's aspirations and career trajectories. Child Development, 72(1), 187-206. doi:10.1111/1467-8624.00273

Bandura, A. (1977). Self-efficacy: Toward a unifying theory of behavioral change. Psychological Review, 84(2), 191-215. doi:10.1037/0033-295X.84.2.191

Bandura, A. (1993). Perceived self-efficacy in cognitive development and functioning. Educational Psychologist. doi:10.1207/s15326985ep2802_3

Bandura, A. (1997). Self-efficacy: The exercise of control. New York, NY: W.H. Freeman and Company.

Brewe, E. (2008). Modeling theory applied: Modeling Instruction in introductory physics. American Journal of Physics, 76(12), 1155. doi:10.1119/1.2983148 
Brewe, E., Sawtelle, V., Kramer, L. H., O'Brien, G. E., Rodriguez, I., and Pamelá, P. (2010). Toward equity through participation in Modeling Instruction in introductory university physics. Physical Review Special Topics - Physics Education Research, 6(1), 010106. doi:10.1103/PhysRevSTPER.6.010106

Brewe, E., Kramer, L., and Sawtelle, V. (2012). Investigating student communities with network analysis of interactions in a physics learning center. Physical Review Special Topics - Physics Education Research, 8(1), 010101. doi:10.1103/PhysRevSTPER.8.010101

Brown, S. D., Lent, R. W., and Larkin, K. C. (1989). Self-efficacy as a moderator of scholastic aptitude-academic performance relationships. Journal of Vocational Behavior, 35(1), 64-75. doi:10.1016/0001-8791(89)90048-1

Bruun, J., and Brewe, E. (2013). Talking and learning physics: Predicting future grades from network measures and Force Concept Inventory pretest scores. Physical Review Special Topics - Physics Education Research, 9(2), 020109. doi:10.1103/PhysRevSTPER.9.020109

Cass, C. A. P., Hazari, Z., Cribbs, J., Sadler, P. M., and Sonnert, G. (2011). Examining the impact of mathematics identity on the choice of engineering careers for male and female students. In 41st ASEE/IEEE Frontiers inn Education Conference (pp. 1-5). Rapid City, SD.

Desbien, D. (2002). Modeling discourse management compared to other classroom management styles in university physics. Ph.D. dissertation, Arizona State University.

Dou, R., and Brewe, E. (2014). Network centrality and student self-efficacy in an interactive introductory physics environment. In P. V. Engelhardt, A. D. Churukian, and D. J. Jones. (Eds.), 2014 PERC Proceedings (pp. 67-70). Minneapolis, MN. http://doi.org/10.1119/perc.2014.pr.013

Dou, R., Brewe, E., Potvin, G., Zwolak, J.P., and Hazari, Z. (Under review). The risks we take: Understanding the development of interest, self-efficacy, and student networks in reformed undergraduate physics courses. Journal of Research in Science Teaching.

Dou, R., Brewe, E., Zwolak, J. P., Potvin, G., Williams, E. A., and Kramer, L. H. (2016). Beyond performance metrics: Examining a decrease in students' physics self-efficacy through a social networks lens. Physical Review Physics Education Research, 12(2), 020124. http://doi.org/10.1103/PhysRevPhysEducRes.12.020124 
Dou, R., and Gibbs, K. D. (2013). Engaging all students in the pursuit of STEM careers. School Science Review, 95(351), 106-112.

Dweck, C. S. (1975). The role of expectations and attributions in the alleviation of learned helplessness. Journal of Personality and Social Psychology, 31(4), 674-685. doi:10.1037/h0077149

Etkina, E., and Heuvelen, A. Van. (2007). Investigative science learning environment - A science process approach to learning physics. Washington, DC. Retrieved from http://www.per-central.org/per_reviews/

Finkelstein, N. D., and Pollock, S. J. (2005). Replicating and understanding successful innovations: Implementing tutorials in introductory physics. Physical Review Special Topics - Physics Education Research, 1(1), 1-13. doi:10.1103/PhysRevSTPER.1.010101

Fencl, H. S., and Scheel, K. R. (2004). Pedagogical approaches, contextual variables, and the development of student self-efficacy in undergraduate physics courses. In J. Marx, S. Franklin, and K. Cummings (Eds.), 2003 Physics Education Research Conference: AIP Conference Proceedings (pp. 173-176). Melville, NY: AIP.

Fencl, H., and Scheel, K. (2005). Engaging students: An examination of the effects of teaching strategies on self-efficacy and course climate in a nonmajors physics course. Journal of College Science Teaching, 35, 20 24.

Forsman, J., Moll, R., and Linder, C. (2014). Extending the theoretical framing for physics education research: An illustrative application of complexity science. Physical Review Special Topics - Physics Education Research, 10(2), 1-13. doi:10.1103/PhysRevSTPER.10.020122

Grunspan, D. Z., Wiggins, B. L., and Goodreau, S. M. (2014). Understanding Classrooms through Social Network Analysis: A Primer for Social Network Analysis in Education Research. Cell Biology Education, 13(2), 167-178. doi:10.1187/cbe.13-08-0162

Hazari, Z., Sonnert, G., Sadler, P. M., and Shanahan, M.-C. (2010). Connecting high school physics experiences, outcome expectations, physics identity, and physics career choice: A gender study. Journal of Research in Science Teaching, 47(8), 978-1003. doi:10.1002/tea.20363

Hestenes, D. (1987). Toward a modeling theory of physics instruction. American Journal of Physics, 55(5), 440. doi:10.1119/1.15129 
Hill, C., Corbett, C., and St. Rose, A. (2010). Why so few? Women in science, technology, engineering and mathematics. Washington, DC.

Kjærnsli, M., and Lie, S. (2011). Students' preference for science careers: International comparisons based on PISA 2006. International Journal of Science Education, 33(1), 121-144. doi:10.1080/09500693.2010.518642

Larkin, K.C., Lent, R.W., and Brown, S.D. (1986) Self-efficacy in the prediction of academic performance and perceived career options. Journal of Counseling Psychology, 33(265).

Larose, S., Ratelle, C. F., Guay, F., Senécal, C., and Harvey, M. (2006). Trajectories of science self-efficacy beliefs during the college transition and academic and vocational adjustment in science and technology programs. Educational Research and Evaluation, 12(4), 373-393. http://doi.org/10.1080/13803610600765836

Laws, P.W. (1997). Millikan Lecture 1996: Promoting active learning based on physics education research in introductory physics courses. American Journal of Physics, 65, 14. http://dx.doi.org/10.1119/1.18496

Lent, R. W., Brown, S. D., and Hackett, G. (1994). Toward a unifying social cognitive theory of career and academic interest, choice, and performance. Journal of Vocational Behavior, 45, 79-122.

Lent, R. W., Brown, S. D., and Larkin, K. C. (1987). Comparison of three theoretically derived variables in predicting career and academic behavior: Self-efficacy, interest congruence, and consequence thinking. Journal of Counseling Psychology, 34(3), 293-298. doi:10.1037/0022-0167.34.3.293

Lent, R. W., Lopez, F. G., and Bieschke, K. J. (1993). Predicting mathematicsrelated choice and success behaviors: Test of an expanded social cognitive model. Journal of Vocational Behavior. doi:DOI 10.1006/jvbe.1993.1016

Lindstrøm, C., and Sharma, M. D. (2011). Self-efficacy of first year university physics students: Do gender and prior formal instruction in physics matter? International Journal of Innovation in Science and Mathematics Education, 19(2), 1-19.

Lynch, D. J. (2010). Motivational beliefs and learning strategies as predictors of academic performance in college physics. College Student Journal, 44(4), 920-927.

National Research Council. (2010). Rising above the gathering storm: Revisited. Washington, DC: National Academies Press. 
National Research Council. (2011). Expanding underrepresented minority participation: America's science and technology talent at the crossroads. Washington, DC: National Academies Press.

National Research Council. (2012). Discipline-based education research: Understanding and improving learning in undergraduate science and engineering. Washington, DC: National Academies Press.

National Research Council. (2013). Adapting to a changing world: Challenges and opportunities in undergraduate physics education. Washington, DC: National Academies Press.

National Science Board. (2014). Science and engineering indicators 2014. Arlington, VA.

Office of Governmental Relations, STEM Success by Numbers (Florida International University, Miami, Florida, 2014). Retrieved from http://government.fiu.edu/federal/stem/stem-success-numbers/index.html

Pajares, F. (1997). Current Directions in Self-Efficacy Research. Advances in Motivation and aAchievement, 10(149), 1 - 49.

Pajares, F. and Urdan, T.C. (2006) in: Adolescence and Education. Information Age.

Potvin, Geoff, and Zahra Hazari. (2013). "The development and measurement of identity across the physical sciences." Proceedings of the Physics Education Research Conference (PERC), Portland, OR: AIP.

President's Council of Advisors on Science and Technology. (2010). Prepare and Inspire: K-12 Education in Science, Technology, Engineering, and Math (STEM) for America's Future: Executive Report. Washington, DC. doi:10.1126/science.1198062

Robert, J., Jeffery, M., Rhett, J., Duane, L., David, S., Carolina, N., and Abbott, D. S. (2000). Introduction to SCALE-UP: Student-Centered Activities for Large Enrollment University Physics. Washington, D.C.

Sawtelle, V., Brewe, E., Goertzen, R. M., Kramer, L. H., Rebello, N. S., Engelhardt, P. V., and Singh, C. (2012). Creating opportunities to influence self-efficacy through modeling instruction. In 2011 Physics Education Research Conference (Vol. 339, pp. 339-342). American Institute of Physics. doi:10.1063/1.3680064 
Sawtelle, V., Brewe, E., and Kramer, L. H. (2012). Exploring the relationship between self-efficacy and retention in introductory physics. Journal of Research in Science Teaching, 49(9), 1096-1121. doi:10.1002/tea.21050

Schunk, D. H. (1983). Ability versus effort attributional feedback: Differential effects on self-efficacy and achievement. Journal of Educational Psychology, $75,848-856$.

Schunk, D.H. (2012). Learning theories: An educational perspective. Boston, MA: Pearson Education.

Siciliano, M. D. (2016). Its the quality not the quantity of ties that matter: Social networks and self-efficacy beliefs. American Educational Research Journal, 53(2), 227-262. http://doi.org/10.3102/0002831216629207

Smist, J. M. (1993). General chemistry and self-efficacy. In National Meeting of the American Chemical Society (pp. 1 - 27). Chicago. Retrieved from http://eric.ed.gov/?id=ED368558

State University System of Florida. (2014). Annual accountability report. Miami, Florida. Retrieved from http://opir.fiu.edu/BOG/FIU_2014_Annual_Report.pdf

Thomas, S. L. (2000). Ties that bind: A social network approach to understanding student integration and persistence. The Journal of Higher Education, 71(5), 591-615.

Wang, X. (2013). Why students choose STEM majors: Motivation, high school learning, and postsecondary context of support. American Educational Research Journal, 50(5), 1081-1121. doi:10.3102/0002831213488622

Zeldin, A. L., Britner, S. L., and Pajares, F. (2008). A comparative study of the self-efficacy beliefs of successful men and women in mathematics, science, and technology careers. Journal of Research in Science Teaching, 45(9), 1036-1058. doi:10.1002/tea.20195

Zeldin, a. L., and Pajares, F. (2000). Against the odds: Self-efficacy beliefs of women in mathematical, scientific, and technological careers. American Educational Research Journal, 37(1), 215-246.

doi:10.3102/00028312037001215 


\section{CHAPTER 2 \\ BEYOND PERFORMANCE METRICS: EXAMINING A DROP IN STUDENTS' PHYSICS SELF-EFFICACY THROUGH A SOCIAL NETWORK LENS}

\subsection{Abstract}

The Modeling Instruction (MI) approach to introductory physics manifests significant increases in student conceptual understanding and attitudes toward physics. In light of these findings, we investigated changes in student selfefficacy while considering the construct's contribution to the career-decision making process. Students in the Fall 2014 and 2015 Ml courses at Florida International University exhibited a decrease on each of the sources of selfefficacy and overall self-efficacy $(N=147)$ as measured by the Sources of SelfEfficacy in Science Courses - Physics (SOSESC-P) survey. This held true regardless of student gender or ethnic group. Given the highly interactive nature of the MI course and the drops observed on the SOSESC-P, we chose to further explore students' changes in self-efficacy as a function of three centrality measures (i.e., relational positions in the classroom social network): inDegree, outDegree, and PageRank. We collected social network data by periodically asking students to list the names of peers with whom they had meaningful interactions. While controlling for PRE- scores on the SOSESC-P, bootstrapped linear regressions revealed POST self-efficacy scores to be predicted by PageRank centrality. When disaggregated by the sources of self-efficacy, PageRank centrality was shown to be directly related to students' sense of mastery experiences. InDegree was associated with verbal persuasion experiences, and outDegree with both verbal persuasion and vicarious learning 
experiences. We posit that analysis of social networks in active learning classrooms helps to reveal nuances in self-efficacy development.

\subsection{Introduction}

For years, academic and political leaders have signaled the need to strengthen the science, technology, engineering, and mathematics (STEM) education enterprise. The STEM disciplines have significant impact on economic growth and national security, as well as improve quality of life (National Research Council [NRC], 2007, 2010). For the United States, the rate of students seeking and completing STEM careers lags behind that which would keep this nation competitive in the global economy (President's Council of Advisors on Science and Technology, 2010). While much attention has been placed on improving student academic performance in STEM, content knowledge alone does not produce STEM professionals; deciding to attain a STEM career is a complex process involving interconnected motivational and behavioral factors, such as self-efficacy, outcome expectations, and social interactions (Lent, Brown, and Hackett, 1994; Tinto, 1997).

Various behavioral, contextual, and individual factors influence students' career decision-making processes and decisions to persist in STEM careers. These factors include learning experiences, interests, perceived barriers to career attainment, ethnicity, gender, self-efficacy, and outcome expectations-to name a few (Lent et al., 1994). Of these, self-efficacy deserves particular attention, because of its primary role in predicting STEM career persistence (Bandura, 2001). 
College-level introductory science courses also play a unique role in the careers of STEM majors. Regardless of the STEM degree sought, colleges and universities across the nation require that students complete introductory courses in the fields of biology, chemistry, and physics. These courses often act as gatekeepers that keep certain students from persisting through the STEM career continuum (Crisp, Nora, and Taggart, 2009). Researchers, educational leaders, and politicians considering how to resolve the issues of low number of STEM majors and underrepresentation of certain groups in STEM careers should consider the function and structure of college-level introductory science courses.

\subsection{Reforming Introductory Physics}

Physics majors, in particular, come to a crossroads in their careers during their freshman or sophomore years when they take their first introductory physics course and its accompanying lab. At Florida International University (FIU), the traditional lecture version of this course, which most students register for, has an approximately $56 \%$ passing rate. This means that over $40 \%$ of students taking introductory physics fail the first time they take the course. The psychological impact that failing a fundamental course has on a students seeking a degree can dissuade those students from continuing through the major, and may cause them to drop out altogether. Additionally, while professors generally want their students to learn, many of them have very little pedagogical training that would equip them to teach students who do not typically succeed in a large-classroom, lecturebased environment. Fortunately, various universities across the country have taken on the challenge of developing reformed physics courses. 


\subsubsection{Modeling Instruction}

Although many reformed instructional approaches for teaching introductory university physics exist (e.g., ISLE, Workshop Physics, Tutorials, SCALE-UP), our research focuses on Modeling Instruction (MI), which differs from typical physics, lecture-based courses. Lecture has been and continues to be the most common strategy for teaching physics. The salient characteristics of lecture courses include high student-teacher ratios, a propensity for instructors to lecture, few solicited student-student or student-lecturer interactions, and theaterstyle classroom settings. By contrast, MI Physics courses tend to have lower student-teacher ratios, shorter lectures, a higher number of solicited studentstudent and student-teacher interactions, and classroom settings designed to promote small group formation and collaborative learning (Halloun and Hestenes, 1987).

Studies have shown that MI has led to increased student understanding in physics and improved attitudes toward physics (Brewe et al., 2010, Brewe, Traxler, De La Garza, and Kramer, 2013). Results documented in Brewe et al. (2010) showed that students in Ml courses have a 6.73 times greater odds-ofsuccess than their counterparts in lecture sections. In addition to successfully passing, students in Ml courses have greater pre-post gains on the Force Concept Inventory than students in traditional, lecture-based courses. The researchers observed these learning advantages for both women and men, though they note that the presence of a "gender gap" remains. Moreover, MI courses, unlike other successful, reformed physics approaches, positively shift 
student attitudes toward physics even when examined across varied instructors (Avg. effect size: Cohen's $d=.45$ )—a feat accomplished by no other study known to the authors (Brewe et al. 2013).

\subsection{Self-Efficacy and MI}

Bandura (1977) describes self-efficacy as a person's beliefs about their ability to succeed on a particular task. In other words, when faced with a particular problem to solve or assignment to accomplish, individuals make selfassessments about how successful they will be at solving said problem or completing said assignment. While somewhat akin to confidence and other expectancy constructs, self-efficacy differs in that the construct fluctuates according to both task and context (Pajares, 1997). For example, an individual may have one set of efficacy beliefs about her ability to solve a math problem, while holding a different set of beliefs about her ability to operate a voltmeter. Furthermore, the same individual may exhibit different self-efficacy beliefs about the same task according to the context in which she is being evaluated (e.g., performing to an audience versus performing in private; Bandura, 1993).

Of the four sources of self-efficacy-mastery experiences, vicarious learning, verbal persuasion, and physiological mechanisms_two exist primarily in social settings: vicarious learning (VL) and verbal persuasion (VP). VL experiences occur when a person makes personal comparisons while observing the success or failure of someone whom that person perceives as similar. VP experiences involve receiving feedback from other individuals (Chen and Usher, 2013). By definition, these behavioral constructs require social interactions. 
Previous studies on MI have explicitly explored students' self-efficacy (Sawtelle, Brewe, Kramer, 2012; Sawtelle et al. 2012). A study by Sawtelle et al. (2010) revealed that respondents taking one of several 30-student capacity MI courses at a public research university, regardless of gender, did not exhibit a significant change in overall self-efficacy. When disaggregated by gender, the results did reveal a significant increase for women on the verbal persuasion subscale of the survey. On the other hand, the same study revealed that both male and female students in lecture-based introductory physics courses exhibited a significant drop in self-efficacy. This drop held true even when disaggregating the results of students' scores by the four sources of self-efficacy.

\subsection{Social Network Analysis}

Not only are we interested in understanding how student self-efficacy changes over the course of a semester of MI Introductory Physics I with Calculus (referred to as MI from here on out), we want to understand whether student interactions are associated with self-efficacy development, given the hyperinteractive context of $\mathrm{MI}$ and the inherently social nature of the VL and VP selfefficacy sources. To understand the relationship between students' classroom interactions and self-efficacy development, we must find a way to measure these variables. Several instruments exist that measure student self-efficacy and its sources in a variety of settings. On the other hand, social interactions can be difficult to capture given their complex, interrelated characteristics of social network data. In order to achieve reliable metrics of students' social behavior, we turn to the field of social network analysis (SNA). 
Although the employment of SNA in sociology has been taking place since the 1930's (Scott, 1988), its use in education research has experienced a growing popularity in recent years (Brewe, Kramer, and Sawtelle, 2012; Bruun and Brewe, 2013; Forsman, Moll, and Linder, 2014; Grunspan, Wiggins, and Goodreau, 2014; Thomas, 2000). Discipline-based education researchers have explicitly encouraged the use of SNA to understand the social networks formed during learning (Grunspan et al., 2014). Even more specific to the field of physics education research (PER), Bruun and Brewe (2013) have suggested that increased application of SNA will better help the field understand student cognition. Many of the above-cited papers may serve as primers to education researchers desiring to further their comprehension of SNA terminology and implementation. Grunspan et al. (2013) present a concise introduction targeted at science education researchers.

In brief, social network analysts endeavor to quantify the role of particular individuals in a network and the characteristics of a network and its evolution (Scott and Carrington, 2011). Our study focuses on measuring the "centrality" of actors (i.e., students) in our network. Centrality can be calculated from students' interactions in a variety of ways. For example, the most basic form of centrality is "degree" centrality, which simply refers to the number of people with whom a person in a network interacts (Bruun and Brewe, 2013). Other measures in the centrality family include inDegree, outDegree, PageRank, Closeness, and Betweenness. These may be calculated using the same student interaction information. 


\subsection{Purpose}

Although some studies performed with students participating in MI take a first step toward our understanding of self-efficacy development in these kinds of active learning environments, missing from the analyses are careful controls for other variables associated with self-efficacy, such as student ethnicity, as well as a more focused approach to understanding the role played by the MI curriculum's most prominent feature: social interactions. Considering additional limitations, such as potential selection bias introduced by the use of online surveys and the amount of unincorporated missing data, the propositions of the referenced studies in MI warrant further exploration. Our investigation will allow us to examine the above. We hypothesize that the classroom structure of an MI course fosters interactions that are congruent with VL and VP experiences such that they influence student self-efficacy (see Figure 9). Specifically, we sought to address the following research questions:

1) Do students in the MI course experience statistically significant changes in physics self-efficacy as measured by pre- and post- scores on a selfefficacy in physics instrument (i.e., Sources of Self-Efficacy in Science Courses - Physics)?

2) Do students in the MI course experience statistically significant changes in physics self-efficacy scores when disaggregated by the four sources of self-efficacy?

3) How are social interactions as measured by student network centrality in the MI classroom associated with changes in students' self-efficacy? 
4) Do other variables historically associated with student success in

physics, such as gender, major, and ethnicity, contribute to the variance in students' post-self-efficacy scores when controlling for pre- scores?

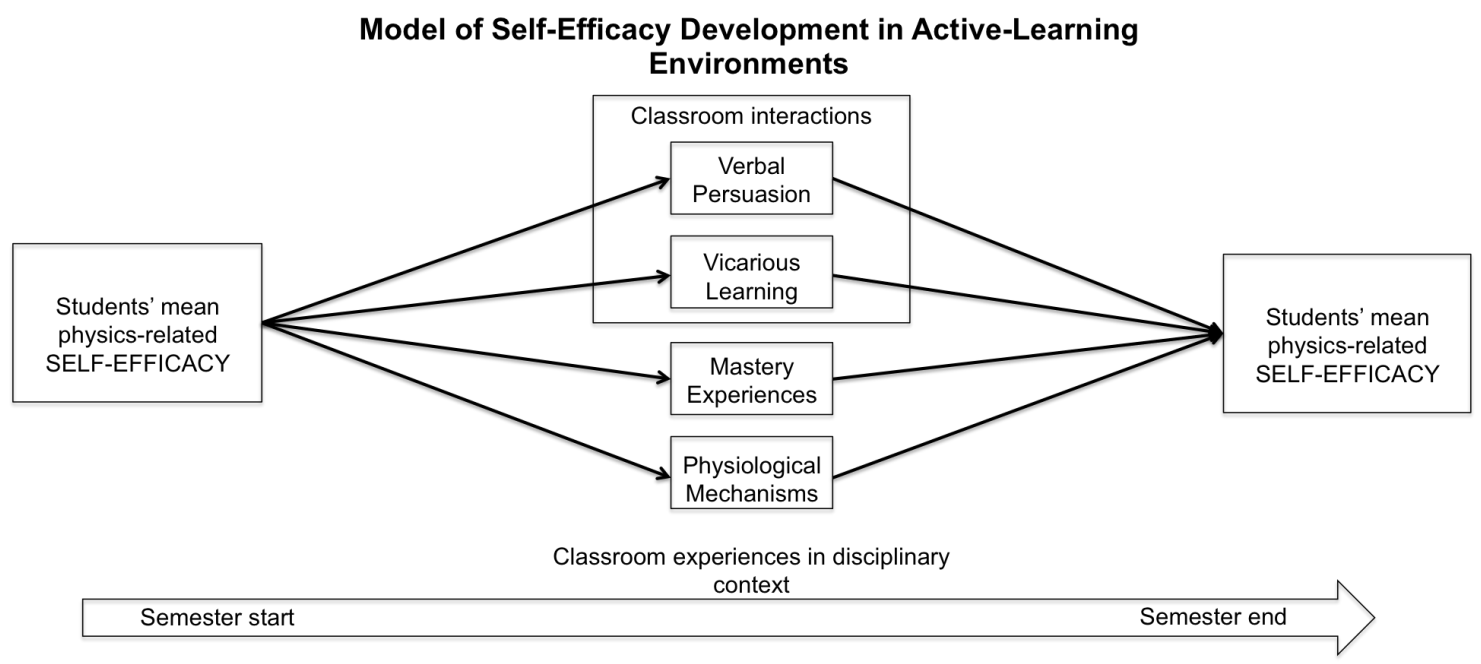

Figure 9. Model of Self-Efficacy Development in Active-Learning Environments: our model of self-efficacy development in active learning environments accounts for students' initial self-efficacy and its subsequent development as a result of classroom experiences. In alignment with theory, some of the development arises from learning experiences not directly related to social interaction (i.e., mastery experiences; Bandura, 1997). In addition, we postulate that the social nature of many active learning environments have the capability of generating opportunities for students to receive verbal feedback or perceive others with whom they relate as successful or unsuccessful on physics tasks (i.e., verbal persuasion and vicarious learning experiences). Thus we posit a link between certain types of classroom interactions and self-efficacy development.

\subsection{Methods}

\subsubsection{Student Data}

Students regardless of major or academic year have the option of selfselecting into one of the Ml sections offered each semester or the lecture-based sections of Introductory Physics I with Calculus. The MI course incorporates the lab credit. It is worth noting that student familiarity with the MI approach varies.

For example, students registered in the Fall $2015 \mathrm{Ml}$ courses responded 
differently to being asked about their expectations for the class. Of the 44 survey respondents, $9 \%$ expected a curriculum only slightly different than lecture, $32 \%$ expected a much more interactive and hands-on experience, while a similar number expected no differences from a traditional, lecture-based course. Remaining students either had no expectations or did not respond. Nevertheless, students acknowledge when they enroll that the Ml course will count for both course and laboratory credit. On the other hand, students in a lecture section usually register concurrently for a respective laboratory course, but are not required to do so. Ml courses for the semesters included in this study (i.e., Fall 2014, Fall 2015) hosted approximately 70 students at a time. Lecture sections at FIU usually have enrollments that range from 120 to nearly 400 students, though some offer much lower class size limits. In the Fall of 2014 only one section of MI was offered, limiting students' scheduling flexibility, but this particular section was the first designed to serve more than 70 students-over twice the number of students previously attempted-in a technology-saturated classroom specifically designed for active learning. Prior iterations of the course limited enrollment capacity at 30 . Two sections of the large-capacity MI course were offered during the Fall 2015 term—one taught by the same experienced instructor who taught the Fall 2014 course and another taught by a postdoc. In order to accommodate the larger number of students, two graduate teaching assistants and three experienced Learning Assistants (i.e., undergraduate students) helped to facilitate instruction during courses in both terms. Only data from classes taught 
by the same primary instructor were used in this study in order to minimize confounding variables introduced by having data from different instructors.

We obtained student demographic data from FIU's database, which keeps a record of student responses to questions answered at the time they apply to the university. The classes were composed of four prominent ethnic groups into which students identified: Asian, White, Hispanic, and Black. The majority of students enrolled in both classes identified themselves as Hispanic (47 women and 58 men), while eight identified themselves as Asian (three women and five men), 13 as White (five women and eight men), and 11 students as Black (two women and nine men). Four students identified as other or more than one race. The race and gender of the remaining six students in our data set were not available. In terms of majors represented in the courses, these included Engineering, Chemistry, Pre-Med, and English. No student in either MI course that was included in this study had declared Physics as a major at the beginning of the semester, though we should note that students who declared dual majors were categorized under a larger umbrella (i.e., DUALFIU), which may include Physics majors.

\subsubsection{Social Network Data}

Since we could not directly measure when a student happens to have a meaningful VP or VL experience, we adopted an indirect approach that quantifies the number and types of social interactions students have using SNA. We also did this to test the model that the quantity and quality of certain kinds of interactions correlates with changes in students' self-efficacy and sources of self- 
efficacy. To measure relevant social interactions we administered a social network survey on the last day of the first week of class and subsequently once a month until the end of the semester for a total of 5 administrations. The development of this short survey took place under the guidance of the PER group at FIU, building off a previously used survey (Brewe et al., 2012). Of the open-ended questions appearing on this survey, only the first is relevant to this study: "Name the individual(s) (first and last name) you had a meaningful classroom interaction with today, even if you were not the main person speaking or contributing. (You may include names of students outside of the group you usually work with)." We provided a note to participants stating, "classroom interaction includes but is not limited to people you worked with to solve physics problems and people that you watched or listened to while solving physics problems." Blank space was provided so that participants could list as few or as many individuals they wished to. We carefully analyzed responses in order to identify the students listed. When $100 \%$ certainty or agreement could not be established as to the identity of a written name, a unique code was created for that specific report. This occurred five times when students with common first names were reported sans last name. To avoid this issue in the Fall 2015 course, we attached a numbered roster of students to the survey.

We collected student network data in order to calculate three specific measures of directed centrality: inDegree, outDegree, and PageRank. InDegree centrality measures direct incoming interactions (i.e., the number of times a student is listed by peers) and outDegree measures direct outgoing interactions 
and in some cases can be thought of as a measure of one's sociability (i.e., the number of peers listed by a student). PageRank takes a more sophisticated approach to measuring the "importance" of a student or actor in a network. The measure captures direct incoming interactions while taking into account the social connectedness of nodes leading to a student. In other words, PageRank offers a measure of weight to being named directly by a student who is often named by others. The PageRank algorithm establishes a node's importance using the number of links to the node, but also each node can then redistribute that importance by its number of outgoing links. Developed by Brin and Page (1998) for the Google search engine algorithm, the measure has been compared to calculating the probability of a random walker on a directed network to arrive at a particular node (Fortunato and Flammini, 2007).

We chose to examine these three measures of centrality (i.e., inDegree, outDegree, PageRank) primarily because they limit our analysis of the relationship between self-efficacy and social interactions to students who had direct interactions with one another. They also follow with the uses and recommendations of past research (Brewe et al., 2012; Forsman et al., 2014; Grunspan et al., 2014; Thomas, 2000), and they are generally understood by researchers outside the field of SNA. Moreover, by examining whether each of these three centrality measures contributes to changes in students' self-efficacy, we may get a clearer picture of the kinds of interactions that matter for student self-efficacy formation in Ml courses. 


\subsubsection{Physics Self-Efficacy Data}

Self-efficacy surveys were administered in-class on the first day of each semester (i.e., pre-) and once during the last week of the semester (i.e., post-). We had an overall $92 \%$ response rate on the pre- based on a total of 147 students who registered for Fall 2014 and Fall 2015 MI courses. Our postadministrations yielded an $80 \%$ response rate. We employed the 33-item Sources of Self-Efficacy in Science Courses - Physics (SOSESC-P) survey to gauge the sources of self-efficacy and to get a measure of overall student selfefficacy. We chose this survey for a variety of reasons, including its specific designation for physics classroom settings given that self-efficacy measures require task-relevant items in order to align with the construct's definition (Pajares, 1997). The SOSESC-P was designed so that responses to statements can be disaggregated by each of the four sources of self-efficacy.

We achieved an overall reliability alpha coefficient of .94 on the SOSESC$\mathrm{P}$, and reliability coefficients of .73 for verbal persuasion ( 7 items), .76 for vicarious learning ( 7 items), .84 for physiological mechanisms ( 9 items), and .86 for mastery experiences (10 items) subscales. These values align with past research led by the instrument's developers (Fencl and Scheel, 2005). In that same study the survey was shown to correlate well with the Self-Efficacy for Academic Milestones Strength scale-a positively recognized and validated instrument. Some of the statements on the survey included the following: "I am capable of receiving good grades on assignments in this class" (mastery experience) and "I will get positive feedback about my ability to recall physics 
ideas" (verbal persuasion). Students used a five-point Likert scale to express agreement or disagreement with these. Overall scores in our study ranged from 79 to 165 . The use of the SOSESC-P also supported continuity with past studies performed at FIU that employed the same instrument.

Though the SOSESC-P was designed for the purpose of measuring overall self-efficacy and the sources of self-efficacy, prominent researchers in the field warn about potential issues caused by combining two or more sources of self-efficacy (Usher and Pajares, 2008). These argue that combining items specific to each source increases ambiguity about what exactly is being measured and that students' context, including gender and ethnicity, may shift the combination of sources that contribute to students' actual self-efficacy. We present this as a limitation of our study and for that reason we report on analyses of each source of self-efficacy separately, in addition to students' total score on the SOSESC-P, which we interpret as a proxy for student self-efficacy. We do so on the grounds that we found significant change on all four sources of selfefficacy and criteria established by past studies (Fencl and Scheel, 2004, 2005; Sawtelle, Brewe, and Kramer, 2011, 2012; Sawtelle et al., 2010).

\subsection{Results}

\subsubsection{Diagnosing Changes in Self-Efficacy}

Prior to performing $t$-tests we imputed student responses to the SOSESC-P in order to preserve the structure of our data, which reduces the rate of Type I error by better accounting for nonresponses than would simply removing those cases from the analysis (Rubin, 1996). Multiple imputation is a Monte Carlo technique 
that replaces missing values using a likelihood function that assumes missing data is missing at random (MAR) and not because of reporting bias not captured by other variables (Schafer, 1999). For that reason we included responses to pre- and post-SOSESC-P surveys, student GPA at the start of the course, gender, and centrality measures when estimating values for the missing data. Given that we had no more than a $20 \%$ nonresponse rate on the SOSESC-P we ran five imputations $(m=5)$ as suggested by the literature using the Amelia II package (Honaker, King, and Blackwell, 2011) in R (R Core Team, 2015). We ran the same analyses on all five data sets and pooled the results according to Rubin (Rubin, 1987; Schafer and Graham, 2002). Since imputed values were generated for missing cases, the resulting $N$ (i.e., $N=147$ ) included all unique participants enrolled in the fall courses during the first week of the semester.

We performed a dependent samples $t$-test to compare the mean total scores of the pre-SOSESC-P responses $\left(M_{\text {pre }}=135.36, S D=13.86\right)$ to those of the post- $\left(M_{\text {post }}=129.11, S D=17.23\right)$. The outcome revealed a statistically significant drop in physics-related self-efficacy from the beginning of the semester to the end of the semester $[t(146)=-4.75, p<.001]$ with a small to medium effect size (Cohen's $d=.40$ ). In order to further explore the breakdown of students' sources of self-efficacy, we disaggregated responses on the SOSESC-P according to the following sources of self-efficacy: mastery experiences (ME), VL (i.e., vicarious learning), VP (i.e., verbal persuasion), and physiological states (PS). Dependent sample $t$-tests on each of these subsections showed a statistically significant drop in students' sources of self- 
efficacy on every portion of the survey even when setting our threshold alpha at 0.0125 in order to apply a Bonferroni correction to diminish Type I error (see Table 1).

\begin{tabular}{|c|c|c|c|c|c|}
\hline \multicolumn{6}{|c|}{$\begin{array}{l}\text { CHANGES IN SOURCES OF SELF-EFFICACY } \\
\text { SCORES: }\end{array}$} \\
\hline \multicolumn{6}{|c|}{$\begin{array}{c}\text { Dependent Samples Comparisons of SOSESC-P } \\
\text { Shifts } \\
\text { (POST-PRE; } N=147 \text { ) }\end{array}$} \\
\hline \multirow{5}{*}{$\begin{array}{c}\text { PRE- } \\
S D \\
\text { POST } \\
S D\end{array}$} & $\begin{array}{l}\text { Total } \\
\text { Score }\end{array}$ & ME & VL & PS & $\mathbf{V P}$ \\
\hline & 135.36 & 40.87 & 29.74 & 34.76 & 30.11 \\
\hline & 13.86 & 4.71 & 3.30 & 4.82 & 2.85 \\
\hline & 129.11 & 38.54 & 28.1 & 33.28 & 28.9 \\
\hline & 17.23 & 6.05 & 4.05 & 6.44 & 3.51 \\
\hline $\begin{array}{c}\text { Diff. in } \\
\text { Mean }\end{array}$ & $-6.25^{* * *}$ & $-2.33^{* * *}$ & $-1.64^{* * *}$ & $-1.48^{* * *}$ & $-1.21 * * *$ \\
\hline$t$-value & -4.75 & -5.21 & -4.68 & -3.28 & -3.81 \\
\hline Cohen's $d$ & 0.40 & 0.43 & 0.39 & 0.27 & 0.32 \\
\hline
\end{tabular}

Table 1. Changes in the Sources of Self-Efficacy Scores: although students in MI courses typically show conceptual and attitudinal gains, these results suggest that students in MI experience a statistically significant drop in physics self-efficacy. This drop also shows up significantly on all subsections of the SOSESC-P.

\subsubsection{Measuring Social Interactions}

We combined students' responses to the social network survey across the first four administrations. We did this with the goal of preserving uniformity of data collection. We planned for five survey administrations with the requirement that they take place during a typical MI class in which student-groups work together on collaborative activities. Student interactions were primarily student generated and participants worked on physics related tasks. We achieved this setting across the first four data collections from both semesters in question, which had response rates of over $75 \%$. Final exam scheduling altered the intended environment for the fifth administration both in the fall of 2014 and in the 
fall of 2015. Still, we pursued collection of data from the last survey, which were given during optional final exam review classes where students who chose to attend were not encouraged to participate in active learning physics related inquiry. This is relevant since social context affects students' interactions, and the student network may reflect this. The uncharacteristic environment of this setting yielded less than $50 \%$ response rates and altered the resulting student network. In order to maintain fidelity of implementation, data from these surveys were not admitted into the final results, though analysis revealed nearly identical outcomes when included.

From the responses to the network survey question we constructed directed edge lists indicating the source of the interaction (i.e., student responding to the survey) and each target listed on the survey (i.e., student name written in response to the question). The edge lists from the first four collections were combined and every interaction given a value of " 1 ". Repeated interactions with the same targets were given a weight of +1 for each additional time the targets were listed on other administrations of the same survey question (see Figure 10 for an example of the Fall 2014 network structure). After combining data from both semesters, students' total inDegree $(M=14.1, S D=6.04)$, outDegree $(M=18.2, \mathrm{SD}=10.4)$, and directed PageRank $(M=1.19 \mathrm{e}-2, \mathrm{SD}=$ 2.56e-3) were calculated in R using the igraph package (Csárdi and Nepusz, 2006). InDegree was calculated by adding up the number of times a student was listed on question one of the four network surveys. OutDegree was calculated by adding up the number of individuals each particular student listed on question 
one of all four surveys, including instructors. Directed PageRank was calculated in igraph from incoming and outgoing links using the algorithm developed by Brin and Page (1998) and represented by equation 1:

$$
p(i)=\frac{q}{n}+(1-q) \sum_{j: j \rightarrow i} \frac{p(j)}{k_{\text {out }}(j)} i=1,2, \ldots, n
$$

where $p$ is the PageRank of node $i, j$ represents a node in the network linked to $i$, $p(j)$ and $k_{\text {out }}(j)$ are the PageRank and outDegree of node $j$, respectively, and $q$ is a damping factor commonly set at 0.15 as precedent in the literature (Csárdi and Nepusz, 2006; Fortunato and Flammini, 2007).

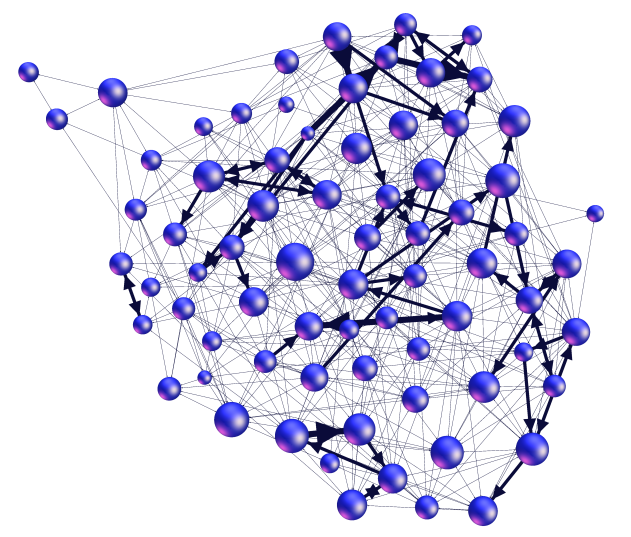

Figure 10. Combined student network in the MI course for Fall 2014: drawn using the Force Atlas algorithm on Gephi ${ }^{a}$. Sphere size represents PageRank centrality and edge thickness represents weight of tie. Instructors have been removed.

${ }^{\mathrm{a}} \mathrm{M}$. Bastian, S. Heymann, and M. Jacomy, in Proc. Third Int. ICWSM Conf. (San Jose, CA, 2009), pp. 361-362.

\subsubsection{Bootstrapped Linear Regressions}

We tested four linear regression models that aimed to predict total postself-efficacy scores while controlling for pre- scores. Because network data often fails to meet the assumption of independence, measures of centrality often result in non-normal distributions. Bootstrapped linear regressions do not require assumptions about the distribution; therefore we used this technique in order to 
account for any dependency in data retrieved from the social network (Fox, 2015). Bootstrapping is a Monte Carlo approach that applies a random resampling of the existing data set to calculate a set of regression coefficients on that sample. We did so over 1000 iterations on each our dataset and created a distribution of coefficients by which to compare the values in our data (Brownstone and Valleta, 2001). 95\% confidence intervals (Cl) for our parameters were calculated using the Bias-Corrected and Accelerated method developed by Efron (1987), which better addresses bias and skewness while producing narrower intervals. These analyses were run on each of our imputations with nearly identical results, which were then pooled. Although, in general, all four models predicted the dependent variable, the models revealed that PageRank was the only statistically significant predictor beside the control variable. Regression coefficients for inDegree and outDegree had confidence intervals that included zero. PageRank explained an additional $3.7 \%$ of the variance in students' post self-efficacy scores (see Table 2). Because of potential collinearity between the centrality measures, we tested these variables using separate models. The correlation between PageRank and inDegree was 0.46 ( $p$ $<.001)$, between PageRank and outDegree was $0.24(p<.01)$, and between inDegree and outDegree was $0.76(p<.001)$. Again, because centrality measures typically fail to meet the assumption of normality required by traditional statistical tests, the above correlations were calculated using a permutation test for correlation, which also employs a Monte Carlo method. 


\subsubsection{Examining Other Relevant Variables}

In order to gauge whether changes in students' self-efficacy scores were related to the presence of other variables associated with student performance, we undertook several additional analyses. Two separate student's independent samples $t$-tests were run to determine whether or not a difference exists between female and male students' pre- and post- scores on the SOSESC-P. The analysis revealed that no statistically significant gender difference existed at the start of the Ml courses or at the end. The same held true when examining the disaggregated sources of self-efficacy. Furthermore, a multiple linear regression model was examined to determine the ability of ethnicity and major, along with gender, to predict the variance in student self-efficacy scores at the end of the course when controlling for pre- scores. The results showed that the model was statistically significant $(p<.001)$, but the only variable that contributed to the model's significance was pre- score. Neither ethnicity nor declared major contributed to the variance in students' post-self-efficacy scores, though to be sure, the low number of representatives from certain ethnic groups (e.g., Black) and majors (e.g., English) limited the power of our model and our ability to make strong claims about the effect of ethnicity and major. Given that gender differences were not seen on pre- or post-self-efficacy scores, we did not expect this variable to be significant. 
Table 2. Models Using Network Variables Predicting Post Self-Efficacy Scores. InDegree and PageRank centralities capture a measure of recognition, but PageRank weighs that recognition according to the popularity of peers interacting with the student. Here we show that only PageRank predicts overall self-efficacy scores. Note standardized regression coefficients (i.e., $\beta$ ) appear in parentheses.

\begin{tabular}{|c|c|c|c|c|}
\hline \multicolumn{5}{|c|}{ Model-level statistics } \\
\hline F-statistic & $F(1,111)=42.34$ & $F(2,110)=25.04$ & $F(2,110)=22.58$ & $F(2,110)=22.76$ \\
\hline R-square & 0.276 & 0.313 & 0.291 & 0.293 \\
\hline \multirow[t]{2}{*}{$95 \% \mathrm{Cl}$ for R-square } & $(0.114,0.445)$ & $(0.159,0.472)$ & $(0.122,0.453)$ & $(0.128,0.451)$ \\
\hline & \multicolumn{4}{|c|}{ Regression Coefficients } \\
\hline Predictors & Model 1 & Model 2 & Model 3 & Model 4 \\
\hline PRE- SOSESC-P & $\begin{array}{c}0.65\left(\beta_{1}=.52\right) \\
\mathrm{CI}[0.41, .0 .88] ; \mathrm{SE}=0.12\end{array}$ & $\begin{array}{c}0.65\left(\beta_{1}=.52\right) \\
\mathrm{Cl}[0.42,0.88] ; \mathrm{SE}=0.12\end{array}$ & $\begin{array}{c}0.64\left(\beta_{1}=.51\right) \\
\mathrm{Cl}[0.40,0.87] ; \mathrm{SE}=0.12\end{array}$ & $\begin{array}{c}0.63\left(\beta_{1}=.51\right) \\
\mathrm{CI}[0.38,0.85] ; \mathrm{SE}=0.12\end{array}$ \\
\hline PageRank & & $\begin{array}{c}1380\left(\beta_{2}=.21\right) \\
\mathrm{CI}[279,2539] ; \mathrm{SE}=586\end{array}$ & & \\
\hline inDegree & & & $\begin{array}{c}0.37\left(\beta_{2}=.13\right) \\
\mathrm{CI}[-0.13,0.80] ; S E=0.24\end{array}$ & \\
\hline outDegree & & & & $\begin{array}{c}0.22\left(\beta_{2}=.13\right) \\
\mathrm{CI}[-0.05,0.47] ; S E=0.13\end{array}$ \\
\hline
\end{tabular}


Bootstrapped analyses revealed no difference between the mean outDegree nor PageRank of female and male students. Nevertheless, male students on average had slightly higher inDegrees than did female students $[t(121.9)=-2.13, p<.05$, Cohen's $d=0.37]($ see Table 3$)$.

Table 3. Gender-based comparisons of network centrality. InDegree and PageRank centralities do not differ significantly by gender. On the other hand, female students report more peers (i.e., outDegree) in response to the network survey question examined.

\begin{tabular}{c|c|c|c|}
\hline & inDegree & outDegree & PageRank \\
\hline $\begin{array}{c}\text { Mean } \\
\text { Differences } \\
\text { (Female-Male) }\end{array}$ & $-2.13^{*}$ & -0.63 & 0 \\
\hline$t$-statistic & -2.14 & -0.49 & 0.74 \\
\hline Cohen's $d$ & 0.37 & 0.09 & 0.13 \\
\hline$* p<.05$
\end{tabular}

\subsection{Discussion}

Our examination of an active learning, introductory physics course format revealed that regardless of gender, major, and ethnicity, students had on average lower beliefs about their ability to successfully complete physics related tasks at the end of the semester than they did at the beginning. This negative change was seen across the self-efficacy survey as a whole and when disaggregated by the four accepted sources of self-efficacy. Students report a decrease in the kinds of experiences that theoretically contribute to positive selfefficacy formation. This contrasts with a previous study in smaller classrooms using the same Ml curriculum that showed no change in overall student selfefficacy and an increase along the verbal persuasion scale (Sawtelle et al., 2010). We suggest as a possibility that these differences may exist for several reasons, including class size and data structure (e.g., handling of missing data). 
Moreover, we set our alpha levels at much steeper thresholds in order to combat Type I error-a correction this prior study did not apply. However the drop we found is relatively small compared to the range of the self-efficacy scale and the variance in student responses. The drop may simply reflect a correction of students' overconfidence (Lindstrom and Sharma, 2011).

In light of past research on student academic outcomes in MI, what captures our interest is that students experienced a decrease as opposed to an increase in all the sources of self-efficacy. In fact, we hypothesized increases both on selfefficacy as a whole and on each of the four-sources. The decrease found was approximately $73 \%$ as large as decreases seen in past studies with students in lecture courses (Sawtelle et al. 2010). These contrary results point to the need for further exploration of this topic, in particular with regard to factors that mediate these shifts. We should also note that our students started at higher levels than previously reported studies using the SOSESC-P (Fencl and Scheel, 2004; Sawtelle et al., 2010). While a variety of variables may have contributed to this latter attribute, any justification would merely be speculative.

Given the inherently social aspects of self-efficacy development in addition to the emphasis on discourse-based learning in the Ml curriculum, we tested whether students' social behavior predicted self-efficacy shifts. We aver that a relationship exists between at least one kind of interaction, as captured by student PageRank centrality, and changes in students' overall efficacy beliefs. We found that the number of times a student is listed by popular peers makes a difference (see PageRank in Table 2). That is to say that being named by a 
student whom others report having a high number of interactions with positively predicts increases in overall self-efficacy. In short, a one standard deviation increase in student PageRank results in a .21 standard deviation increase in post-self-efficacy after controlling for pre- scores (see Table 2). On the other hand, we did not find that the number of peers a student has a meaningful interaction with (i.e., outDegree) nor the number of times a students is recognized by his or her peers as having contributed to a meaningful interaction (i.e., inDegree) affect changes on the self-efficacy scale as a whole.

With regard to the sources of self-efficacy, PageRank also positively predicted mastery experience scores. This deserves some unpacking, as this source of self-efficacy is not typically associated with social interactions, but often plays a primary role in self-efficacy formation, especially for men (Zeldin, Britner, and Pajares, 2008). Moreover, both the number of incoming and outgoing interactions positively predicted verbal persuasion scores, while only outgoing interactions positively predicted vicarious learning scores. None of the interactions examined had a statistically significant association with students' physiological state.

These results align with our model of self-efficacy development in active learning environments (see Figure 9), but also expand on it. They support our belief that specific kinds of social academic experiences, as quantified using centrality measures, partially predict students' post measures on the inherently social sources of self-efficacy. Yet, the analyses also support expansion of the model as centrality was found to have an even stronger relationship with ME, 
which we did not consider as a source of self-efficacy related to social networks. In other words a student exhibiting a drop because of having poor results on a mastery experience (e.g., exam) did not necessarily strike us as an experience directly related to the student's network of peers. Nevertheless, indirectly, it may be possible that access to a support group in the class may provide students with capital that leads to improved performance as implied by previous studies on teacher networks and capital theory (Bourdieu, 1983; Siciliano, 2016).

Although our linear models only explain a relatively small portion of additional variance, they forge a valuable link between SNA and the sources of self-efficacy. As expected, an increase in the number of times peers interact with a particular student increases the chances this student has positive verbal persuasion experiences. The specific items on the SOSESC-P suggest that the student is receiving encouragement about his or her physics ability. This aligns with the fact that others are reporting having salient academic interactions with this student. The same occurs with regard to a student's outDegree, but this kind of outgoing interaction-in the sense that it represents how often students reach out to peers-is also positively related with vicarious learning experiences. Since vicarious learning experiences theoretically indicate situations where one learns from watching someone with whom one relates, it is possible that these individuals are the ones students seek out. Although the data in this particular study does not allow us to make a definitive conclusion in that regard, it certainly offers some value to an examination of the kinds of individuals different students reach out to. This is further supported by the observed relationship between 
PageRank and mastery experiences. PageRank does more than simply tally the number of social interactions (i.e., outgoing or incoming), but also captures with whom the interaction occurs. Interactions coming from popular individuals as defined by their inDegree positively predict a students' sense that they can learn and get good grades in physics. Because students did not know each other's inDegree, we can infer that students recognize, in some capacity, who these popular individuals may be and have a perception about their academic popularity. A highly social setting may catalyze these peer-to-peer judgments.

Active learning environments, such as $\mathrm{Ml}$, create the kind of social space that allows students the flexibility to interact in different ways with different people (Sawtelle et al., 2012). Though no relationship was found between gender and self-efficacy, female and male students differ in the kinds of interactions they experience. Male students in this class are the subjects of others' meaningful interactions more so than female students. While we did not intend to focus on gender differences, we do present these results as evidence that certain students experience the social aspects of this type of environment differently. In our case, major and ethnicity did not contribute to these differences, but that may have been a result of our relatively low sample size in certain subgroups. The value of having examined several measures of centrality is justified in our ability to conclude that the types of interactions students experience and with whom they have these interactions matters with regard to self-efficacy formation. The characteristic of PageRank as a measure of the kinds of people whom students interact with may also help to explain why PageRank is a slightly better predictor 
of overall self-efficacy than inDegree or outDegree. Additionally, we know from past studies that mastery experiences, a source we found associated with PageRank, often plays a greater role in self-efficacy formation in physics courses than other sources (Sawtelle, Brewe, and Kramer, 2012; Zeldin et al., 2008).

Our surprising results encourage us to think about ways to mitigate effects of the social structure of MI on students' efficacy beliefs and vice versa. This might manifest itself through the purposeful stimulation of interactions between certain groups of students. Altering how students participate in the social aspects of a classroom in a way that gives all an equitable chance then becomes, in part, an issue of how students recognize the value of their peers. We suspect that the highly social nature of this learning approach exposes students to academic judgment from peers and can initiate introspective evaluation, specifically while students solve problems in groups and when they present solutions to the larger classroom. The increased number of interaction events may provide students with more opportunities to generate perceptions about their peers' ability to contribute to a physics-related task and, in turn, influence whom they work with or whom they list when asked to recall meaningful academic interactions. These perceptions can drive changes in interactions. Although in this example we have suggested that these changes may relate to academic perceptions, they may also relate to students' ability to communicate effectively, helpfulness, or even friendliness.

We faced certain limitations worth noting. No student in the Fall 2014 and 2015 course had declared physics as a sole major. Physics majors may be less 
susceptible to changes in self-efficacy via peer-recognition because of their strong physics identity relative to those pursuing other STEM fields (Hazari, Sonnert, Sadler, and Shanahan, 2010). The absence of physics majors in these MI courses might also point to a possibly unidentified source of self-selection bias. Furthermore, the MI classrooms in question were among the first at FIU to host that many students at once. The novelty of implementing this curriculum with more students in a brand new classroom may have led to unrecognized shortcomings. Further investigation should take place to more clearly understand how these factors relate to our study.

Knowing the powerful role that introductory physics courses play on career persistence and the underrepresentation of certain groups of students (NRC, 2013), we are pressed to search for ways to ensure that students complete the semester feeling more confident in their ability to perform physics tasks rather than less confident-regardless of the gradient. Though we report a somewhat minor $3.79 \%$ overall drop in students' physics self-efficacy, this is an average measure. Individually, students ranged from a $29 \%$ decrease from pre- score to a $46 \%$ increase from pre- score. This variance offers a living example of how students in the course can exhibit contrary, affective outcomes. Our study showed that part of what accounted for these differences are the kinds of interactions students had. Similar learning environments, particularly those that focus on active learning mediated by student interactions, may exhibit parallel outcomes. Our holistic approach to student learning motivates us to explore ways to improve $\mathrm{MI}$ and interactive learning approaches in the introductory classroom 
such that the maximal number of students leave not just academically prepared, but also affectively equipped to persist in physics careers. Our study aims to highlight the value of examining these facets of student outcomes in these environments, specifically self-efficacy development and course-related social interactions. It is not enough to simply say that students are learning more. This is especially true in the realm of career decision-making where self-efficacy plays a central role even for STEM related professions, partially explaining the underrepresentation of certain groups in these fields (Rittmayer and Beier, 2009). Bandura (1993) explains:

...the stronger people's belief in their efficacy, the more career options they consider possible, the greater the interest they show in them, the better they prepare themselves educationally for different occupations, and the greater their staying power and success in difficult occupational pursuits.

Our exploration of this matter reflects our commitment to not only help our students better understand physics, but also motivate some to join the physics community. This requires that we focus on more than just content matter.

References (Chapter 2)

Bandura, A., Barbaranelli, C., Caprara, G. V, and Pastorelli, C. (2001). Selfefficacy beliefs as shapers of children's aspirations and career trajectories. Child Development, 72(1), 187-206. doi:10.1111/1467-8624.00273

Bandura, A. (1993). Perceived self-efficacy in cognitive development and functioning. Educational Psychologist. doi:10.1207/s15326985ep2802_3

Bandura, A. (1997). Self-efficacy: The exercise of control. New York, NY: W.H. Freeman and Company. 
Bourdieu, P. (1986). The forms of capital. In J. Richardson (Ed.), Handbook of Research for the Sociology of Education (pp. 241-258). Wesport, CT: Greenwood. http://doi.org/10.1002/9780470755679.ch15

Brewe, E., Sawtelle, V., Kramer, L. H., O'Brien, G. E., Rodriguez, I., and Pamelá, P. (2010). Toward equity through participation in Modeling Instruction in introductory university physics. Physical Review Special Topics - Physics Education Research, 6(1), 010106. doi:10.1103/PhysRevSTPER.6.010106

Brewe, E., Traxler, A., De La Garza, J., and Kramer, L. H. (2013). Extending positive CLASS results across multiple instructors and multiple classes of Modeling Instruction. Physical Review Special Topics - Physics Education Research, 9(2), 1-10. http://doi.org/10.1103/PhysRevSTPER.9.020116

Brewe, E., Kramer, L., and Sawtelle, V. (2012). Investigating student communities with network analysis of interactions in a physics learning center. Physical Review Special Topics - Physics Education Research, 8(1), 010101. doi:10.1103/PhysRevSTPER.8.010101

Brin, S., and Page, L. (1998). The anatomy of a large-scale hypertextual web search engine. In Seventh International World Wide Web Conference (pp. 107-117). Brisbane, Australia. http://doi.org/10.1016/S0169-7552(98)00110$\mathrm{X}$

Brownstone, D., and Valletta, R. (2001). The Bootstrap and multiple imputations: Harnessing increased computing power for improved statistical tests. The Journal of Economic Perspectives, 15(4), 129-141.

Bruun, J., and Brewe, E. (2013). Talking and learning physics: Predicting future grades from network measures and Force Concept Inventory pretest scores. Physical Review Special Topics - Physics Education Research, 9(2), 020109. doi:10.1103/PhysRevSTPER.9.020109

Chen, J. a., and Usher, E. L. (2013). Profiles of the sources of science selfefficacy. Learning and Individual Differences, 24, 11-21. http://doi.org/10.1016/j.lindif.2012.11.002

Crisp, G., Nora, A., and Taggart, A. (2009). Student characteristics, precollege, college, and environmental factors as predictors of majoring in and earning a STEM degree: An analysis of students attending a Hispanic serving institution. American Educational Research Journal, 46(4), 924-942.

Csárdi, G., and Nepusz, T. (2006). The igraph software package for complex network research. InterJournal Complex Systems. Retrieved from http://igraph.sf.net 
Efron, B. (1987). Better bootstrap confidence intervals. Journal of the American Statistical Association, 82(397), 171-185. http://doi.org/10.2307/2289144

Finkelstein, N. D., and Pollock, S. J. (2005). Replicating and understanding successful innovations: Implementing tutorials in introductory physics. Physical Review Special Topics - Physics Education Research, 1(1), 1-13. doi:10.1103/PhysRevSTPER.1.010101

Forsman, J., Moll, R., and Linder, C. (2014). Extending the theoretical framing for physics education research: An illustrative application of complexity science. Physical Review Special Topics - Physics Education Research, 10(2), 1-13. doi:10.1103/PhysRevSTPER.10.020122

Fortunato, S., and Flammini, A. (2007). Random walks on directed networks: The case of PageRank. International Journal of Bifurcation and Chaos, (1), 15. http://doi.org/10.1142/S0218127407018439

Fox, J. (2015). Bootstrapping regression models. In Applied Regression Analysis and Generalized Linear Models (3rd ed., pp. 587-606). Thousand Oaks: SAGE Publications, Inc.

Grunspan, D. Z., Wiggins, B. L., and Goodreau, S. M. (2014). Understanding classrooms through social network analysis: A primer for social network analysis in education research. Cell Biology Education, 13(2), 167-178. doi:10.1187/cbe.13-08-0162

Hazari, Z., Sonnert, G., Sadler, P. M., and Shanahan, M.C. (2010). Connecting high school physics experiences, outcome expectations, physics identity, and physics career choice: A gender study. Journal of Research in Science Teaching, 47(8), 978-1003. doi:10.1002/tea.20363

Halloun, I. A., and Hestenes, D. (1987). Modeling instruction in mechanics. American Journal of Physics, 55(5), 455-462.

Honaker, J., King, G., and Blackwell, M. (2011). AMELIA II: A program for missing data. Journal of Statistical Software, 45(7), 1-54.

http://doi.org/10.1.1.149.9611

Lent, R. W., Brown, S. D., and Hackett, G. (1994). Toward a unifying social cognitive theory of career and academic interest, choice, and performance. Journal of Vocational Behavior, 45, 79-122. 
Lent, R. W., Brown, S. D., and Larkin, K. C. (1987). Comparison of three theoretically derived variables in predicting career and academic behavior: Self-efficacy, interest congruence, and consequence thinking. Journal of Counseling Psychology, 34(3), 293-298. doi:10.1037/0022-0167.34.3.293

Lent, R. W., Lopez, F. G., and Bieschke, K. J. (1993). Predicting mathematicsrelated choice and success behaviors: Test of an expanded social cognitive model. Journal of Vocational Behavior. doi:DOI 10.1006/jvbe.1993.1016

Lindstrøm, C., and Sharma, M. D. (2011). Self-efficacy of first year university physics students: Do gender and prior formal instruction in physics matter? International Journal of Innovation in Science and Mathematics Education, 19(2), 1-19.

National Research Council. (2007). Rising above the gathering storm: Energizing and Employing America for a brighter economic future. Washington, DC: National Academies Press.

National Research Council. (2010). Rising above the gathering storm: Revisited. Washington, DC: National Academies Press.

National Research Council. (2013). Adapting to a changing world: Challenges and opportunities in undergraduate physics education. Washington, DC: National Academies Press.

Pajares, F. (1997). Current directions in self-efficacy research. Advances in Motivation and Achievement, 10(149), 1 - 49.

President's Council of Advisors on Science and Technology. (2010). Prepare and Inspire: K-12 Education in Science, Technology, Engineering, and Math (STEM) for America's Future: Executive Report. Washington, DC. doi:10.1126/science.1198062

Rittmayer, M. A., and Beier, M. E. (2009). Overview: Self-efficacy in STEM. Retrieved from http://www.engr.psu.edu/AWE/ARPresources.aspx

Rubin, D.B. (1987). Multiple imputation for nonresponse in surveys. New York, NY: J. Wiley and Sons.

Rubin, D. B. (1996). Multiple imputation after $18+$ years. Journal of the American Statistical Association, 91(434), 473-489. 
Sawtelle, V., Brewe, E., Goertzen, R. M., Kramer, L. H., Rebello, N. S., Engelhardt, P. V., and Singh, C. (2012). Creating opportunities to influence self-efficacy through modeling instruction. In 2011 Physics Education Research Conference (Vol. 339, pp. 339-342). American Institute of Physics. doi:10.1063/1.3680064

Sawtelle, V., Brewe, E., Kramer, L. H., Singh, C., Sabella, M., and Rebello, S. (2010). Positive impacts of Modeling Instruction on self-efficacy. In 2010 Physics Education Research Conference (Vol. 289, pp. 289-292). American Institute of Physics. http://doi.org/10.1063/1.3515225

Schafer, J. L. (1999). Multiple imputation: A primer. Statistical Methods in Medical Research, 8(1), 3-15. http://doi.org/10.1191/096228099671525676

Schafer, J. L., and Graham, J. W. (2002). Missing data: Our view of the state of the art. Psychological Methods, 7(2), 147-177. http://doi.org/10.1037/1082989X.7.2.147

Scott, J. (1988). Trend report: Social network analysis. Sociology, 22(1), 109_ 127. http://doi.org/10.1177/0038038588022001007

Scott, J., and Carrington, P.J. (2011). The sage handbook of social network analysis. London, England: Sage.

Siciliano, M. D. (2016). It's the quality not the quantity of ties that matter: Social networks and self-efficacy beliefs. American Educational Research Journal, 53(2), 227-262. http://doi.org/10.3102/0002831216629207

Tinto, V. (1997). Classrooms as communities: Exploring the educational character of student persistence. The Journal of Higher Education, 68(6), 599-623.

Thomas, S. L. (2000). Ties that bind: A social network approach to understanding student integration and persistence. The Journal of Higher Education, 71(5), 591-615.

Usher, E. L., and Pajares, F. (2008). Sources of self-efficacy in school: Critical review of the literature and future directions. Review of Educational Research, 78(4), 751-796. http://doi.org/10.3102/0034654308321456

Zeldin, A. L., Britner, S. L., and Pajares, F. (2008). A comparative study of the self-efficacy beliefs of successful men and women in mathematics, science, and technology careers. Journal of Research in Science Teaching, 45(9), 1036-1058. doi:10.1002/tea.20195 


\section{CHAPTER 3}

THE RISKS WE TAKE: UNDERSTANDING THE DEVELOPMENT OF INTEREST, SELF-EFFICACY, AND STUDENT NETWORKS IN REFORMED UNDERGRADUATE PHYSICS COURSES

\subsection{Abstract}

The proliferation of active learning curricula in undergraduate introductory STEM courses follows from research and policy that affirms their vantage over traditional pedagogies with regard to students' academic outcomes. In the physics domain, of the variety of reformed undergraduate introductory courses that exist, Modeling Instruction (MI) serves as an example of an active learning, student-centered curriculum grounded in a sociocultural framework and has been shown to improve student attitudes and conceptual understanding. Student interactions play a salient role in the MI classroom. The impact of student interactions on the central constructs of preeminent career theories such as the Social cognitive career theory (SCCT) and the identity framework has not been thoroughly explored. Here we describe a study of the change in students' physics self-efficacy and physics interest, and the effect that academic relationships had on their development. Our ${ }^{7}$ examination of three large capacity MI courses that took place in the fall of 2014 and fall of $2015(N=221)$ revealed a decrease in both students' physics self-efficacy and interest with small to medium effect sizes. Using the tools of network analysis to quantify student interaction, we tested three structural equation models, which showed that student interactions as measured by PageRank centrality have small, but positive contributions to

\footnotetext{
7 See Footnote 4 in Chapter 1 for authorship information.
} 
self-efficacy development, but none to interest development, achieving moderate measures of fit. Surprisingly, we also found that participants' physics interest predicted the development of their physics self-efficacy and not the other way around, as had been suggested by SCCT and identity framework. This work suggests more nuanced applications of SCCT and identity framework in the context of reformed STEM curricula and has implications on how active learning settings influence constructs related to career decision-making.

Keywords: physics, self-efficacy, interest, career, social network analysis, classroom interactions

\subsection{Introduction}

The nationally recognized need to increase the number of students majoring in science, technology, engineering, and mathematics (STEM) fields behoove researchers to examine the processes that lead to higher retention and persistence of undergraduate STEM majors (National Academies of Sciences, 2016). The contribution of domain-specific self-efficacy and interest to STEM recruitment has been well examined (Bandura, 1993, 1997; Schunk, 2012). In particular, these constructs have been shown to predict career choice behavior better than do academic achievement or personality-based theories (Bandura, Barbaranelli, Caprara, and Pastorelli, 2001; Kjærnsli and Lie, 2011; Lent, Brown, and Larkin, 1987). Two prominent career theories affirm the contribution of selfefficacy and interest. Lent, Brown, and Hackett's (1994) Social cognitive career theory (SCCT) supports the mediating role that self-efficacy and vocational outcome expectations play between learning experiences and interest. In turn 
student interest can have an effect on students' goals and goal accomplishments, such as completing a STEM major. Using an identity-based approach, Hazari, Sonnert, Sadler, and Shanahan (2010) have made the case that "performance/competence," a construct that shares some similarities with self-efficacy, influences students' interests in a particular field, which can then contribute to how students identify with that field. The field-specific identity framework has been shown to predict career choices of physicists and engineers (Hazari et al., 2010; Godwin, Potvin, Hazari, and Lock, 2016).

Given our current national focus on implementing student-centered, interactive learning curricula, their impact on career shaping constructs like selfefficacy and interest deserves attention (President's Council of Advisors on Science and Technology, 2010; National Academy of Sciences, 2016). Bandura (1993) defined self-efficacy as students' beliefs about their ability to complete particular tasks. He posits an inherent relationship between the development of this construct and social interactions, specifically citing the role of vicarious learning and verbal persuasion experiences (Pajares, 1997). These kinds of experiences where students learn from watching their peers fail or succeed at specific tasks (i.e., vicarious learning) or where they receive encouragement or discouragement from others about their abilities (i.e., verbal persuasion) often exist in greater abundance where active learning pedagogies characterize the teaching format (Sawtelle, Brewe, Goertzen, and Kramer, 2012; Fencl and Scheel, 2005). The relationship between self-efficacy and interactions motivates our examination of relationships in active learning physics courses. 


\subsection{Overlaps in Career Theories: SCCT and Identity}

The overlaps between SCCT and the identity framework point to the predictive value of both self-efficacy and interest with regard to career related behaviors. Both models share direct paths from self-efficacy to interest. Both also establish direct paths from self-efficacy to the constructs that mediate career attainments (i.e., choice goals in SCCT model and identity in the identity framework), as well as indirect paths mediated by interest. Although differences exist between the two models, the similarities support our focus on self-efficacy and interest along these well-established pathways.

Extending Bandura's (1989) social cognitive theory, Lent et al. (1994) developed SCCT as a comprehensive model of vocational choice. Their work has received much attention, finding verification in part through research in various science related contexts (e.g., Dickinson, 2007; Lent, Lopez, Lopez, and Sheu, 2008; Navarro, Flores, and Worthington, 2008; Smith and Fouad, 1999). Meta-analyses, too, have exhibited generally high levels of model agreement with SCCT (Brown et al., 2008; Sheu et al., 2010). The model posits that learning experiences mitigated by person-inputs (e.g., gender, race/ethnicity) directly contribute to individuals' domain-specific self-efficacy and outcome expectations. The latter two in turn predict their interests, goals, and relevant behavior. These then contribute to performance attainments (e.g., GPA, career persistence), looping back around to learning experiences (see Figure 11). The social cognitive career theory has been corroborated with various populations, including 
young children, college students, and adults, as well as people from various minority groups (Nauta, Kahn, Angell, and Cantarelli, 2002).

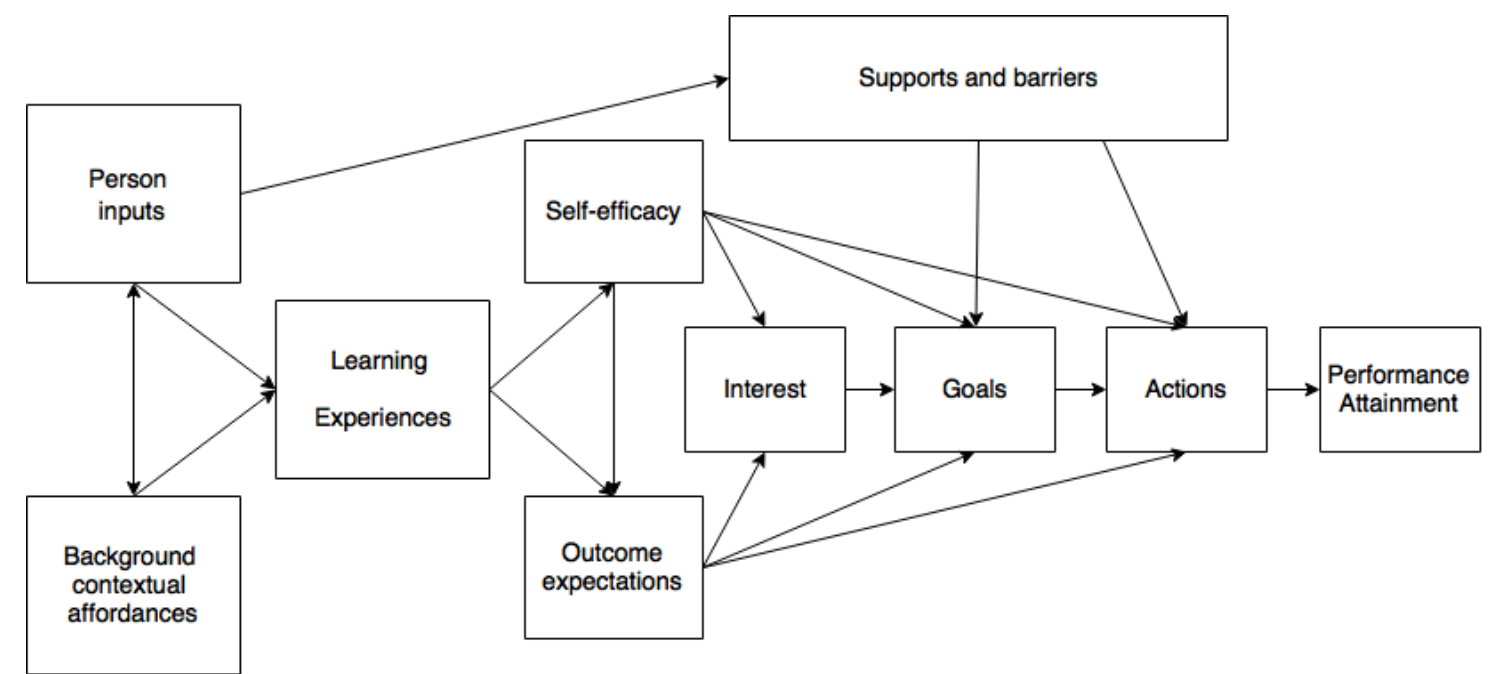

Figure 11. Model of SCCT adapted from Lent et al. (2003).

The identity framework of vocational choice developed by Hazari et al. (2010) makes the case for three latent constructs as predictors of students' domain-specific identity (e.g., physics identity). These constructs include performance/competence, interest, and recognition, such that performance/competence beliefs contribute to interest in a field and sense of recognition from members who participate in that field. Interest and recognition predict individuals' sense of identity in a particular domain (see Figure 12). Grounded in the work of Shanahan $(2007,2008)$, Hazari et al. (2010) have presented identity as a construct related to how a person sees himself or herself. For example, individuals who see themselves as physics people have high physics identity. Physics identity turns out to have meaningful implications for career choice (Godwin et al., 2016; Hazari et al., 2010). 


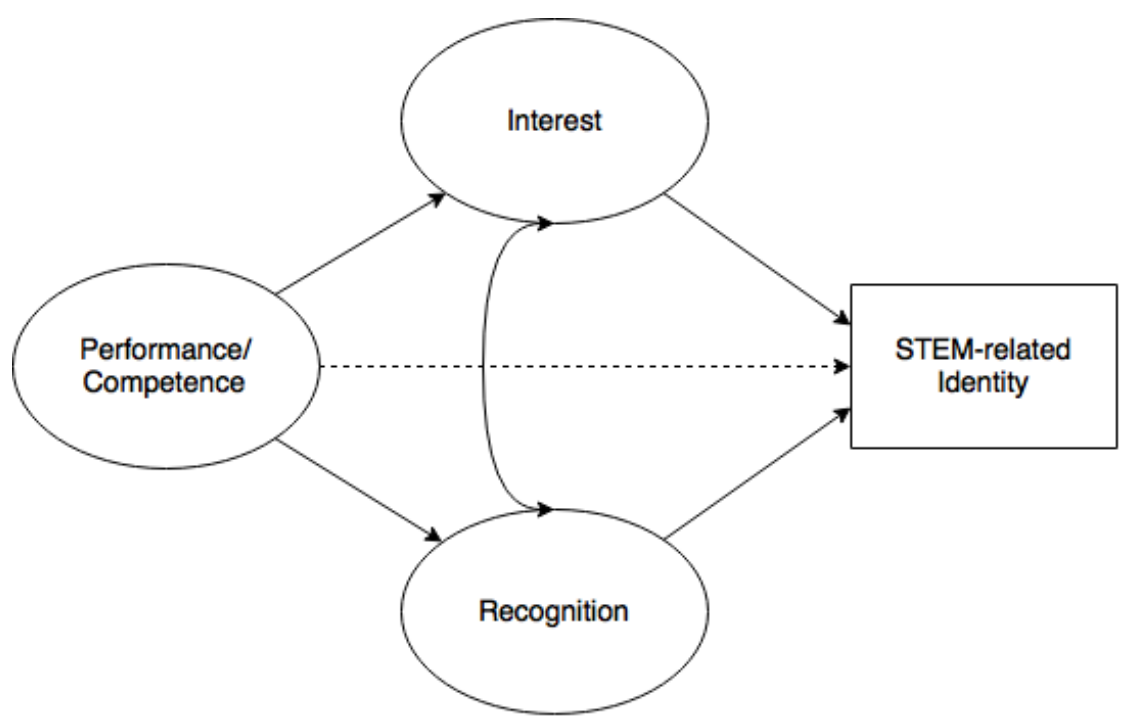

Figure 12. Model of the identity framework adapted from Godwin et al. (2016).

As alluded to earlier the link between SCCT and the identity framework exists in the overlap between two preeminent constructs pertaining to these models: interest and self-efficacy. Hazari et al.'s (2010) identity framework draws directly from SCCT in their inclusion of interest as part of the structure of their model, and makes parallels between performance/competence and self-efficacy. The authors define performance/competence as students' beliefs about both their ability to understand physics concepts and perform physics related tasks. The latter portion aligns closely with well-established definitions of self-efficacy (Bandura, 1997; Usher and Pajares, 2008). In practice, these constructs may or may not measure the same things. Although Godwin et al. (2016) have recognized the similarities, they state explicitly that performance/competence beliefs are somewhat more coarse grained than the "task-scale" behaviors typically targeted by measures of self-efficacy. Yet, it is worth noting that the literature on measurement of students' self-efficacy supports the use of items 
that lie on a continuum of tasks ranging from very specific to general (Lent and Brown, 2006; Usher and Pajares, 2008), further affirming the similarities between the constructs.

These two approaches to understanding the mechanisms that lead to career choice do differ on a variety of other points. The "output" and "input" variables accounted for by these models, not including self-efficacy and interest, mark the most obvious contrast between the identity framework and SCCT. For example, the identity-based model considers identity as the primary predictor of career choice, while SCCT places the onus on choice goals--the career-related goals of the individual--as the predictor of performance attainment, which is mediated by choice actions. These two outcomes (i.e., career choice and choice goals) are similar, but differ in nuanced ways. Career choice, as measured by Godwin et al. (2016) and Hazari et al. (2010), generally refers to students' selfreported likelihood to pursue a particular career path (e.g., chemical engineering, bioengineering, physics). Choice goals, as defined by Lent et al. (1994), may include long-term goals, such as pursuing a degree in a specific field, but also refer to short-term goals that might lead to achieving long-term goals (e.g., passing Introduction to Physics I with an "A"). Another obvious difference between SCCT and Hazari et al.'s (2010) identity framework is the incorporation of several additional input variables in Lent et al.'s (1994) work. These include vocational outcome expectations, learning experiences, person-inputs, background contextual affordances, and contextual influences on choice behavior. This encompassing approach more explicitly integrates factors 
influencing career choice, such as gender, which both Hazari et al. (2010) and Godwin et al. (2016) have given attention to and taken into account in their analyses, though not explicitly as a part of their model.

\subsection{Self-Efficacy and Interest}

Preeminent in the models described above, self-efficacy and interest have exhibited a practical usefulness in predicting student outcomes that matter to science education researchers--in particular physics education researchers-including increased student grades and desire to pursue physics careers. The positive relationship between students' physics self-efficacy and course grade has been found in a variety of contexts, from private institutions in New England to public universities in South Florida (Lynch, 2010; Sawtelle, Brewe, and Kramer, 2012). The same can be observed in academic settings outside of the United States (e.g., Lindstrøm and Sharma, 2011). As a related point, physics interest has been shown to correlate with student retention. For example, Sadler, Sonnert, Hazari, and Tai (2012) analyzed data from a national random sample of

students from 34 different higher education institutions and found that those who reported higher physics interest in high school were more likely to persist in their intent to pursue a STEM career by the time they enrolled in college.

Research has established a consistent relationship between self-efficacy and physics interest in a myriad of contexts with participants from various ethnic backgrounds (Bieschke, Bishop, and Garcia, 1996; Lenox and Subich, 1994; Lopez, Lent, Brown, and Gore, 1997; Tang, Fouad, and Smith, 1999). Despite this positive correlation--typically ranging from .2 to .7 --the constructs are 
different, both conceptually and in practice where each distinctly explains some of the variance in career choice (Donnay and Borgen, 1999; Smith and Fouad, 1999). In terms of the cause-and-effect relationship between self-efficacy and interest, research describes some reciprocity between the two where self-efficacy contributes to interest development, but interest may lead to engaging in a novel activity, which can result in experiences that lead to self-efficacy formation (Bandura, 1997; Lent et al., 1994; Nauta et al., 2002). Still, as pointed out by Nauta et al. (2002), the visual model representations and language used by career development researchers tend to emphasize a causal directionality leading from self-efficacy to interest (e.g., Bandura, 2001; Godwin et al., 2016; Lent et al., 2008; Sheu et al., 2010; Smith and Fouad, 1999).

\subsection{Self-Efficacy in the Active learning Physics Classroom}

The specific classroom elements that contribute to changes in student self-efficacy have not been fully understood. Previous studies have shown that the nature of the physics classroom matters when it comes to self-efficacy formation. Physics instructors that employ alternative teaching strategies (e.g., discussion, inquiry-lab exercises, conceptual problem assignments) instead of traditional strategies (e.g., lecture, directed lab exercises, demonstrations) will likely find students who report higher scores on a survey of self-efficacy and its sources (Fencl and Scheel, 2005). In fact, Fencl and Scheel (2004) found that when comparing all the teaching strategies they examined, collaborative learning had the highest correlation with end-of-semester physics self-efficacy. 
With regard to the development of self-efficacy, Sawtelle et al. (2010) showed that students taking introductory physics courses at a large Hispanic Serving Institution reported having lower self-efficacy at the end of the semester when compared to the start of term if the instructor had used traditional, lecturebased teaching methods. Students whose instructors implemented Modeling Instruction--an active learning introductory physics curriculum--did not report any significant changes in their self-efficacy from pre to post, which is commendable given the often-seen drop in physics self-efficacy found in introductory courses that results from students adjusting their overconfidence (Boekaerts and Rozendaal, 2010; Mann and Golubski, 2013; Multon, Brown, and Lent, 1991; Pajares and Kranzler, 1995). This beneficial interaction between pedagogy and self-efficacy may have some limitations. For example, Sawtelle et al. (2010) saw no change in student self-efficacy in Modeling Instruction courses that had a capacity of 30 students. In larger sections implementing the same curriculum, students' self-efficacy decreased over the course of the semester, albeit not as much as the self-efficacy of those in lecture-based sections (Dou et al., 2016).

\subsubsection{The Modeling Instruction Curriculum}

The progression of physics education research has led to the development of curricula, particularly in introductory courses, that shy away from lecture-based teaching styles (e.g., Etkina and Van Heuvelen, 2001; Finklestein and Pollock, 2005). Of these, Modeling Instruction (MI) has been examined at both the high school and undergraduate level and exhibited various positive results (Hestenes, 1987; Brewe, 2008). Research into MI has shown that college 
students taking Introductory Physics with Calculus not only pass at greater rates than students taking the equivalent lecture-based courses, but also score higher on well-established concept inventories (Brewe et al., 2010b). This outcome aligns with the strong consensus that active learning strategies, even when broadly defined, help students achieve higher scores on exams and concept inventories (Freeman et al., 2014). Yet, these positive academic outcomes stand contrary to decreases in student self-efficacy exhibited by students in classrooms of $70+$ peers, as described in Dou et al. (2016). In Dou et al., the overall decrease in self-efficacy was observed regardless of student gender or ethnicity, and suggests the presence of structures generated by this active learning curricula that may negatively impact the factors that motivate students to pursue careers in STEM. These structures may include, among many, students' social interactions in the classroom as those who received attention from academically popular peers (i.e., perceived by others as meaningful academic resources) were more likely to see increases in their individual self-efficacy scores. In other words, both the kinds of classroom interactions that took place, as well as the type of persons with whom those interactions took place in terms of academic influence, were associated with students' self-efficacy development.

For context, MI Introductory Physics I with Calculus courses (referred to as $\mathrm{MI}$ from here on out) follow patterns expected of curricula designed with a sociocultural, interactive framework in mind. Created by Hestenes (1987) and further developed for college-level introductory physics by Desbien (2002) and Brewe (2008), the most salient characteristic of the curriculum is the application 
of student discourse as a tool for knowledge construction, particularly around a few, key disciplinary concepts. Students work in small and large groups on carefully designed, inquiry-based activities meant to stimulate discussion that leads to learning. As a result, students can often be seen initiating conversations with their tablemates or collaborating with peers at other parts of the room in order to reach consensus.

Brewe, Kramer, and O'Brien (2010a) showed that students in MI courses see increased opportunities to engage with peers on academic content than do students in lecture-based sections of the course. The authors calculated the number of connections made between students in lecture-based and MI introductory physics courses by asking them at the beginning and end of the semester who they worked with to learn physics. Students in MI reported ten times the number of interactions. Moreover, by the end of the course, all MI students reported interacting with at least one other person in class, while a great majority of those in lecture-based courses still reported no peer-to-peer interactions. The authors made the case that both the physical layout of the MI classroom (i.e., open space with moveable furniture) and the instructional design of the curriculum help to facilitate socialization in the context of physics learning.

Qualitative analyses of student participation in Ml courses revealed the existence of self-efficacy experience opportunities (SEOs)--occurrences aligned with one of the four sources of self-efficacy (i.e., mastery experiences, vicarious learning, verbal persuasion, physiological states) that have the potential to impact its development (Sawtelle et al., 2012). For example, while trying to 
complete a position versus time graph two students discuss the importance of having a reference point; mutual agreement on what the reference point is in this particular problem can potentially serve as a mastery experience, and therefore, an SEO. The authors do not directly attribute the abundant presence of these types of experiences to $\mathrm{Ml}$ as a whole, but rather to the model-eliciting group activities that are part of the curriculum.

\subsection{The Role of Student Interactions in Physics Self-Efficacy Formation in MI Classrooms}

The connection between peer collaborations and self-efficacy development stands not only on classroom evidence, but also well-established theory. Bandura's (1993) descriptions of his four sources of self-efficacy posit some dependence on socially active environments.While "mastery experiences" can occur in isolation when students find themselves failing or succeeding at a task, by definition, "vicarious learning" experiences require the presence of others with whom students relate. A vicarious learning experience can occur when students observe their peers succeeding or failing at a specific task. If students associate themselves with those peers, they may expect the same results from their own efforts. "Verbal persuasion" experiences not only require the presence of others, but direct interactions. Explicit encouragement or discouragement from peers or instructors can lead students to form beliefs about their abilities that shape their self-efficacy. While interacting with others is not a requirement of mastery experiences or "physiological states" (e.g., anxiety, 
excitation, depression, hunger), vicarious learning and verbal persuasion experiences exist primarily in social settings.

Given the sociocultural learning framework of the Ml curriculum, both peer-to-peer and peer-to-instructor interactions occur on a frequent basis. Whether in small groups working on model building activities or sharing progress in larger group meetings ranging from 20 to 30 students, a variety of opportunities to experience a vicarious learning or verbal persuasion events exist. As students interact with one another, they sit or stand in close proximity, capable of watching their peers succeed or fail in the tasks at hand (i.e., vicarious learning). They also engage in verbal exchanges with each other or with instructors that sometimes result in encouragement or discouragement (i.e., verbal persuasion). The increased opportunities to have these experiences suggests, in theory, that Ml fosters an environment where students' physics selfefficacy may develop.

Studies in MI in particular have attributed value to the examination of student-student interactions in the physics classroom (Zwolak, Dou, Williams, and Brewe, 2017). Quantifying student interactions using the tools of social network analysis (SNA), Dou et al. (2016) found a correlation between students' academic popularity as measured by various classroom network measures and improved self-efficacy development. Similarly, classroom network measures, such as PageRank centrality (see "In-class Social Network Data"), have exhibited positive relationships with gains on the Force-Motion Concept Evaluation (FMCE)—a well-established introductory physics concept inventory (Thorton et 
al., 2998; Williams, Brewe, Zwolak, and Dou, 2015). This, too, aligns with past studies showing better student understanding when constructing knowledge in group settings (Alexopoulou and Driver, 1996; Stump, Hilpert, Husman, Chung, and Kim, 2011). Though this may be somewhat oversimplified, in general, students who report a greater number of academic interactions in the active learning MI classroom have a greater chance of understanding content matter and feeling more confident about their ability to perform physics tasks.

\subsection{Social Network Analysis}

Recent interest in network analysis as a tool used by STEM education researchers has highlighted the value of its implementation as it relates to understanding student interactions. The examination of relationships through social network analysis (SNA) has revealed complexity in the social and academic networks of physics students, changes in study-group networks and their relationship with biology exam performance, and how students from varying STEM majors participate in informal student networks (Brewe, Kramer, and Sawtelle, 2012; Forsman, Moll, and Linder, 2014; Grunspan, Wiggins, and Goodreau, 2014). Developed by sociologists in the 1930s, SNA allows researchers to quantify interactions between people and examine hidden relational structures found in their relationships (Scott, 1988). Member of a network are often referred to as "nodes" and the relational links between them as "ties."

The web of interactions between participants can be used to calculate network-level and node-level measures. Whole network measures include 
characteristics like density (i.e., number of ties divided by total possible number of ties), diameter (i.e., largest relationship distance between two participants), and the number of sub-communities found in the network. In our case, we are particularly interested in node-level measures, specifically "centrality." Centrality is a term used in network analysis that refers to a specific node's relational position in a network and can come in many forms (Scott and Carrington, 2011). For example, in the case of a classroom network, directed degree centrality quantifies the total number of incoming and outgoing interactions experienced by a particular student, while PageRank centrality ranks students according to the popularity of the peers with whom they interact using an algorithm initially developed by Brin and Page (1998) for the Google search engine. The current study builds on our use of these tools in undergraduate physics contexts.

\subsection{Purpose}

Our study seeks to further situate the contribution of students' classroom interactions in the larger context of physics self-efficacy and physics interest development. Both SCCT and the identity framework posit that self-efficacy and interest directly and indirectly influence the constructs antecedent to STEM career choice, yet the role of classroom interactions in the evolution of these two former constructs is only partially understood (Dou et al., 2016; Hazari et al., 2010; Lent et al., 1994). SNA allows us to quantify classroom interactions using measures of centrality--students' position in a social network. By testing various model pathways between these variables (i.e., centrality, self-efficacy, interest) we can further understand the directional influence of physics related student 
interactions. Given the literature, we expect that even when students' interest and self-efficacy at the beginning of the course are accounted for, student centrality will have an indirect effect on post physics interest mediated by post physics self-efficacy. Given the reciprocal connection between self-efficacy and interest, we also tested models with varying paths between these two variables with the goal of answering the following research questions (see Figure 13):

1. Do classroom interactions as measured by social network centrality directly influence students' physics interest in MI courses?

2. Do classroom interactions as measured by social network centrality indirectly influence students' physics interest via their physics self-efficacy in Ml courses?

3. Do reciprocal relationships exist between physics self-efficacy and physics interest in an active learning introductory physics course? 


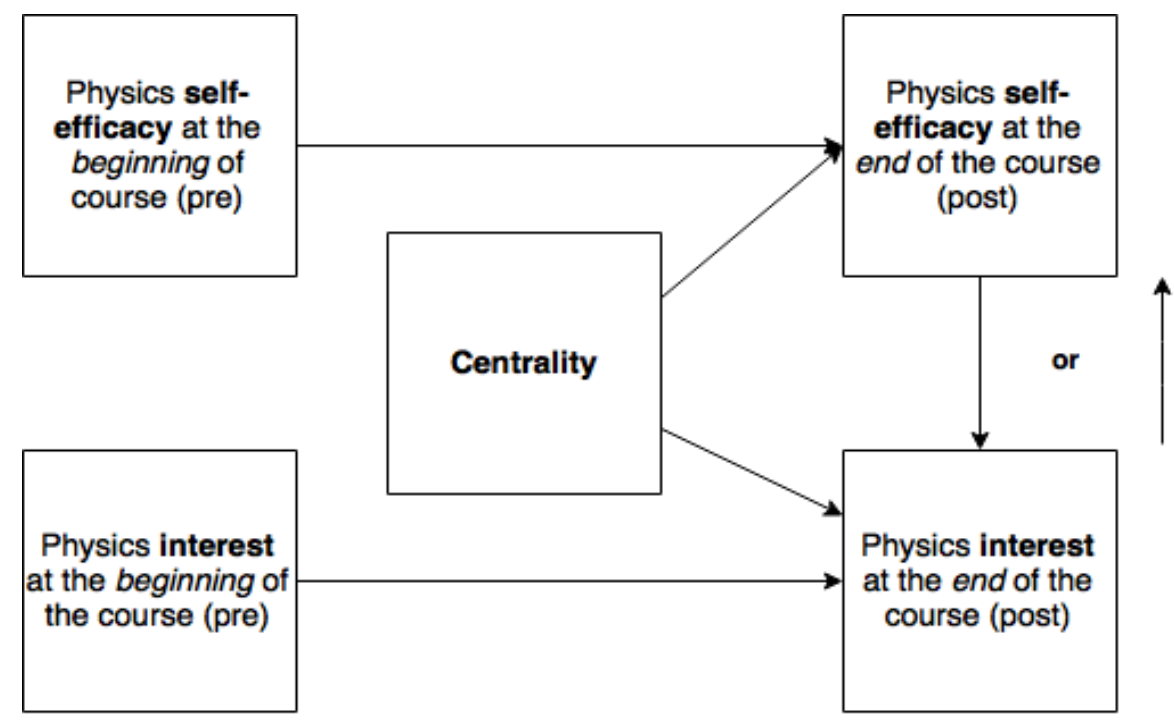

Figure 13. General Model of Interactions of Self-Efficacy, Interest, \& Centrality.

\subsection{Design}

\subsubsection{Data}

Data for this study came from three Ml courses taught in the fall 2014 and fall 2015 semesters at a large Hispanic Serving Institution (HSI) in South Florida. While the majority of students at this institution register for traditional sections of Introductory Physics I with Calculus taught in auditorium-style settings, a few sections of MI become available to all students, permitting their schedule and requisites complement the course. Students sign up on a first-come-first-served basis. For nearly a decade this institution has offered a few 30 -student capacity sections each semester. In 2014 new state-of-the-art science classrooms became available each with a capacity of approximately 80 students. Only one section of MI was offered in the new classroom in fall 2014 and in fall 2015 two sections were offered. The same instructor who taught in fall 2014 also taught in fall 2015. An additional instructor taught the second MI section offered in fall 
2015. Both instructors had experience with reformed teaching strategies geared at introductory physics students and both received support from faculty in the physics department, as well as from Teaching Assistants and Learning Assistants, in the implementation of the MI curriculum.

Participating students from these three sections $(N=221)$ primarily identified as Hispanic (i.e., 71\%) and most remaining students reported being Asian, White, or Black (see Table 4). The majority of these students were male (i.e., $56 \%$ ), while $43 \%$ identified as female. Demographic and/or gender information for six students was not available. Of the 35 majors represented in these courses, only about $1 \%$ of students had elected to pursue a bachelor's degree in physics at the time they took the course. The majors with greatest representation included Biology (i.e., 24\%), Mechanical Engineering (i.e., 12\%), and Computer Science (i.e., 10\%). Almost all of the remaining students were pursuing majors in a STEM domain. At this institution, introductory physics is a requisite for most STEM degrees. 
Table 4. Participant Characteristics.

\section{Demographics}

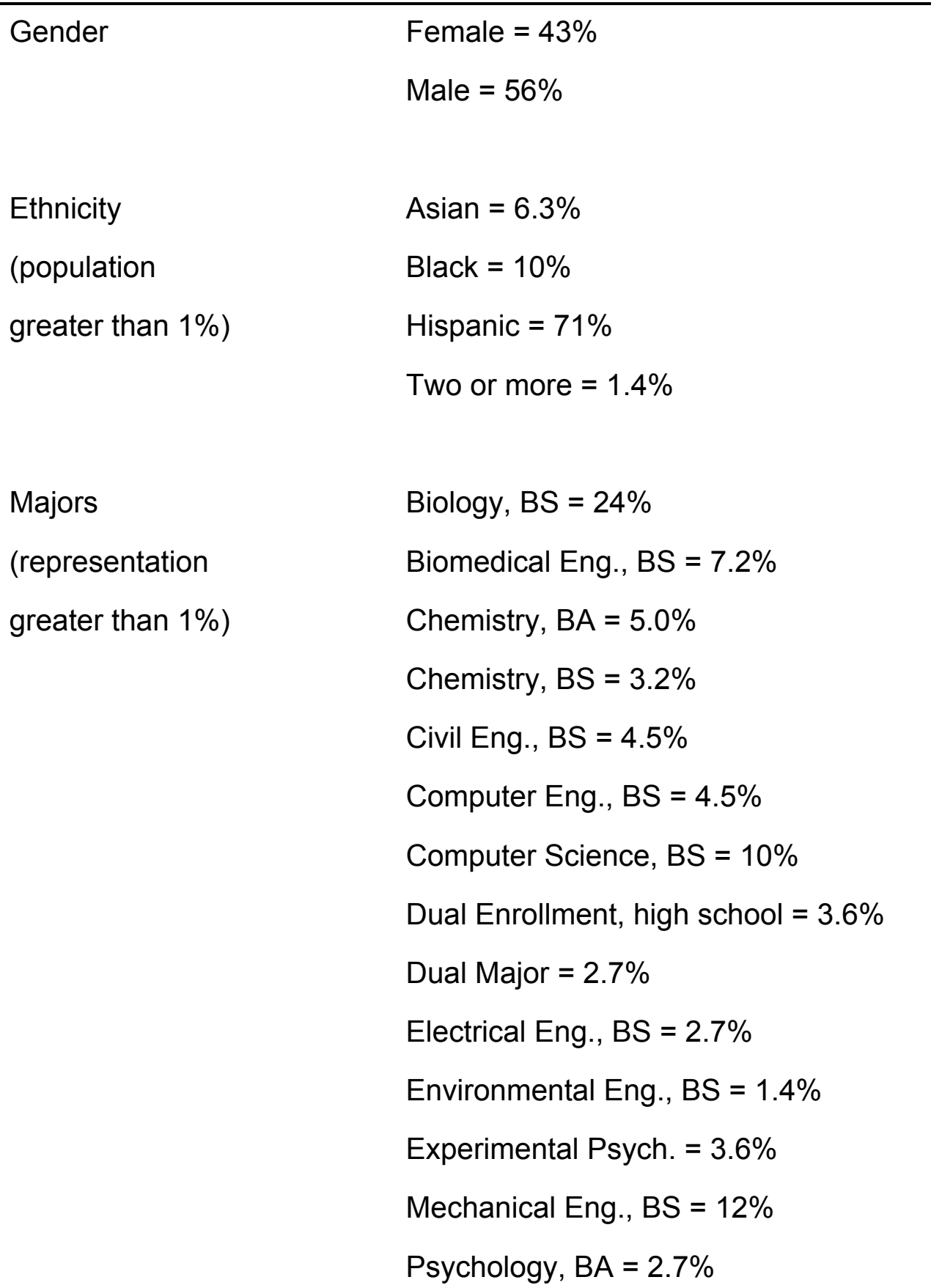

Psychology, $\mathrm{BA}=2.7 \%$ 


\subsubsection{In-class Social Network Data}

We collected student interaction information by surveying students five times throughout a course, asking them to respond to the following query: "Please choose from the presented list people from your physics class that you had a meaningful interaction with in class this week, even if you were not the main person speaking or contributing. You may include names of students outside of the group you usually work with." Beneath the prompt, students were provided with blank space divided into three columns where they could indicate both who they worked with, as well as how often they worked with each person (see Supplementary Materials). Students were also asked about the individuals they worked with on physics-related material outside of class. For the purpose of this study we did not address students' out-of-class interactions. After the fall 2014 semester, we began providing students with randomly ordered lists of their peers' and instructors' names for the sake of efficiency and to avoid name confusion.

Student responses to each survey were used to generate edgelists, which contain interaction information about the student responding to the survey (i.e., source) and the students listed as responses to the social network queries (i.e., targets). We then used the resulting student interaction matrix to calculate student centrality using the igraph package in R (Csárdi and Nepusz, 2006; R Core Team, 2015). For this study we concentrated on students' PageRank centrality for two primary reasons: (a) PageRank not only incorporates the number of incoming and outgoing interactions students experience, but also the 
kinds of peers with whom they interact in terms of academic popularity, and (b) PageRank centrality, unlike degree centrality, has been shown to be predictive of students' overall self-efficacy development (Dou et al., 2016).

\subsubsection{Physics Self-Efficacy Instrument}

Both at the beginning and end of the MI course, students completed the Sources of Self-Efficacy in Science Courses - Physics (SOSESC-P) survey. This 33-item survey measures the sources of self-efficacy (i.e., mastery experiences, vicarious learning, verbal persuasion, physiological mechanisms) and acts as a proxy for students' overall self-efficacy (Fencl and Scheel, 2005; Sawtelle et al., 2012). We selected this survey because of its introductory physics context specificity--a characteristic of effective self-efficacy surveys (Pajares, 1997) and to maintain research continuity with previous studies in active learning introductory courses. Students indicated how much they agreed with a variety of self-efficacy related statements using a 5-point Likert scale. Statements included the following: "I will have difficulty with the exams/quizzes in this class" and "I will get positive feedback about my ability to recall physics ideas." We achieved an alpha reliability coefficient of .93 for the instrument.

\subsubsection{Physics Interest}

Students' interest in physics and physics related content at the beginning and end of the class was measured using the Physics Identity Development (PID) survey (Potvin and Hazari, 2013). This questionnaire captures a series of variables related to students' sense of identity as a physics person, their performance competence, their general science interest, and their physics 
interest. In the current study, we were only concerned with students' responses to questions about interest in specific topics related to physics (i.e., mechanics, optics/waves, electromagnetism, relativity/modern physics, history and people in physics, current topics in physics). Indication of interest was demarcated on a 7point anchored Likert scale ranging from "No Interest" to "Very Interested". We achieved an alpha coefficient of reliability of .88 on the subset of interest items as a whole. Confirmatory factor analysis affirmed the use of the aggregate.

Table 5. Summary of student responses to surveys.

Variables

Centrality

PageRank, $(M=0.0119, S D=$ 0.00226)

Self-efficacy

pre SOSESC-P, $(M=134, S D=14.1)$

post SOSESC-P, $(M=129, S D=17.4)$

Interest

pre PID, $(M=25.6, S D=6.89)$

post PID, $(M=23.3, S D=8.25)$

\subsection{Analysis and Results}

In general, we administered social network surveys on the last day of class for selected weeks. Weeks were chosen ahead of time and were distributed throughout the semester. Five network data collection events took place: one at the beginning of the semester, one at the end, and three in 
between. We also strove to ensure that data collection happened on weeks when students participated in active learning activities that required both large and small group cooperation and discourse. We achieved this setting for the first four data collection events each term. Nevertheless, on at least one occasion the last survey collection of the semester took place on a week dedicated to final exam review and student participation in inquiry activities was not solicited. Response rates exhibit this contrast, coming in at greater than $75 \%$ percent for survey administrations during the first four weeks of a semester and at less than $50 \%$ on the last survey given in the fall 2014 semester. Given the sensitivity of networks to context, responses from the fifth survey administered that semester were dropped, and subsequently those were also dropped for all other courses in order to maintain homogeneity of the network data and avoid inflated network measures of students in fall 2015 . We should note, however, that even after performing separate analyses of fall 2014 data and fall 2015 data the outcomes agree with the results of the combined semesters' analyses presented in this paper.

To generate an overall measure of student interactions we compiled responses across the first four social network surveys administered during each course by pooling the edgelists. We focused on capturing occurrence of interactions with peers for each week data were collected, ignoring the frequency of interactions per week students reported for each peer listed. Duplicate interactions between the same two individuals across the semester were weighed according to the number of occurrences. For example, if student $A$ 
named student $B$ as someone with whom he or she had a meaningful interaction with during the first week of the semester, that edge (i.e., link between two nodes) is given a weight of one. If student A named student B on one or more surveys administered later in the semester, the tie between $A$ and $B$ received a weight of plus one for each instance. We selected this approach in order to capture the overall structure and strength of students' networks across the semester.

The final pooled edgelist was used to calculate participants' PageRank centrality. PageRank centrality has been shown to be a valuable measure in the prediction of students' physics performance, self-efficacy, and participation in a physics learning center (Brewe et al., 2012; Bruun and Brewe, 2013; Dou et al., 2016). PageRank has often been characterized as the probability of a random walker on a network to arrive at a particular node (Fortunato and Flammini, 2007). It is a function of the number of incoming edges such that edges from popular nodes increases a given node's PageRank. This standardized network measure is represented in the following equation:

$$
p(i)=\frac{q}{n}+(1-q) \sum_{j: j \rightarrow i} \frac{p(j)}{k_{\text {out }}(j)} \quad i=1,2, \ldots n
$$

Here $p(i)$ stands for the PageRank of node $i, n$ is the number of nodes in the network, $p(j)$ represents the PageRank of node $j$ and $k_{\text {out }}$ its outDegree (i.e., number of outgoing interactions). We set the damping factor $q$ to 0.15 as suggested in previous literature (Csárdi and Nepusz, 2006; Fortunato and 
Flammini, 2007). After calculating PageRank we removed instructors from the final network in order to focus on peer interactions.

\subsection{1. $t$-Tests and Factor Analyses}

Prior to proceeding with our model tests we performed dependent samples $t$-tests to determine whether student self-efficacy and interest changed throughout the semester. Mean self-efficacy scores decreased significantly by 4.42 points from pre to post, indicating that students $(N=171$, after pairwise deletion) reported having lower physics self-efficacy at the end of the course than they did at the beginning $[t(170)=3.83, p<.001$, Cohen's $d=0.29]$. This represents a $5 \%$ drop based on the overall range of student scores (i.e., 78 165). Similarly, students' physics interest decreased significantly by 2.34 points or $6.5 \%$ of the scale $[t(169)=4.98, p<.001$, Cohen's $d=0.38]$. We should note that even after performing single imputation techniques to account for missing data, we achieved similar results with larger effect sizes for both constructs (i.e., Cohen's $d=0.35$ and Cohen's $d=0.43$, respectively).

We first examined our measurement model using confirmatory factor analyses (CFA) to test how well our survey items measured the latent variables (i.e., physics self-efficacy and interest). After imputing our data in order to account for missingness, single factor loadings for physics self-efficacy items on the SOSESC-P ranged from 0.41 to 0.85 when we removed eight items that fell below a 0.40 cutoff (Stevens, 1992). All of the items on our physics interest survey fell within an acceptable single factor loading range of 0.46 to 0.88 . Allowing covariances among the constructs yielded a moderate fit for the 
measurement model $\left(x^{2}=4687.3, \mathrm{df}=1823, \mathrm{x}^{2} / \mathrm{df}=2.57, \mathrm{RMSEA}=0.084\right.$, $\operatorname{SRMR}=0.082, \mathrm{CFI}=0.64)$

\subsubsection{Structural Equation Modeling}

Our use of structural equation modeling (SEM) was predicated by its handling of multiple dependent variables and robustness of its incorporation of latent variables (Harlow, 2014). SEM can be generally described as a two-part process, which begins with a CFA of the latent variables (i.e., variables that cannot be directly observed). This analysis tests for the hypothesized number of latent factors measured by a set of items. In our study, we measured two latent variables (i.e., physics self-efficacy and interest) using two different instruments. Although our self-efficacy instrument included 25 items and our interest instrument 9 items, each was hypothesized to measure a single construct. The analysis of our CFA described in the previous section confirmed our hypotheses. The second part of SEM allows researchers to test complex, multipath relationships between constructs where a plurality of both dependent and independent variables exist. Specific patterns of predictions can be tested that better take into account both prediction and measurement error.

We tested our primary model (i.e., model A) with paths running directly from PageRank centrality to both post physics self-efficacy (i.e., at the end of the course) and post physics interest, as well as a path from post physics selfefficacy to post physics interest (see Figure 14). In this model we also controlled for students' physics self-efficacy and physics interest at the beginning of the course (i.e., pre). The path leading from PageRank directly to post physics self- 
efficacy was significant $(B=114.3, \beta=0.21, p<.001)$, as well as the path from post physics self-efficacy to post physics interest $(B=.32, \beta=0.27, p<.001)$.

The path from PageRank to post physics interest was not significant. This model had moderately acceptable fit measures $\left(x^{2}=4779.6, \mathrm{df}=1885, \mathrm{X}^{2} / \mathrm{df}=2.54\right.$, RMSEA $=0.083$, SRMR $=0.085, \mathrm{CFI}=0.64)$, which suggests possibly some weak relationships between some of our variables.

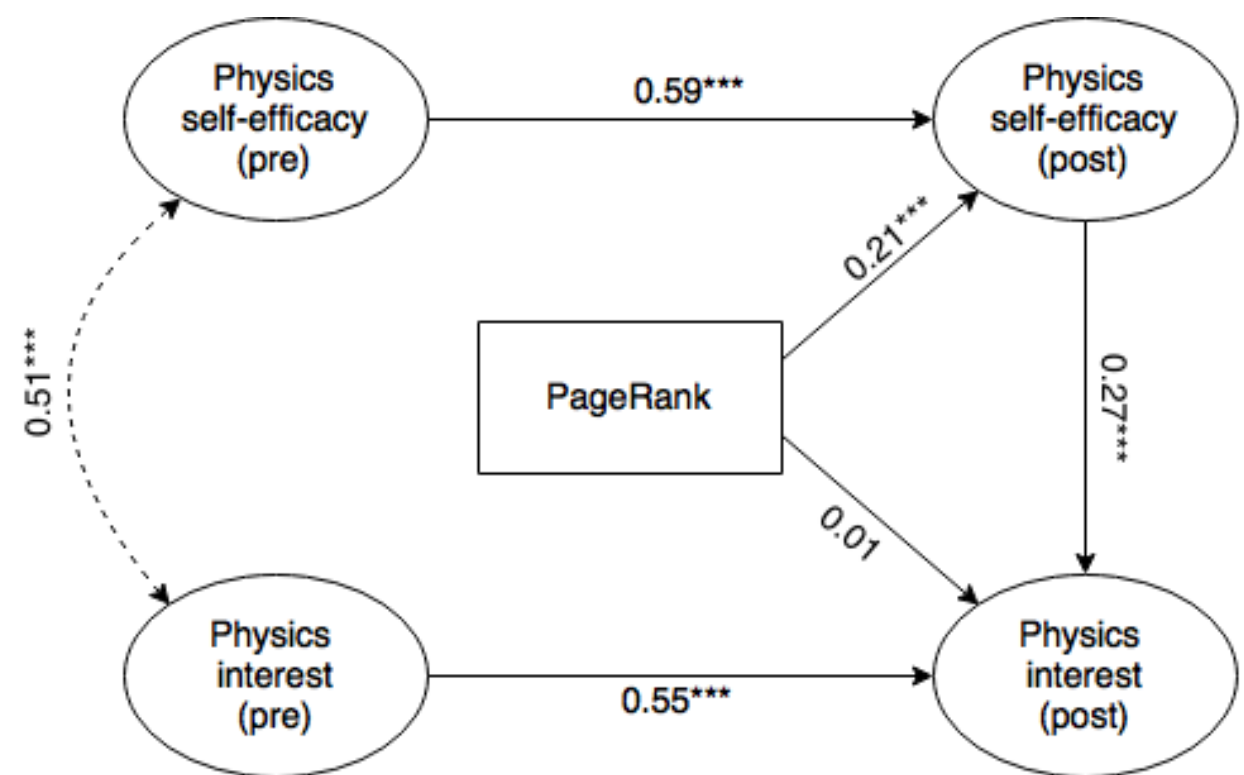

Figure 14. Results of SEM analyses - Model A: showing standardized path coefficients and significance $\left(^{* * *} p<0.001\right)$.

Because of the reciprocal relationship sometimes exhibited between selfefficacy and interest, we tested a model similar to model A, reversing the path from post physics self-efficacy to post physics interest (i.e., model B). This model, too, revealed significant paths from PageRank centrality to post physics self-efficacy $(B=106.4, \beta=0.18, p<.001)$ and from post physics interest to post physics self-efficacy $(B=0.33, \beta=0.34, p<.001)$. Models $A$ and $B$ shared nearly identical fit measures $\left(x^{2}=4768.18, \mathrm{df}=1885, \mathrm{X}^{2} / \mathrm{df}=2.53, \mathrm{RMSEA}=0.083\right.$, 
SRMR $=0.082, C F I=0.64)$, which makes the directionality of the relationship between self-efficacy and interest more difficult to determine in this case.

In order to better understand the interaction between physics self-efficacy and interest we ran a third model (i.e., model C), taking advantage of the longitudinal nature of our data to determine whether students' self-efficacy contributes to their interest or vice versa. In trying to illuminate this directionality we included paths from students' physics self-efficacy at the beginning of the course to their physics interest at the end of the course. Similarly, we included paths from pre physics interest to post physics self-efficacy. No direct path was included between post physics self-efficacy and post physics interest, allowing these variables to covary. The remaining paths mirrored those of models $A$ and $B$ (see Figure 15). Paths common to models A and B exhibited similar significance. The path from students' physics self-efficacy at the start of the course to their physics interest at the end of the course was not significant, while the path from pre physics interest to post physics self-efficacy was $(B=0.25, \beta=0.20, p=$ 0.01). The model also yielded moderately acceptable fit measures $\left(x^{2}=4767.4\right.$, $d f=1883, x^{2} / d f=2.53$, RMSEA $=0.083$, SRMR $\left.=0.082, C F I=0.64\right)$. The results given by the test of this model indicate that students' interest in course content likely contributes to their self-efficacy development and not the other way around as we hypothesized. 


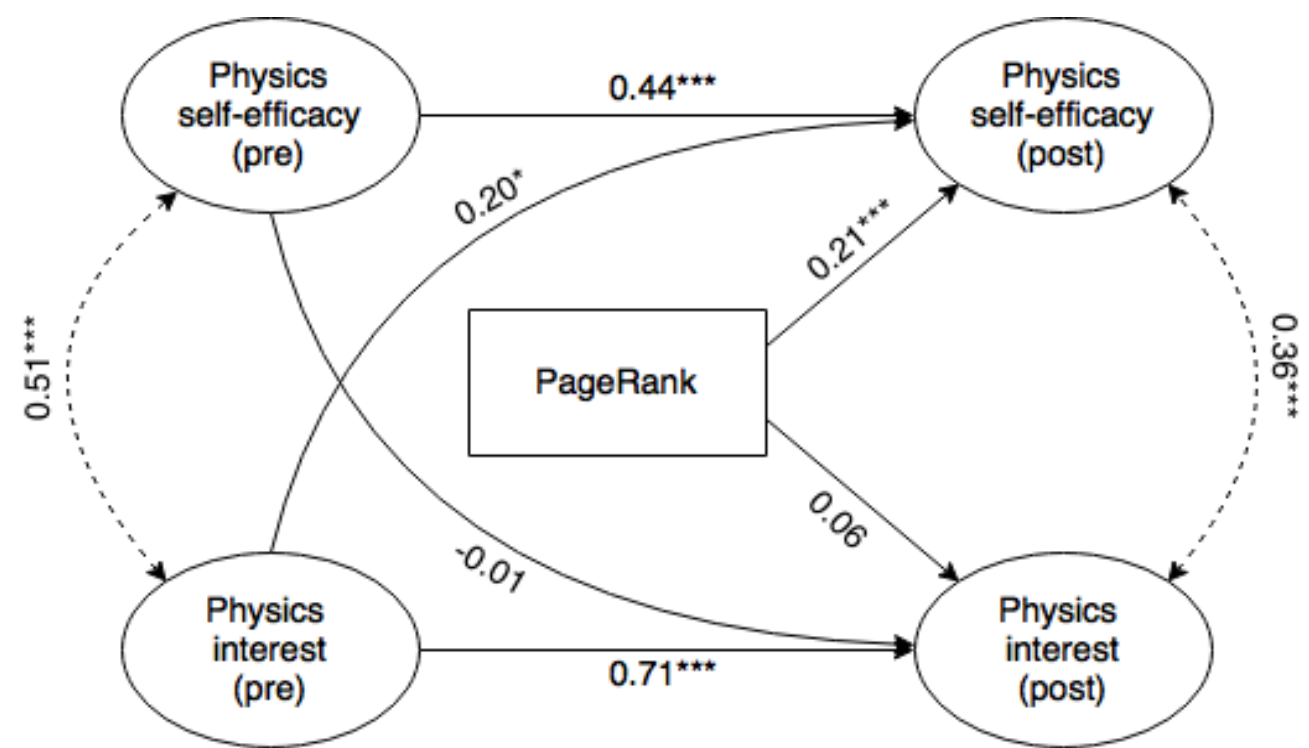

Figure 15. Results of SEM analyses - Model C: showing standardized path coefficients and significance $\left({ }^{*} p<0.05,{ }^{* *} p<0.01,{ }^{* * *} p<0.001\right)$.

Given the models' similarities in fit measures and Akaike information

criterion (AIC) values, we chose to compare them using log likelihood ratio tests.

The additional parameters in model $\mathrm{C}$ explain significantly more of the variance in our data than model A where we include a path from post physics self-efficacy to post physics interest $\left[X^{2}(2)=12.2, p<0.01\right]$. Yet, model $C$ was not a significantly better model than model B, further supporting a latent variable directionality going from post physics interest to post physics self-efficacy. This is further supported by model B's slightly lower AIC value when compared to model A's (i.e., 31269 and 31281, respectively) . All three models (i.e., A, B, and C, respectively) explained significantly more variance than similar models without the PageRank centrality variable $\left[X^{2}(2)=2073.6, p<0.001 ; X^{2}(2)=2085.0, p<\right.$ $\left.0.001 ; x^{2}(4)=2085.8, p<0.001\right]$. 


\subsection{Discussion}

The results of our analyses offer different starting points for interpretation. The most straightforward of these involve the outcomes of our dependent samples $t$-tests that indicated a decrease in both students' physics self-efficacy and physics interest. The documented benefit of active learning curricula with regard to student learning, particularly MI, stands seemingly contrary to these drops. While on the one hand, past research shows this curriculum helps students develop a better understanding of physics content than those in lecture sections (Brewe et al., 2010), participants in this study left the class feeling less confident about their ability to complete physics-related tasks and less interested in physics subjects. We might attribute this development directly to the MI curriculum, but it could also result from a re-calibration of students' perspectives. This latter explanation aligns with research indicating a kind of over-confidence or unrealistic expectations that incoming students in introductory courses hold (Boekaerts and Rozendaal, 2010; Lindstrøm and Sharma, 2011). Whether or not the decreases we observed explain an adjustment in students' task-specific confidence and expectations, they do appear smaller than decreases found in lecture-based introductory physics courses (Fencl and Scheel, 2004; Sawtelle et al., 2010).

As educators our concern here is not so much that students' self-efficacy and interest did not increase overall, though that would have been a welcome outcome, but rather that a significant drop took place. The value that the identity framework and SCCT place on student self-efficacy and interest as career-choice 
indicators motivated us to consider which aspects of our curriculum or context might contribute to the shifts seen in these constructs. Because of the particular emphasis that MI places on student interactions, and the relationship between interactions and self-efficacy development, in particular, we examined how student networks relate to affective development. Our structural equation modeling tested a variety of connections between physics self-efficacy, physics interest, and PageRank centrality, which we used as a proxy for student interactions. We discovered that students' PageRank centrality significantly predicted students' self-efficacy at the end of the course even when controlling for their self-efficacy at the beginning of the course. That is to say, how students interacted with one another in this active learning environment predicted their self-efficacy development regardless of where they scored on the self-efficacy survey at the beginning of the course. This association posits a direct link between classroom relationships and the confidence students develop regarding the successful completion of physics tasks. We should note that the strength of this link where, in general, a one standard deviation increase (or decrease) in a student's Pagerank would correspond to a 0.21 standard deviation change in a student's post physics self-efficacy.

Although centrality in the classroom network did not directly predict physics interest at the end of the course, we wanted to test whether a mediated relationship exists between these two variables via self-efficacy. We based this hypothesis on our theoretical framework and prior research indicating a directional link from self-efficacy to interest. Models with pathways going in both 
directions yielded nearly equal fit measures (i.e., model A: post self-efficacy $\rightarrow$ post interest; model B: post interest $\rightarrow$ post self-efficacy), which hindered our ability to recognize self-efficacy as a mediator of students' interest. Nevertheless, our test of model $\mathrm{C}$ helped to untangle how these variables influenced one another. The acceptable fit of model C confirmed that students' incoming interest predicted their outgoing self-efficacy (and not the other way around). Still, that link only speaks to the relationship between the constructs on a longitudinal scale (i.e., pre to post) rather than a cross-sectional perspective (i.e., post versus post). To further unpack what these models might be suggesting, we compared models $A$ and $B$ to model $C$ using log likelihood ratio tests. Here we found that our more complex model (i.e., C) outperformed model $\mathrm{A}$ in which we defined a path from post self-efficacy to post interest. Yet, model C did not outperform model B in which we defined a path from post interest to post self-efficacy (see Figure 16). The combination of this evidence points toward the conclusion that students' interest development in this course played an important role in their self-efficacy development (i.e., Interest $\rightarrow$ Self-efficacy)—not vice versa.
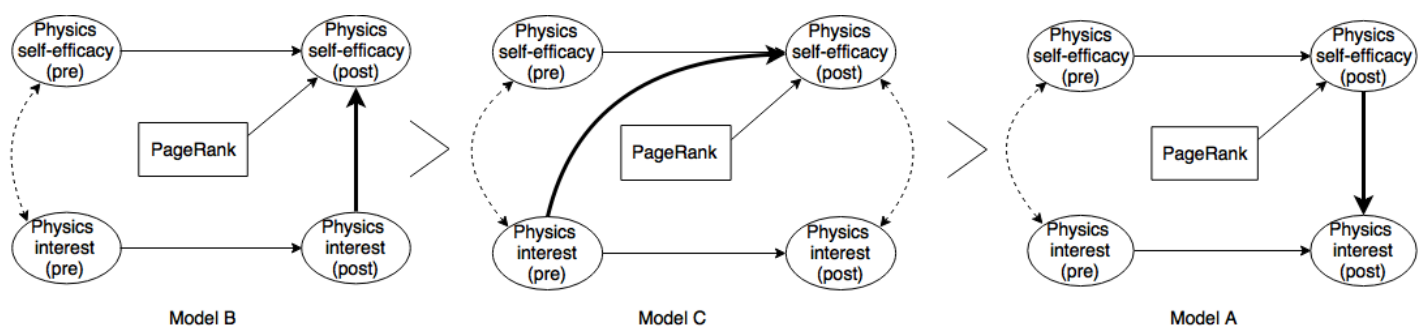

Figure 16. Comparison of Three Models. 
In light of research grounded in the SSCT and the identity framework, this unexpected outcome at the very least suggests that those performing research in the context of reformed teaching environments consider this alternative pathway. Our findings also imply that students who come into the course with high interest in physics stand poised for success with regard to affective learning. The models do not favor students who come in with low interest. In fact, students as a whole experienced a general decrease in physics interest, which may only further contribute to their decrease in physics self-efficacy. The development of physics interest is unaffected by interacting with academically popular peers (i.e., PageRank centrality). This seems counterintuitive when considering that these relationships help students develop improved physics self-efficacy. Despite some students' higher outlook regarding their abilities, interest remained unaffected, and for students who foster beneficial academic relationships, the benefit on selfefficacy is relatively small.

From a theoretical perspective, both Bandura (1997) and Lent et al. (1994) proposed that interest may play an important role in self-efficacy development during events where participants find themselves in novel situations or environments. When participants find themselves in new circumstances, interest helps to drive engagement in unfamiliar tasks. The successful or unsuccessful completion of those tasks, as well as the encouragement or emotions experienced during the tasks, could then shape participants' self-efficacy. With regard to our study, we know that students who participate in reformed or active learning courses, particularly in introductory physics, may experience a sense of 
discomfort or unfamiliarity, which can vary according to classroom grading practices, instructor, and instructional norms (Turpen and Finkelstein, 2010; Villasenor and Etkina, 2006). Anecdotal and student interview data also suggests student discomfort exists in $\mathrm{Ml}$ courses and is the topic of ongoing research. Interview data supports the idea that a subset of students may experience anxiety as they adjust to the new mode of learning. In this context, it is possible that interest in physics as a subject helps to maintain (or hinder) student engagement in tasks that lead to self-efficacy development. The requirement for students who have elected a STEM major like biology, pre med, or chemistry, to take physics strengthens the likelihood that students majoring in other subjects have relatively less interest in physics (Hazari et al, 2010). Introductory physics courses often represent students' first sustained exposure to physics content, particularly for those who did not take physics in high school. This paints a bleak picture for those entering $\mathrm{MI}$, especially when we take into account that only $1 \%$ of our participants had declared physics as their major.

Carlone (2004) also offers a plausible mechanism for the decrease we saw in student physics self-efficacy and perhaps even interest. Her study of a reformed-based high school physics classroom showed that participants who had "good-student identities" as defined by their ability to listen, memorize, and reproduce knowledge resisted the active learning curriculum, especially when their perceived recognition as good students or their class grade appeared to be in jeopardy. In essence, their not knowing the rules-of-the-game in the unfamiliar environment increased their discomfort and affected their participation. Students 
who were more interested in the subject matter, had learning oriented mindsets, and/or were less concerned about preserving good-student identities expressed more positive attitudes. Though Carlone (2004) limited her study to female, high school students, a similar mechanism may be at work in the MI classroom. Because STEM courses are typically characterized by lecture-based pedagogies, STEM majors with good student identities have learned to succeed in these settings. When placed in environments where the rules for success are different and where activities require students to do more than just memorize and retain facts, MI participants may experience discomfort and/or develop negative attitudes that affect their participation. This, in combination with low initial interest in physics as a field, particularly for non-physics majors, could explain the lack of increase in self-efficacy, which depends largely on engaged participation in tasks and interest. Though the current design of our study cannot confirm this explanation, as described by Carlone (2004), current and future studies might lend credence to that scenario.

Despite the content learning that takes place, participants in our study faced the risk of decreased interest and self-efficacy in the subject matter. It may be tempting then to compare these declines in self-efficacy and interest to those found in lecture courses as a way to justify the continued use of active learning curricula. This approach redirects attention that can be placed on finding ways to improve the impact of active learning classrooms on affective constructs. For that reason we chose to focus on the MI course alone, though we were aware of past studies that have compared decreases in physics self-efficacy and found drops 
ranging from approximately zero percent in small class settings to $75 \%$ in large class settings of those seen in lecture-based sections (Dou et al., 2016; Sawtelle et al., 2012). Regardless, the breadth of the decrease in self-efficacy and interest is consequential as it relates to the recruitment of students to physics careers and STEM careers in general where we see large groups of students dropping out or switching majors (National Research Council, 2013).

We initially set out to better understand the role of classroom interactions in active learning courses. Indeed, both the number of interactions that students have, as well as the kinds of people students interact with, matters to selfefficacy development in the subject area. We showed that interactions in this active learning environment, as quantified by PageRank centrality, helped to shape students' self-efficacy, thus situating students' network positioning in the larger framework of career theory research. Though the contribution to selfefficacy is small, all of our models outperformed models without our centrality variable. Notwithstanding this meaningful advancement in our understanding, our model testing highlights shortcomings experienced by some students of reformed curricula, particularly curricula that may share similar characteristics with MI, active learning, collaborative environments. According to the results of our study, lower interest at the start of the Ml course resulted in lower interest at the end of the course and, in turn, lower self-efficacy. It is not surprising then that the affective benefits of the course are biased towards those who begin with high physics interest. 
While we have focused on the environment created by the MI curriculum, this work prepares the stage for a deeper exploration of active learning pedagogies that should take place. Given the momentous spread of active learning teaching strategies—a proliferation that will likely not slow downeducation researchers may want to keep an open eye for changes in factors that motivate students to pursue careers in the field, identify the aspects of the curriculum or instruction that contributes to those changes, and develop interventions or strategies to mitigate negative effects. The extent to which our research achieves these goals is limited by our design. While we saw decreases in self-efficacy and interest, confirmed pathways related to the development of those constructs, and situated classroom social networks as part of those pathways, we cannot directly attribute our outcomes to any particular aspect of the MI curriculum (e.g., small group activities, class discussions, model building, group assessments). Moreover, the context of our study is not easily replicated, occurring in an $\mathrm{HSI}$ where great cultural diversity exists even within groups who identify as Hispanic. This university further differs from others across the nation in size-among the largest in the country—and in additional student characteristics, including a large population of commuters (i.e., approximately $90 \%$ ), first and second generation migrants, and high numbers of students with either part-time or full-time jobs. These qualities inspire caution in the generalizations we make about our results. $\mathrm{Ml}$, too, as an active learning introductory physics curriculum, differs in some ways from others implemented elsewhere. Yet, our examination of these data across three different courses, two 
different instructors, and two separate academic years make us confident about the existence of these effects in our local community. The work of others referenced in this paper, who have shown the broad applicability and effects of self-efficacy, interest, and active learning pedagogies across a variety of cultures and contexts, suggests to us that the likelihood of finding similar results in other university settings is not small. We hope to continue this work, looking specifically for the mechanisms driving these effects and developing interventions to ensure that the depth of our students' physics knowledge continues to grow in such a way that they finish the course feeling more confident and interested in the subject matter regardless of their starting point.

References (Chapter 3)

Alexopoulou, E., and Driver, R. (1996). Small-group discussion in physics: Peer interaction modes in pairs and fours. Journal of Research in Science Teaching, 3(10), 1099-1114.

Bandura, A. (1989). Human agency in social cognitive theory. The American Psychologist, 44(9), 1175-84. Retrieved from http://www.ncbi.nlm.nih.gov/pubmed/2782727

Bandura, A. (1993). Perceived self-efficacy in cognitive development and functioning. Educational Psychologist. doi:10.1207/s15326985ep2802_3

Bandura, A. (1997). Self-efficacy: The exercise of control. New York, NY: W.H. Freeman and Company.

Bandura, A., Barbaranelli, C., Caprara, G. V, and Pastorelli, C. (2001). Selfefficacy beliefs as shapers of children's aspirations and career trajectories. Child Development, 72(1), 187-206. doi:10.1111/1467-8624.00273

Bieschke, K.J., Bishop, R.M., and Garcia, V.L. (1996). The utility of the Research Self-Efficacy Scale. Journal of Career Assessment, 4, 59-75. 
Boekaerts, M., and Rozendaal, J.S. (2010). Using multiple calibration indices in order to capture the complex picture of what affects students ' accuracy of feeling of confidence. Learning and Instruction, 20(5), 372-382. http://doi.org/10.1016/j.learninstruc.2009.03.002

Brewe, E. (2008). Modeling theory applied: Modeling Instruction in introductory physics. American Journal of Physics, 76(12), 1155. doi:10.1119/1.2983148

Brewe, E., Kramer, L.H., and O'Brien, G.E. (2010a). Changing participation through formation of student learning communities. AIP Conference Proceedings, 1289, 85-88. http://doi.org/10.1063/1.3515255

Brewe, E., Kramer, L., and Sawtelle, V. (2012). Investigating student communities with network analysis of interactions in a physics learning center. Physical Review Special Topics - Physics Education Research, 8(1), 10101. http://doi.org/10.1103/PhysRevSTPER.8.010101

Brewe, E., Sawtelle, V., Kramer, L.H., O’Brien, G.E., Rodriguez, I., and Pamelá, P. (2010b). Toward equity through participation in Modeling Instruction in introductory university physics. Physical Review Special Topics - Physics Education Research, 6(1), 010106. doi:10.1103/PhysRevSTPER.6.010106

Brin, S., and Page, L. (1998). The anatomy of a large-scale hypertextual web search engine. In Seventh International World Wide Web Conference (pp. 107-117). Brisbane, Australia. doi:10.1016/S0169-7552(98)00110-X

Brown, S.D., Tramayne, S., Hoxha, D., Telander, K., Fan, X., and Lent, R.W. (2008). Social cognitive predictors of college students' academic performance and persistence: A meta-analytic path analysis. Journal of Vocational Behavior, 72(3), 298-308. http://doi.org/10.1016/j.jvb.2007.09.003

Bruun, J., and Brewe, E. (2013). Talking and learning physics: Predicting future grades from network measures and Force Concept Inventory pretest scores. Physical Review Special Topics - Physics Education Research, 9(2), 20109. http://doi.org/10.1103/PhysRevSTPER.9.020109

Carlone, H.B. (2004). The cultural production of science in reform-based physics: Girls' access, participation, and resistance. Journal of Research in Science Teaching, 41(4), 392-414. http://doi.org/10.1002/tea.20006 
Csárdi, G., and Nepusz, T. (2006). The igraph software package for complex network research. InterJournal Complex Systems. Retrieved from http://igraph.sf.net

Desbien, D. (2002). Modeling discourse management compared to other classroom management styles in university physics. Ph.D. dissertation, Arizona State University.

Dickinson, J. (2007). An examination of the applicability of social cognitive career theory for African American college students. Unpublished doctoral dissertation. University of Akron.

Donnay, D.A.C., and Borgen, F. H. (1999). The incremental validity of vocational self-efficacy: An examination of interest, self-efficacy, and occupation. Journal of Counseling Psychology, 46(4), 432-447. http://doi.org/http://dx.doi.org/10.1037/0022-0167.46.4.432

Dou, R., Brewe, E., Zwolak, J. P., Potvin, G., Williams, E. A., and Kramer, L. H. (2016). Beyond performance metrics: Examining a decrease in students' physics self-efficacy through a social networks lens. Physical Review Physics Education Research, 12(2), 20124. http://doi.org/10.1103/PhysRevPhysEducRes.12.020124

Etkina, E., and Heuvelen, A.Van. (2007). Investigative science learning environment: A science process approach to learning physics. Washington, DC: AIP. Retrieved from http://www.percentral.org/per_reviews/

Fencl, H.S., and Scheel, K.R. (2004). Pedagogical approaches, contextual variables, and the development of student self-efficacy in undergraduate physics courses. In J. Marx, S. Franklin, and K. Cummings (Eds.), 2003 Physics Education Research Conference: AIP Conference Proceedings (pp. 173-176). Melville, NY: AIP.

Fencl, H.S., and Scheel, K.R. (2005). Engaging students: An examination of the effects of teaching strategies on self-efficacy and course climate in a nonmajors physics course. Journal of College Science Teaching, 35, 20 24.

Finkelstein, N.D., and Pollock, S.J. (2005). Replicating and understanding successful innovations: Implementing tutorials in introductory physics. Physical Review Special Topics - Physics Education Research, 1(1), 113. http://doi.org/10.1103/PhysRevSTPER.1.010101 
Forsman, J., Moll, R., and Linder, C. (2014). Extending the theoretical framing for physics education research: An illustrative application of complexity science. Physical Review Special Topics - Physics Education Research, 10(2), 1-13. http://doi.org/10.1103/PhysRevSTPER.10.020122

Fortunato, S., and Flammini, A. (2007). Random walks on directed networks: The case of PageRank. International Journal of Bifurcation and Chaos, (1), 15. http://doi.org/10.1142/S0218127407018439

Freeman, S., Eddy, S.L., McDonough, M., Smith, M.K., Okoroafor, N., Jordt, H., and Wenderoth, M.P. (2014). Active learning increases student performance in science, engineering, and mathematics. Proceedings of the National Academy of Sciences of the United States of America, 111(23), 8410-5. http://doi.org/10.1073/pnas.1319030111

Godwin, A., Potvin, G., Hazari, Z., and Lock, R. (2016). Identity, critical agency, and engineering: An affective model for predicting engineering as a career choice. Journal of Engineering Education, 105(2), 312-340. http://doi.org/10.1002/jee.20118

Grunspan, D.Z., Wiggins, B.L., and Goodreau, S.M. (2014). Understanding classrooms through social network analysis: A primer for social network analysis in education research. Cell Biology Education, 13(2), 167-178. http://doi.org/10.1187/cbe.13-08-0162

Harlow, L.L. (2014). The essence of multivariate thinking: Basic themes and methods ( $2^{\text {nd }}$ ed.). New York, NY: Routledge.

Hazari, Z., Sonnert, G., Sadler, P.M., and Shanahan, M.C. (2010). Connecting high school physics experiences, outcome expectations, physics identity, and physics career choice: A gender study. Journal of Research in Science Teaching, 47(8), 978-1003. doi:10.1002/tea.20363

Hestenes, D. (1987). Toward a modeling theory of physics instruction. American Journal of Physics, 55(5), 440. doi:10.1119/1.15129

Kjærnsli, M., and Lie, S. (2011). Students' preference for science careers: International comparisons based on PISA 2006. International Journal of Science Education, 33(1),121-144. http://doi.org/10.1080/09500693.2010.518642

Lenox, R.A., and Subich, L.M. (1994). The relationship between self- efficacy beliefs and inventoried vocational interests. The Career Development Quarterly, 42, 302-313. 
Lent, R.W., and Brown, S.D. (2006). On conceptualizing and assessing social cognitive constructs in career research: A measurement guide. Journal of Career Assessment,14(1), 12-35. http://doi.org/10.1177/1069072705281364

Lent, R.W., Brown, S.D., and Hackett, G. (1994). Toward a unifying social cognitive theory of career and academic interest, choice, and performance. Journal of Vocational Behavior, 45, 79-122.

Lent, R.W., Brown, S.D., and Larkin, K.C. (1987). Comparison of three theoretically derived variables in predicting career and academic behavior: Self-efficacy, interest congruence, and consequence thinking. Journal of Counseling Psychology, 34(3), 293-298. http://doi.org/10.1037/0022-0167.34.3.293

Lent, R.W., Lopez, A.M., Lopez, F.G., and Sheu, H. Bin. (2008). Social cognitive career theory and the prediction of interests and choice goals in the computing disciplines. Journal of Vocational Behavior, 73(1), 52-62. http://doi.org/10.1016/j.jvb.2008.01.002

Lindstrøm, C., and Sharma, M.D. (2011). Self-efficacy of first year university physics students: Do gender and prior formal instruction in physics matter? International Journal of Innovation in Science and Mathematics Education, 19(2), 1-19.

Lopez, F.G., Lent, R.W., Brown, S.D., and Gore, P.A. (1997). Role of socialcognitive expectations in high school students' mathematics-related interest and performance. Journal of Counseling Psychology, 44, 44-52.

Lynch, D.J. (2010). Motivational beliefs and learning strategies as predictors of academic performance in college physics. College Student Journal, 44(4), 920-927.

Mann, M.J., and Golubski, C. (2013). Self-efficacy and first year biology majors. In 2013 NABT Biology Education Research Symposium (pp. 1-6). Atlanta, GA: National Association of Biology Teachers.

Multon, K.D., Brown, S.D., and Lent, R.W. (1991). Relation of self-efficacy beliefs to academic outcomes: A meta-analytic investigation. Journal of Counseling Psychology, 38(1), 30-38.

National Academy of Sciences. (2016). Barriers and opportunities for 2-Year and 4-Year STEM degrees: Systemic change to support diverse student pathways. Washington, DC: The National Academies Press. Retrieved from http://www.nap.edu/catalog/21739 
National Research Council. (2013). Adapting to a changing World: Challenges and opportunities in undergraduate physics education. Washington, DC: National Academies Press.

Nauta, M.M., Kahn, J.H., Angell, J.W., and Cantarelli, E.A. (2002). Identifying the antecedent in the relation between career interests and self-efficacy: Is it one, the other, or both? Journal of Counseling Psychology, 49(3), 290301. http://doi.org/10.1037//0022-0167.49.3.290

Navarro, R.L., Flores, L.Y., and Worthington, R.L. (2007). Mexican American middle school students' goal intentions in mathematics and science: A test of social cognitive career theory. Journal of Counseling Psychology, 54(3), 320-335. http://doi.org/10.1037/0022-0167.54.3.320

Pajares, F. (1997). Current directions in self-efficacy research. Advances in Motivation and Achievement, 10(149), 1 - 49.

Pajares, F., and Kranzler, J. (1995). Self-efficacy beliefs and general mental ability in mathematical problem-solving. Contemporary Educational Psychology, 20, 426-443.

Potvin, G., and Hazari, Z. "The development and measurement of identity across the physical sciences." Proceedings of the Physics Education Research Conference (PERC), Portland, OR: AIP. 2013.

President's Council of Advisors on Science and Technology (PCAST). (2010). Prepare and Inspire: K-12 Education in Science, Technology, Engineering, and Math (STEM) for America's Future: Executive Report. Washington, DC. doi:10.1126/science. 1198062

R Core Team (2015). R: A language and environment for statistical computing. $\mathrm{R}$ Foundation for Statistical Computing, Vienna, Austria. https://www.Rproject.org/.

Sadler, P.M., Sonnert, G., Hazari, Z., and Tai, R. (2012). Stability and volatility of STEM career interest in high school: A gender study. Science Education, 96(3), 411-427. http://doi.org/10.1002/sce.21007

Sawtelle, V., Brewe, E., Goertzen, R.M., and Kramer, L.H. (2012). Creating opportunities to influence self-efficacy through modeling instruction. In 2011 Physics Education Research Conference (Vol. 339, pp. 339-342). American Institute of Physics. http://doi.org/10.1063/1.3680064 
Sawtelle, V., Brewe, E., and Kramer, L. H. (2012). Exploring the relationship between self-efficacy and retention in introductory physics. Journal of Research in Science Teaching, 49(9), 1096-1121. doi:10.1002/tea.21050

Sawtelle, V., Brewe, E., Kramer, L.H., Singh, C., Sabella, M., and Rebello, S. (2010). Positive impacts of modeling instruction on self-efficacy. In 2010 Physics Education Research Conference (Vol. 289, pp. 289-292). American Institute of Physics. http://doi.org/10.1063/1.3515225

Schunk, D.H. (2012). Learning theories: An educational perspective. Boston, MA: Pearson Education.

Scott, J. (1988). Trend report: Social network analysis. Sociology, 22(1), 109127. http://doi.org/10.1177/0038038588022001007

Scott, J. and Carrington, P.J. (2011). The SAGE handbook of social network analysis. London, England: SAGE 2011.

Shanahan, M.C. (2007) Playing the role of a science student: Exploring the meaning of the science student role and its relationship to students' identification in science. Doctoral dissertation, Ontario Institute for Studies in Education, University of Toronto.

Shanahan, M.C. (2008). What does it mean to be a science person? Exploring the meaning and impact of identity development in science. Presented at the Canadian Society for the Study of Education Annual Conference 2008, Vancouver, BC, Canada (May 31-June 3, 2008).

Sheu, H.B., Lent, R.W., Brown, S.D., Miller, M.J., Hennessy, K.D., and Duffy, R.D. (2010). Testing the choice model of social cognitive career theory across Holland themes: A meta-analytic path analysis. Journal of Vocational Behavior, 76(2), 252-264. http://doi.org/10.1016/j.jvb.2009.10.015

Smith, P.L., and Fouad, N.A. (1999). Subject-matter specificity of self-efficacy, outcome expectancies, interests, and goals: implications for the socialcognitive model. Journal of Counseling Psychology, 46(4), 461-471. http://doi.org/10.1037/0022-0167.46.4.461

Stevens, J.P. (1992). Applied multivariate statistics for the social sciences, (2nd edition). Hillsdale, NJ: Erlbaum.

Tang, M., Fouad, N.A., and Smith, P.L. (1999). Asian Americans' career choices: A path model to examine factors influencing their career choices. Journal of Vocational Behavior, 54, 142-157. 
Thornton, R. K., and Sokoloff, D. R. (1998). Assessing student learning of Newton's laws: The Force and Motion Conceptual Evaluation and the evaluation of active learning laboratory and lecture curricula. American Journal of Physics, 66(4), 338-352. http://doi.org/10.1119/1.18863

Turpen, C., and Finkelstein, N.D. (2010). The construction of different classroom norms during Peer Instruction: Students perceive differences. Physical Review Physics Education Research, 6, 020123:1-22. http://doi.org/10.1103/PhysRevSTPER.6.020123

Usher, E.L., and Pajares, F. (2008). Sources of self-efficacy in school: Critical review of the literature and future directions. Review of Educational Research, 78(4), 751-796. http://doi.org/10.3102/0034654308321456

Villasenor, M.R., and Etkina, E. (2007). Reformed physics instruction through the eyes of students. In 2006 Physics Education Research Conference (pp. 105-108). Syracuse, NY: American Institute of Physics.

Williams, E., Brewe, E., Zwolak, J., and Dou, R. (2015). Understanding centrality: Investigating student outcomes within a classroom social network. In Physics Education Research Conference (pp. 2-5). Washington, DC.

Zwolak, J. P., Dou, R., Williams, E. A., \& Brewe, E. (2017). Students' network integration as a predictor of persistence in introductory physics courses. Physical Review Physics Education Research, 13(1), 1-14. http://doi.org/10.1103/PhysRevPhysEducRes.13.010113 


\section{CHAPTER 4 \\ LONGITUDINAL ANALYSIS OF STUDENTS' SOCIAL POSITIONING IN AN ACTIVE LEARNING INTRODUCTORY PHYSICS CLASSROOM}

\subsection{Abstract}

Undergraduate introductory STEM courses sit at a critical point in the career trajectory of STEM majors. They often provide the first significant academic hurdle students face. Success in these courses has been shown to predict academic performance and persistence in STEM fields, as well as the switching over to a STEM major by those previously pursuing non-STEM careers. Moreover, in commuter schools, these classrooms present a critical interface between the institution and the students for the fostering or hindering of social integration. This kind of social integration into the fabric of an academic institution is critical for the success of STEM majors, in particular those from Hispanic backgrounds. Recently, social network analysis (SNA) has been used as a tool to measure and examine social integration in introductory physics classrooms, but a true longitudinal perspective of the development of students' integration in this context has yet to be presented. Here we present the results of our research on the development of students' inDegree and outDegree centrality (i.e., incoming and outgoing interactions) in an active learning introductory physics course at a Hispanic Serving Institution (HSI). We found that students invest in relationships with peers beyond those in their immediate work groups, and present these findings from the perspective of social and cultural capital theory. Hierarchical linear modeling (HLM) also revealed that students' centrality increases rapidly during the first half of the course and decreases during the 
second half. These findings align well with our capital framework. Given our discussion of the limitations of this study, this work sets a precedent in physics education research for longitudinal approaches to the development of student centrality.

\subsection{Introduction}

Due to an increase in the adoption of active learning pedagogy, some fields of science, technology, engineering and mathematics (STEM) education research have recently experienced a renewed surge of interest regarding the development of student social networks in classroom environments (Bruun and Brewe, 2013; Brewe, Kramer, and Sawtelle, 2012; Grunspan, Wiggins, and Goodreau, 2014). Active learning courses often present students with environments that nurture peer-to-peer and peer-to-instructor relationships, which lead to the natural development of social networks. Physics education researchers, in particular, have gone as far as to employ social network analysis (SNA) to test a variety of models that use students' positions in their networks to predict course grade, Force Concept Inventory scores, self-efficacy, and even participation in informal learning communities (Brewe et al., 2010; Brewe, Kramer, and Sawtelle, 2012; Dou and Brewe, 2014; Sawtelle et al., 2010). Yet, much of this type of research lacks an authentic longitudinal perspective on how students' network centrality (i.e., position in a social network) changes over time. Understanding the mechanisms of how social integration evolves over time in the classroom has various implications for student persistence in STEM careers. 


\subsection{Social Network Development as a Factor of Classroom Success}

Current theories of persistence and retention of college students emphasize the importance of student integration in the fabric of a university, even calling out social network analysis explicitly as a potentially useful tool for understanding this aspect of student behavior (Tinto, 1997). Similarly, Nora's (2003) Model of Student Engagement describes a series of factors that contribute to undergraduate students' degree attainment. Included in this model are factors related to the social integration of students. These consist of menteementor relationships with faculty, participation in out-of-class social organizations, informal peer learning, and in-class interactions with peers and instructors. The latter may be particularly important for student degree attainment when they take place in "gatekeeper," introductory courses. Crisp, Nora, and Taggart (2009) showed that both switching from a non-STEM major to a STEM major, as well as completing a STEM degree, were predicted by student enrollment in Biology I or higher and Algebra I or higher, so long as these courses were not taken in the first college semester. While this research does not specifically call out interactions that take place in the classroom, it does point to the introductory courses taken by STEM majors as crucial points in the progress of their STEM careers. Compounding the role these classes play, Tinto (1997) stresses the importance of the classroom environment, citing studies that link student persistence with the connections they make with peers and faculty. His own examination of classrooms as learning communities highlights the function of the classroom as a facilitator of the link between social and academic 
networks, which predict student persistence. This is especially salient for students in largely commuter schools where the primary interface between students and the university occurs in classes.

SNA is quantitatively poised to capture the complex relational structures formed by classroom interactions. With its roots in sociology, dating as far back as the 1930s, SNA has recently received renewed attention particularly in the social sciences, including science education research circles (Borgatti, Mehra, Brass, and Labianca, 2009; Scott, 1998). For example, Bruun and Brewe (2013) implemented SNA to show how introductory physics students' network metrics predict their final grades in future classes when controlling for scores on concept inventories. In the field of biology, Grunspan et al. (2014) present a primer for the use of SNA by biology education researchers, showcasing the various network features of student study groups pertaining to an introductory biology course. Their research showed not only that the study group networks changed over time, in a descriptive sense, but also that the positioning of students in each study group network correlated with their performance on the relevant exam.

\subsection{Centrality and Social Capital}

The language of SNA shifts somewhat depending on the community of practice, but the basic aspects remain the same (Scott and Carrington, 2011). In short, network analysts examine the structure of ties (i.e., relationships) between actors (i.e., participants) in predefined networks. This may result in network-level metrics or actor-level metrics. Network-level metrics include a variety of characteristics that apply to the network as a whole (e.g., density, diameter, size 
of giant component). Actor-level metrics typically refer to the social positioning of participants in the network, which can be referred to as an actor's centrality. Various centrality measures exist that capture the nuanced relationships present in networks. The simplest metrics include inDegree and outDegree centralities, which represent the number of incoming and outgoing ties, respectively, leading to or from a particular actor. A myriad of additional algorithms exist that measure everything from how much an actor brokers relationships between groups of actors to the popularity of actors as factors of the popularity of those with whom they associate. In this study we focus on inDegree and outDegree centralities since they are the foundation for how all other centralities are calculated.

A foundational assumption of our operating philosophy is that the nature of ties developed by actors in student networks may offer certain advantages to particular students. We have seen this relationship in the context of active learning, undergraduate introductory physics courses. Dou et al. (2016) found a relationship between student centrality and physics self-efficacy development. Students with high outDegree centrality were more likely to experience positive changes in both the verbal persuasion and vicarious learning sources of selfefficacy, while those with high PageRank centrality were more likely to see positive changes in their overall self-efficacy. Zwolak, Dou, Williams, and Brewe (2017) showed that introductory Physics I students with high inDegree and outDegree centrality persisted in taking introductory Physics II the following semester, regardless of the grade they received in the class. This link between persistence in a course sequence as a factor of students' social positioning had 
not been previously examined. Zwolak et al.'s (2017) study, such as Dou et al.'s (2016), took place in an active learning context. These works and some of those referenced earlier lend credence to our operating philosophy that the structure of social relationships between students matter with regard to their performance, persistence, and beliefs. Moreover, this association between student networks and classroom outcomes may be particularly salient in active learning environments where students are more likely to interact with one another. In some cases, the number of peer-to-peer interactions that take place in active learning classrooms differs drastically from traditional, lecture-based courses (Brewe, Kramer, and O'Brien, 2010).

In other contexts, social capital has been identified as the mechanism that drives disparate success among individuals along differences in their relationships as quantified by SNA. For example, Abbassi, Wigand, and Hossain (2014) calculated a variety of centrality measures based on ties defined by coauthorship on papers published on "information science" between 2001 and 2010 ( $N=4579$ publications). These measures included degree centrality (i.e., inDegree plus outDegree), weighted degree centrality, which gives more weight to having multiple co-authorships with the same people. They also calculated two proposed measures-power diversity index (PDI) and power-tie-diversity-index (PTDI). The PDI takes into account ties between authors and co-authors who are highly valued as measured by a citation-count index (i.e., $h$-index). PTDI does the same, but assigns greater weight to multiple collaborations between authors and co-authors with high $h$-indices. Degree centrality and weighted degree 
centrality exhibited highly significant correlations with citation count- 0.22 and 0.23 , respectively. PDI and PTDI correlated more so with authors' citation count -0.45 and 0.44 , respectively. Based on these results, Abbasi et al. (2014) argued that not only do authors' social networks correlate with their overall citation count, but when taking into account the value of the individuals the authors are connected to, a stronger association with citation count exists. They propose that being connected to co-authors with strong $h$-indices provide greater social capital to individual authors. This added value helped to explain the closer association with citation-count than simply having a large number of co-authors.

The results of Siciliano's (2016) study align with those of Abbasi et al. (2014), which also suggests that the value of the peers one associates with could grant actors certain advantages (i.e., social capital). Abbasi et al. (2014) surveyed teachers in an urban school district in Midwestern United States. The 424 teachers who responded provided information about their collaboration with peers on lesson plan development and implementation. The surveys also included items related to teacher self-efficacy, demographics, and evaluation of peer attributes. The outcomes of this research support a weak link between teachers' peer network and their self-efficacy, but a stronger link when taking into account the attributes of peers in their network, which included knowledge and willingness to help.

While the work of examining students' in-class social networks remains largely unexplored, Siciliano (2016) and Abassi et al. (2014) have made a strong argument in favor of success as a result of both the number of ties in academic 
networks and the quality of those ties. It stands to reason then that similar mechanisms exist in classrooms, particularly those where student-student interactions dominate the social context. The promotion of active learning pedagogies in STEM by national reports and meta-analyses has increased the occurrence of interactive settings across K-12 and higher education institutions (Freeman et al., 2014; National Research Council [NRC], 2012, 2013, 2014). In fact, we have seen changes to the national $\mathrm{K}-12$ science standards that encourage educational agencies and educators to create environments where students actively learn through peer collaboration and discourse (NGSS Lead States, 2013). Undergraduate physics education researchers have seen similar growth in curricula and pedagogies that solicit academic social discourse (NRC, 2013). Our implementation of and research on one of these approachesModeling Instruction for introductory physics_-prompts our current analysis of students' in-class social networks.

\subsection{Modeling Instruction in Context}

For the past 10 years, Florida International University's (FIU) Physics Department, in conjunction with the Department of Teaching and Learning, has honed a course curriculum called Modeling Instruction (MI). MI introductory physics courses showcase high levels of solicited student-student interactions, minimizing the role of the instructor, and take a sociocultural, constructive approach to learning (Brewe et al., 2010). This studio-format course combines the "lecture" and "lab" sections into a single class where students spend most of their time examining natural phenomena via experimentation and developing 
scientific models from their observations. Model development occurs through small group consensus (i.e., approximately three students) and model refinement takes place in larger group meetings (i.e., approximately 20 students). This learning format lends itself to the creation of social networks within the class as students interact in small groups, across small groups, and in the larger group setting.

At the focal point of the Ml curriculum lies the belief that learning and social interactions are interdependent (Bruun and Brewe, 2013; Vygotsky, 1986). This guiding philosophy stems from the sociocultural framework that grounded this curriculum's development (Brewe, 2008; Desbien, 2002). Sociocultural learning theory implies two major classroom manifestations: (a) soliciting students' prior knowledge and experiences and (b) constructing new knowledge by building on prior knowledge. Language plays a major role in facilitating these two products of a sociocultural learning environment (Schunk, 2012). We therefore expect social interactions to prevail in the MI setting. A study comparing the academically related classroom interactions of students in an MI introductory physics course $(N=30)$ and students in an equivalent lecture-based course $(N=$ 80) reported two major findings. One, when surveyed at the beginning and end of the semester, students in the MI course reported a significant increase in their number of classroom interactions, while those in the lecture-based course showed no change. Second, the density of the MI and the lecture course networks were significantly different at both pre and post data collection points, such that students in the Ml course reported many more interactions than those 
in the lecture-based course even after taking into account the number of students in the two courses. In fact, of the $30 \mathrm{Ml}$ participants, all reported at least one interaction on the post network survey, while only 15 out of the 80 lecture course participants interacted with at least one other peer (Brewe, Kramer, and O'Brien, 2010).

Research shows that students taking Ml outperform their peers in equivalent lecture-based sections of the course on attitudinal assessments and conceptual understanding (Brewe, Kramer, and O'Brien, 2009; Brewe et al., 2010). Students pass at greater rates, exhibit positive attitudes toward the material, and have deeper understanding of the content. On the other hand, studies have also shown that students' physics self-efficacy -their expectations to successfully complete physics related tasks-and physics interest in these courses drops (Dou et al., 2016; Dou, Brewe, Potvin, Zwolak, and Hazari, Under review). These constructs (i.e., self-efficacy and interest) deserve close attention due to their central role in students' career choice development (Fouad and Smith, 1996; Lent, Brown, and Hackett, 1994; Bandura, Barbaranelli, Caprara, and Pastorelli, 2001). Changes in student self-efficacy are often correlated with interactions that take place in learning settings (Bandura, 1993). The development of physics self-efficacy in MI courses has been linked to both the number and kinds of interactions that students experience in the classroom (Dou et al., 2016). 


\subsection{Examining Students' Centrality Development}

While a few studies exist that link particular student outcomes, such as academic performance and self-efficacy, to the social networks found in active learning science classrooms (e.g., Bruun and Brewe, 2013; Dou et al., 2016; Grunspan et al., 2014), longitudinal explorations of how students' position in these networks develops over time have yet to take place. This is especially true for undergraduate physics courses. Approaching this aim, Traxler (2015) examined changes in the number of student communities that existed within several first-semester introductory physics courses. She surveyed student interactions at the beginning and end of the course (i.e., pre and post), using responses to calculate whether students belonged to particular subgroups (i.e., communities) within the classroom. Surprisingly she found that students in courses dominated by traditional teaching strategies belonged to a variety of subgroups at the beginning of the course, suggesting that some students come into these courses having previously established connections with peers. Over time the number of subgroups, as well as the network density of lecture courses decreased, while those of the active learning courses remained the same, which indicated an increased amount of coherence in student connections in the lecture courses, but not in the active learning courses. This outcome stood diametrically opposed to the researcher's belief that the number of communities in active learning courses would decrease as student subgroups join and expand due to increased interactions, but this seemed to take place more so in the lecturebased courses. 
Yang, Nainabasti, Brookes, and Brewe (2014) collected longitudinal data regarding physics' students' informal interactions (i.e., course-related interactions that took place outside of class), but took a cross-sectional approach to analysis. After collecting data about students' out-of-class interactions each week, they compiled all the interactions into a single matrix by adding up interactions across all surveys. If student $A$ reported interacting with students $B$ and $C$ during week one, but only reported interacting with student $\mathrm{C}$ during week two, then student A's cumulative network would reflect one interaction with student $B$ and two with student C. By doing so, Yang et al. (2014) were able to determine that students in active learning physics courses develop many more ties with peers outside of class than students in lecture-based courses. While the advantage of this approach lies in offering a holistic and summative picture of student networks, it does so by flattening out the temporal dimension and thus eliminating nuances about the development of student networks.

Understanding how student networks develop in the classroom may hold the key to discovering the components that facilitate classroom integration in the sciences. These components may vary across contexts, and therefore the network development may vary as well. For example, students in lecture-based courses who are not encouraged to interact with one another may interact with other students haphazardly or at random based of whom they sit next to in class or whom they happen to have known in other contexts. On the other hand, students in active learning courses designed to foster critical thinking around team-based projects have more opportunities to engage with peers and may 
form networks differently. This particular setting intrigues us due to the recent attention on and growth in active learning curricula. Active learning approaches grounded in sociocultural learning theories, such as $\mathrm{MI}$, posit success in learning as a factor of relational interactions. If so, we could imagine knowledge gained in the classroom as a form of cultural capital, which is transmitted socially (Bourdieu, 1986). Bourdieu (1986) describes the transmission of cultural capital as being facilitated by social capital. If so, students in these courses would find themselves searching for the right peer-to-peer relationships that support the kind of learning success they seek (i.e., purposely building social capital).

To understand the mechanisms of social integration in the active learning science classroom a true longitudinal approach must be undertaken. We believe this should go further than what has been previously done, such that both the design and the analysis account for the temporal dimension. This would include multiple waves of data collection beyond just pre- and post-, so as to better grasp the nuances of what occurs throughout the course. This kind of data collection should be met with a complementary longitudinal statistical analysis that rather than compress the temporal dimension, takes advantage of the variance that exists over time. Such an approach would also provide precedence for future longitudinal analyses of social networks in active learning science courses.

\subsection{Purpose}

The purpose of this study is to examine the development of students' social positioning in an active learning physics classroom. This study examined two particular variables as they relate to social network growth: student centrality 
and gender. With regard to centrality, we have focused on student inDegree and outDegree because they represent the fundamental unit of measurement between actors in a network. Taking a longitudinal approach to analysis, we used hierarchical linear modeling (HLM) to gauge whether linear and/or quadratic patterns of centrality development exist over time. Significant linear growth would allow us to state whether students' social behavior increases or decreases throughout the course of the semester, while significant quadratic growth would help to tease out potential nuances that may otherwise remain unseen.

HLM also allows us to test whether other factors are associated with growth. In this case, we examine the effect of gender on social network development. Physics fields, in particular, suffer from evident underrepresentation of women (Hazari et al., 2013; Dabney \& Tai, 2013). This characteristic often manifests itself at the undergraduate level in the form of gender gaps found in student concept inventories (Brewe et al., 2010). Known and unknown aspects of physics career pathways contribute to this unfair striation (McCullough, 2004). Examining whether gender plays a role in the students' social development in introductory courses may help bring attention to the role of interactions as a possible contributor to gender-based differences in certain student outcomes.

Specifically, we sought to answer the following research questions:

1. Does student centrality as measured by inDegree and outDegree exhibit linear growth over time?

2. Does student centrality exhibit quadratic growth over time? 
3. Does student gender play a significant role in students' centrality and its development over time?

\subsection{Methods}

Data were collected during the Fall 2014 and Fall 2015 semesters at FIU—a large Hispanic Serving Institution (HSI) in southern Florida. FIU is an urban, R1 "Highest Research Activity" institution. Over $90 \%$ of students enrolled at FIU commute to school. For the semesters in question, one section of MI Introductory Physics I with Calculus (hereto referred as MI) was offered the first year (i.e., Fall 2014) and two in the second, such that an additional professor was brought on to teach the second course in Fall 2015. Only the data collected from classes taught by the same professor were included in this study in order to control for possible instructor effects $(N=147)$. Students voluntarily registered for MI at their own discretion. It is worth noting that the typical Introductory Physics I course offered at FIU requires a separate laboratory credit, which students may enroll in at the time they take the lecture course or subsequently. MI incorporates the lab credit. While students understand this when enrolling, they come in with varying expectations about the nature of the curriculum, ranging from traditional lecture-based teaching to hands-on, interactive learning (Dou et al., 2016).

\subsubsection{Classroom Context}

Demographic information was retrieved from the university system, including gender and ethnicity, which reflects what students report when applying to the institution. Combined, $40 \%$ of the students enrolled in the Ml courses identified as "male" and $56 \%$ as "female" when first applying to the university. Six 
students did not provide gender information. The majority of students also reported their ethnicity as Hispanic (i.e., $71 \%$ ), $9 \%$ as White, $7 \%$ as Black, and $5 \%$ as Asian, confirming a predominantly Hispanic population. The remaining students pertained to two or more races, or chose not to answer this question. Gender distributions within students' ethnic or racial group mirrored those of the general classroom population. When interpreting our results we took into account that of the 31 student majors represented, no student in either course had chosen physics as a major at the time this data were collected. Most students pursued STEM majors (e.g., civil engineering, chemistry, computer science) with the majority of the student population pursuing bachelor degrees in biology (i.e., $18 \%)$.

Students were directed to work in groups nearly everyday. The classroom was designed to facilitate physically active group work. Rather than desks affixed to the ground, students sat around tables placed throughout the large room. Both the tables and the chairs could freely move by means of wheels. Six students split into two groups of three sat around each table. Each group of three worked on activities together, though oftentimes groups at the same table exchanged ideas. Students were also allowed to move about the entire room in search of peer or instructor input. Initial student group formation took place haphazardly with most students joining groups based on who sat at their table during the first week of class. The instructor switched student groups three times throughout the semester to allow for fresh exchanges of ideas and facilitate student network formation. 
At the end of small group activities, the class was split into three large groups of 20 to 25 students where summaries were shared and discussions took place. Student groups presented their conclusions using diagrams and other representations on portable white boards. Each of these larger group discussions was facilitated by either the instructor or a Teaching Assistant (TA). Two TAs were assigned to the class in Fall 2014 and one in Fall 2015. The TAs were graduate students in the department of physics familiar with reformed teaching approaches. In addition to the TAs, three undergraduate Learning Assistants (LAs) walked around the room to offer help when needed. LAs were required to have previously passed Introductory Physics I with Calculus with at least a "B" grade, and attended orientation and training seminars throughout the course in support of their educational role.

\subsubsection{Social Network Survey}

Five times (i.e., for five waves) throughout each semester students were given a pencil and paper survey that asked, "Please choose from the presented list people from your physics class that you had a meaningful interaction with in class this week, even if you were not the main person speaking or contributing." Written instructions further encouraged the inclusion of peers not part of students' assigned group when appropriate. To help students with identification, the survey included a randomized list of the names of every classmate and instructor. This list was generated in response to student difficulty when trying to remember their peers' names during the Fall 2014 semester. For that reason only students in the Fall 2015 semester received this list. Although the overall 
number of peers reported in response to the survey question did increase from Fall 2014 to Fall 2015, the major characteristics of the network as a whole were very similar. This included overall size, density, and outDegree centralization (Zwolak et al., 2017).

Each administration occurred toward the end of a small group (i.e., three students), experimental activity designed to solicit the construction of physical science concepts through discourse. The only exception was the last administration of the Fall 2014 semester, which occurred during an optional exam review session. This led to an atypical response rate of $43 \%$; all other administrations exhibited response rates ranging from $78 \%$ to $97 \%$. In order to retain conformity of learning context and to avoid introducing confounding variables we dropped the last survey administration that took place each semester from the analysis.

\subsubsection{Calculating inDegree and outDegree}

Every time a particular student was named by one of his or her peers on the social network survey, that student received an inDegree of plus one on a given survey administration. For example, in a classroom of six students, $1-6$, if students $1,2,3$, and 5 mention having a meaningful interaction with student 6 , then student 6 receives an inDegree of four (see Figure 17). A student's outDegree was calculated simply by adding up the number of peers he or she reported having a meaningful interaction with. So as illustrated in this example, because student 6 reports having a meaningful interaction with students 1 and 4 , then student 6 is given an outDegree of two. Note that in this example student 6 
does not mention having had a meaningful interaction with students 2,3 , and 5 , though they reported student 6 on their survey.

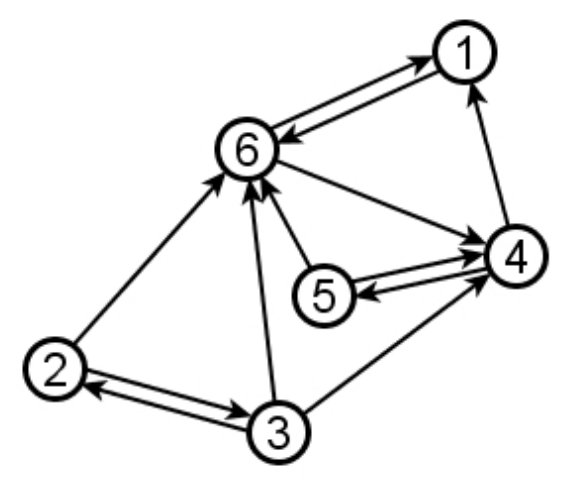

Figure 17. Example Network to Illustrate InDegree and OutDegree. Each circled number is referred to as an actor. Incoming arrows indicate inDegree and outgoing arrows outDegree. Arrows are typically referred to as ties or edges.

In a bound social network where the inDegree and outDegree of every actor is known, these two centrality measures are equal across the whole network. For every outDegree coming from a "source" actor in the network, there is a corresponding inDegree for the "target" actor. Figure 17 helps to illustrate this. For example, actor number 5 has an outDegree of two. Each of those ties grants actor 4 and 6 with an inDegree of one for a total of two. If the same applies to every actor, then the overall network outDegree adds up to the sum of the overall network inDegree. This fact is worth mentioning, as our analysis will exclude instructors from final calculations of inDegree given that instructors did not fill out surveys and therefore would not contribute to students' inDegree. Instructors named by each student will count toward their outDegree calculations, but instructors will be removed from the final analyses; the development of 
instructor centrality is not the focus of this study. We expect the final student network to have a higher average outDegree than inDegree. For example, the network in Figure 17 has a total inDegree and outDegree of 12, but if we consider node 6 as an instructor, we would calculate the network as having a total outDegree of 10 and an inDegree of six.

\subsubsection{Using HLM in Longitudinal Data Analysis}

Standard linear regressions, and other common statistical tools, rely on the assumption that data is independently observed. In social science, for example, data meets this assumption when a participant's response to a survey question does not depend on the response of any other participant. Longitudinal data, by definition, fails to meet this assumption, as an individual's response on a survey item will typically relate in some way to previous responses by that individual on the same survey item taken at an earlier date. Not accounting for this correlation between individuals' multiple responses to the same query over time could result in compressed standard errors that will ultimately yield inaccurate significant results (i.e., Type I error; Hox, 2002).

HLM addresses the dependence in longitudinal data by taking into account both between person variation (i.e., differences in responses from one individual to the next on an item) and within person variation (i.e., differences in responses from the same individual on the same item over time). In multilevel analyses, like HLM, longitudinal data is treated as multilevel data where individuals' responses to a particular item are nested within the individual. Here, we categorize student-level variables, such as gender, as level-2 variables (i.e., 
between student level variables), and their responses to the same items over time as level-1 variables (i.e., within student level variables). Modeling data in this way offers a variety of advantages, including robust accounting for either fixed or variable temporal spacing of survey administration, growth curves that vary according to different participants' responses, and analyses that better handle missing data, particularly when using maximum likelihood estimation (Hox, 2002).

\subsection{Description of Models}

We ran several longitudinal growth models using HLM 6 software (Raudenbush, Bryk, \& Congdon, 2004). Two unconditional models with only student centrality as outcomes allowed us to get a baseline reading of lower and higher level variance. Model A tested inDegree as an outcome and Model B tested outDegree as an outcome. Additional iterations of these models included "time" as a predictor of linear and quadratic trends for each respective outcome variable. Students' gender was included as a level-2 predictor. We report on the unconditional and final models for each outcome variable.

We time centered at wave one in order to capture intercepts indicating students' average inDegree and outDegree after the first week of the course. Significant time trends indicated whether linear or quadratic growth patterns existed with regard to students' in-class interactions. The inclusion of gender as a level-2 predictor revealed whether or not this variable had an effect on student centrality at the beginning of the course and on its change over time. 


\subsection{Results}

The unconditional Model A, positing inDegree as the outcome variable, identified a grand mean estimate for student inDegree of 3.80 [SE $=0.11, t(140)$ $=33.4, p<.001]$. Students were named by their peers approximately four times per survey when averaging out data from all collection waves. This analysis also indicated a significant amount of level-2 (i.e., student level) variance $\left[\sigma^{2}=1.29\right.$, $\left.X^{2}(140)=478.6, p<.001\right]$, showing us a $95 \%$ interval range of 1.57 to 6.03 student degree across all four collection waves. We used the level-2 and level-1 variance to calculate an intraclass correlation (ICC) of .39, revealing that $39 \%$ of the variance in inDegree can be explained at the between student level, and $61 \%$ at the within student level.

We found that students had an inDegree of 3.78 on average at the beginning of the course [SE $=0.15, t(139)=25.4, p<.001]$. Student gender showed no significant relationship with the intercept or growth trends at the $\alpha=$ 0.05 level, but was meaningfully close $(p$-value $=0.054)$. Student inDegree centrality did not exhibit a significant linear trend, nevertheless a significant and negative quadratic trend was present [Estimate $=-0.13, \mathrm{SE}=0.06, t(526)=-$ $2.16, p<.05]$. The population of students exhibited a rapid growth in centrality during the first half of the course and then a decrease during the second half (see Figure 18). 


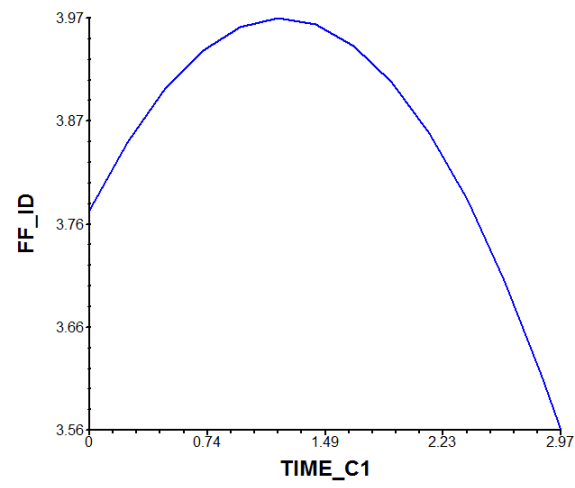

Figure 18. Pattern of quadratic growth of inDegree centrality: showcasing a rapid increase during the first half of the course followed by a rapid decrease.

Despite these significant results, this more complex model only explained about $1 \%$ of the level- 2 variance identified in the unconditional model [i.e., $\sigma_{\text {explained }}^{2}=\left(\sigma_{\text {uncond. }}^{2}-\sigma_{\text {model }}^{2}\right) / \sigma_{\text {uncond. }}^{2}$. Similarly, the model only explained about $1 \%$ of the level-1 variance identified. This was not surprising, considering that gender was not a significant predictor of variance. The ICC continued to indicate that $39 \%$ of the residual variance in student inDegree remained at the between student level, suggesting that other variables beside gender may help to explain some of the variance in student inDegree.

Analyses of Model B addressed outDegree as the outcome variable. The grand mean estimate for overall student outDegree across all data collection events was $4.94[\mathrm{SE}=0.22, t(135)=22.7, p<.001]$. Given a significant level-2 variance component $\left[\sigma^{2}=5.09, \mathrm{X}^{2}(135)=634.5, p<.001\right]$, we calculated an ICC for this unconditional model of .55 , indicating that $49 \%$ of the variance in our outcome variable can be explained by between student differences and the remaining variance by within student differences. We calculated a $95 \%$ interval range for student outDegree of 0.52 to 9.36 . 
We tested several interim models employing gender and growth as predictors of outDegree. Similar to the inDegree model, we found that gender does not significantly predict changes in outDegree over time. Students had an average outDegree during the first data collection of 4.74 [SE $=0.20, t(134)=$ 23.5, $p<.001]$. Student outDegree exhibited a significant and positive linear trend [Estimate $=0.61, \mathrm{SE}=0.29, t(511)=2.073, p<.05]$. The data revealed a negative quadratic trend, which suggested that students' outDegree rapidly increased over time during the first half of the course and rapidly decreased during the second half of the course [Estimate $=-0.20$, SE $=0.10, t(511)=-2.13$, $p<.05$; see Figure 19]. We calculated an ICC of .50 based on the significant level-2 variance $\left[\sigma^{2}=5.14, \mathrm{X}^{2}(134)=637.6, p<.001\right]$. Like the unconditional model, this indicates that about $50 \%$ of the residual variance in outDegree can be explained by between student level variables and the remaining $50 \%$ by within student level variables.

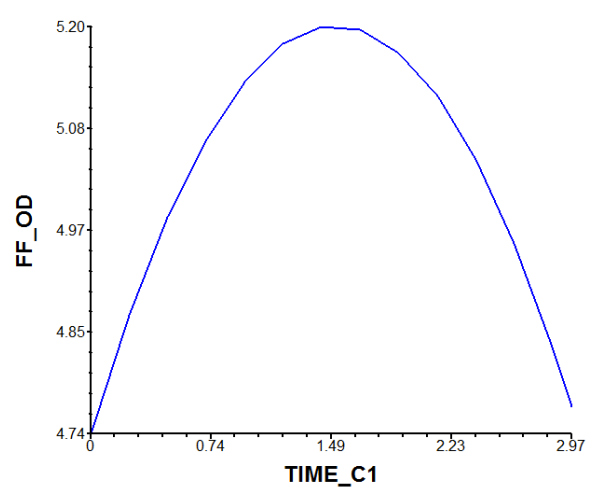

Figure 19. Pattern of quadratic growth of outDegree centrality: showcasing a rapid increase during the first half of the course followed by a rapid decrease. 


\subsection{Conclusion}

As befits the use of hierarchical linear modeling, our results offer various levels of interpretation. At one level these analyses support the conclusion that differences exist in the direction of student interactions that take place in the active learning physics classroom. To expand, we found that on average a student reported having more meaningful interactions overall (i.e., 4.94) than she or he is the subject of (i.e., 3.80). As mentioned earlier, in a closed network where all actors and ties are known, the number of incoming and outgoing interactions should equal the same number. We would expect these two values, even after maximum likelihood estimation, to resemble one another. The difference we found exists because of the way we calculated these centrality measures. Because students named instructors on surveys and because instructors were removed as targets on the final edge list used for calculation, it makes sense that additional points of outDegree exist that do not correspond with additional points of inDegree. In other words, the missing inDegree value represents outgoing interactions occurring with instructors (i.e., professor, TAs, LAs). The disparity illuminates student behavior worth examining: only about one-fifth of all "meaningful academic interactions" reported by students included an instructor.

This outcome reflects the student-centric nature of the MI classroom. Most reported interactions took place with other students, as opposed to instructors. This aligns with the goals and intentions of the MI curriculum, which aims for student learning to increase through peer-to-peer discourse. This does not 
necessarily mean that the instructor fails to play a meaningful role. While responding to the survey, a student has a much larger pool of peers than instructors to name. When considering the ratio of students to instructors (approx. 18:1), if one out of every five meaningful interactions takes place between a student and an instructor, then we can support the idea that students value their interactions with instructors more than they do with peers.

With that said, the results also point to different primary sources for the variances found in inDegree and outDegree. Unlike outDegree scores, InDegree scores do not reside directly in a particular student's control, but rather in the perception of that student's peers. It is therefore worth noting that more of the inDegree variance can be explained by between student differences than within student differences. That is to say that the perception of a student by his or her peers over time dominates changes in that particular student's inDegree over time. A variety of plausible factors could contribute to this (e.g., the perception of a student's popularity, helpfulness, academic mastery). When taking into account our research design and self-reported nature of the SNA survey, we expect to conclude that the inDegree of students in our study depended more on peers' perception than on characteristics inherent to the students themselves (e.g., gender). That is not to say that these factors do not play major roles in contributing to students' centrality, but the analyses indicated that their effect is likely indirect through the mediation of peers' perceptions.

Variance in outDegree, on the other hand, was found to be about the same at the between and within student level. How often students interacted with 
peers or reported having meaningful academic interactions with peers could be explained by characteristics of the students, as well as changes in students' behavior over time. We should take note that we only examined one between student level variable — gender. In our case, gender was not a significant predictor of inDegree and outDegree, nor of their longitudinal development. Identifying as either male or female did not contribute differentially to students' academic interactions. Yet, we should also take note of the borderline significance of student gender on linear growth of inDegree centrality, suggesting that female students may be reported less often than their male counterparts as someone with whom peers have meaningful academic interactions.

The results of our HLM models indicate that both of these centrality measures (i.e., inDegree and outDegree) exhibit significant negative quadratic growth patterns. Thus the number of interactions reported (and received) increase rapidly throughout the first half of the semester and decrease during the second half of the semester. We, therefore, see a complex pattern of interactions taking place in this active learning, introductory physics course-the rate of outgoing and incoming interactions changes from positive to negative as the semester progresses. Bruun and Bearden (2014) found a strikingly similar pattern of student social behavior using a different set of analyses in introductory physics courses at the University of Copenhagen.

When thinking about plausible mechanisms that may drive the rates of interactions among students, one possibility lies in the curriculum itself, soliciting different kinds and types of interactions. The consistency of the MI curriculum 
with regard to patterns of activities and assignments belies the changes in patterns of reported interactions. The curriculum itself does not change significantly such that more interactions are required or solicited at the beginning of the semester than at the end or vice versa. Instead the collaborative "level" of the activities remains the same: activities happen in groups of three, which then report out to a larger group of approximately 20 students. Therefore it is unlikely that curriculum is the driver of behavior change. We also note that the grand average inDegree and outDegree are greater than two (i.e., 3.83 and 4.98 , respectively), which indicate that students are part of meaningful academic interactions that include students outside of the two other members in their designated groups. This finding suggests that students find value in interactions that extend beyond those that take place with their immediate group members, and the MI environment presents several opportunities, both structured and unstructured, for these additional interactions to take place.

Possible explanations for the presence of this behavior may be found in cultural and social capital theory (Bordieu, 1986), which supposes that interactions with individuals in class may result from a search to increase capital with which to accomplish a goal or sets of goals. In the classroom setting, we can reasonably assume that the goals of most students include understanding the material and/or successfully completing the course. Increases in peer interactions beyond those in students' immediate, three-person group may reflect their seeking of cultural capital to aid in accomplishing classroom related tasks that help them achieve their goals. By design, in a constructivist learning 
environment, cultural capital (i.e., the information needed to achieve goals) reside with peers, hence students' need to make social connections with others in order to gain access to this capital. The early growth of academic interactions supports the idea that students seek to increase their capital. Students, indeed, report interacting with an increasing number of peers during the first half of the course. This is not a reflection of simply meeting new people as a result of changes in group assignments; regardless of who students are assigned to work with, the groups always have two members, and therefore, if their meaningful interactions occur only in this small group setting, then their inDegree and outDegree should remain at just two at most, regardless of the identity of those two individuals. But this is not what occurs. Students are interacting with others beyond those in their small groups, and the number of those meaningful interactions continues to increase throughout the course. These interactions require time and attention that might detract from students' immediate goals (e.g., successfully completing an activity worksheet), but because they occur and because students find them meaningful and academic, we could reasonably assume that students value the capital gained from those interactions and therefore the investment of their time and attention is aligned with and supports the accomplishment of their goals.

We must also consider that although students report interacting more as the course progresses, the rate of this increase changes after the first half of the course. We believe this could reflect a certain contentment students achieve with their social capital where they have acquired that which helps them achieve their 
goals and/or they no longer see the investment they have to make to build capital as worthwhile. This decreasing rate of interactions seen during the second half of the course may also be related to students perceiving a kind of social saturation in terms of the number of people in the class they believe can help them achieve their goals. Toward the end of the semester students have had a chance to interact with many, if not all of their peers, and form perceptions of who they want to interact with for academic purposes. Having gotten a sense of who is in their class, however shallow a process, they may limit their search for capital to those they believe would help them most. This aligns with social network analysis that indicates that in certain social and educational settings, the quality ${ }^{8}$ of ties matters more than the quantity (Siciliano, 2016). In short, we find that students made important connections with peers primarily during the first half of this active learning introductory physics course-more so than during the second half of the course. Thus, interventions aimed at helping students forge connections with resourceful peers should target this critical time period.

While we find informative trends in the patterns of interactions between students, much of the variance in student responses is left to be explained. Despite the findings of growth, the unexplained variance our models reflects the inability of the gender variable to predict variance in student centrality over time. This confirms what we have seen in past research on $\mathrm{Ml}$ environments and the relationship of gender with social network metrics (Dou et al., 2016; Williams,

\footnotetext{
${ }^{8}$ We should point out that this quality, which students enact in their interpretation of the phrase "meaningful academic interaction," is expressed exclusively from the point-of-view of the student.
} 
Brewe, Zwolak, \& Dou, 2015; Zwolak et al., 2017). Future studies should examine other factors, such as student progress in a course, which may serve as better predictors of social behavior, given that these could point to highly resourced individuals.

Nevertheless, the purpose of this study was not to determine whether particular variables predict variance in the development of centrality, but rather we sought to execute a preliminary step, which was to determine whether development in social behavior takes place over time in a relatively large active learning science course. The insight gained from analysis of students' academic social networks will hopefully lead to better understandings of how the classroom interface helps them integrate with the social fabric of a university, a factor particularly important for student persistence (Nora, 2003; Tinto, 1997). This is especially true at HSIs like FIU and in introductory, gatekeeper courses, which are crucial requirements for STEM majors and often mark students' first foray into their career (Crisp, Nora, \& Taggart, 2009).

The current study represents not only an example of the value that comes from using the tools of social network analysis to examine various outcomes that result from interactions in active learning courses, but also one of the first longitudinal examinations of social development in an introductory physics classroom using the tools of SNA. Disseminating and incorporating these techniques and others, such as latent growth modeling, will help move the field forward, especially in an era when more educators are adopting the call to foster interactive learning environments. This could one day lead to generating social 
interventions that take place during or prior to a course with a purpose to help students maximize both their academic and affective outcomes as a result of the social framework set in place by the instructor and the curriculum.

References (Chapter 4)

Abbasi, A., Wigand, R. T., \& Hossain, L. (2014). Measuring social capital through network analysis and its influence on individual performance. Library \& Information Science Research, 36(1), 66-73. http://doi.org/10.1016/j.lisr.2013.08.001

Bandura, A. (1993). Perceived self-efficacy in cognitive development and functioning. Educational Psychologist. http://doi.org/10.1207/s15326985ep2802_3

Bandura, a, Barbaranelli, C., Caprara, G. V, \& Pastorelli, C. (2001). Self-efficacy beliefs as shapers of children's aspirations and career trajectories. Child Development, 72(1), 187-206. http://doi.org/10.1111/1467-8624.00273

Borgatti, S. P., Mehra, A., Brass, D. J., \& Labianca, G. (2009). Network analysis in the social sciences. Science, 323, 892-895. http://doi.org/10.1126/science.1165821

Bourdieu, P. (1986). The forms of capital. In Handbook of Research for the Sociology of Education (pp. 241-258). http://doi.org/10.1002/9780470755679.ch15

Brewe, E. (2008). Modeling theory applied: Modeling Instruction in introductory physics. American Journal of Physics, 76(12), 1155. doi:10.1119/1.2983148

Brewe, E., Kramer, L., \& O'Brien, G. (2009). Modeling instruction: Positive attitudinal shifts in introductory physics measured with CLASS. Physical Review Special Topics - Physics Education Research, 5(1), 013102. http://doi.org/10.1103/PhysRevSTPER.5.013102

Brewe, E., Kramer, L. H., \& O'Brien, G. E. (2010). Changing participation through formation of student learning communities. AIP Conference Proceedings, 1289, 85-88. http://doi.org/10.1063/1.3515255 
Brewe, E., Kramer, L., \& Sawtelle, V. (2012). Investigating student communities with network analysis of interactions in a physics learning center. Physical Review Special Topics - Physics Education Research, 8(1), 010101. http://doi.org/10.1103/PhysRevSTPER.8.010101

Brewe, E., Sawtelle, V., Kramer, L. H., O’Brien, G. E., Rodriguez, I., \& Pamelá, P. (2010). Toward equity through participation in Modeling Instruction in introductory university physics. Physical Review Special Topics - Physics Education Research, 6(1), 010106. http://doi.org/10.1103/PhysRevSTPER.6.010106

Bruun, J., \& Bearden, I. G. (2014). Time development in the early history of social networks: link stabilization, group dynamics, and segregation. PloS One, 9(11), e112775. http://doi.org/10.1371/journal.pone.0112775

Bruun, J., \& Brewe, E. (2013). Talking and learning physics: Predicting future grades from network measures and Force Concept Inventory pretest scores. Physical Review Special Topics - Physics Education Research, 9(2), 020109. http://doi.org/10.1103/PhysRevSTPER.9.020109

Crisp, G., Nora, a., \& Taggart, a. (2009). Student characteristics, pre-college, college, and environmental factors as predictors of majoring in and earning a STEM degree: An analysis of students attending a Hispanic Serving Institution. American Educational Research Journal, 46(4), 924942. http://doi.org/10.3102/0002831209349460

Dabney, K. P., \& Tai, R. H. (2013). Female physicist doctoral experiences. Physical Review Special Topics - Physics Education Research, 9(1), 010115. http://doi.org/10.1103/PhysRevSTPER.9.010115

Desbien, D. (2002). Modeling discourse management compared to other classroom management styles in university physics. Ph.D. dissertation, Arizona State University.

Dou, R., Brewe, E., Zwolak, J. P., Potvin, G., Williams, E. A., \& Kramer, L. H. (2016). Beyond performance metrics: Examining a decrease in students' physics self-efficacy through a social networks lens. Physical Review Physics Education Research, 12(2), 20124. http://doi.org/10.1103/PhysRevPhysEducRes.12.020124

Fouad, N. a., \& Smith, P. L. (1996). A test of a social cognitive model for middle school students: Math and science. Journal of Counseling Psychology, 43(3), 338-346. http://doi.org/10.1037//0022-0167.43.3.338 
Grunspan, D. Z., Wiggins, B. L., \& Goodreau, S. M. (2014). Understanding classrooms through social network analysis: A primer for social network analysis in education research. Cell Biology Education, 13(2), 167-178. http://doi.org/10.1187/cbe.13-08-0162

Hazari, Z., Potvin, G., Lock, R. M., Lung, F., Sonnert, G., \& Sadler, P. M. (2013). Factors that affect the physical science career interest of female students: Testing five common hypotheses. Physical Review Special Topics Physics Education Research, 9(2), 020115. http://doi.org/10.1103/PhysRevSTPER.9.020115

Lent, R. W., Brown, S. D., \& Hackett, G. (1994). Toward a unifying social cognitive theory of career and academic interest, choice, and performance. Journal of Vocational Behavior, 45, 79-122.

Mccullough, L. (2004). Gender, context, and physics assessment. Journal of International Women's Studies, 5(4), 20-30.

National Research Council. (2012). A framework for K-12 science education: Practices, crosscutting concepts, and core ideas. Washington, DC: National Academies Press.

National Research Council. (2013). Adapting to a changing world: Challenges and opportunities in undergraduate physics education. Washington, DC: National Academies Press.

National Research Council. (2014). Reaching students: What research says about effective instruction in undergraduate science and engineering. Washington, DC: National Academies Press.

Raudenbush, S.W., Bryk, A.S, \& Congdon, R. (2013). HLM 6.01 for Windows [Computer software]. Skokie, IL: Scientific Software International, Inc.

Sawtelle, V., Brewe, E., Kramer, L. H., Singh, C., Sabella, M., \& Rebello, S. (2010). Positive impacts of Modeling Instruction on self-efficacy. In 2010 Physics Education Research Conference (Vol. 289, pp. 289-292). American Institute of Physics. http://doi.org/10.1063/1.3515225

Scott, J. (1988). Trend report: Social network analysis. Sociology, 22(1), 109127. http://doi.org/10.1177/0038038588022001007

Scott, J. \& Carrington, P.J. (2011). The SAGE handbook of social network analysis. London, England: SAGE 2011. 
Siciliano, M. D. (2016). It's the quality Not the quantity of ties that matter: Social networks and self-efficacy beliefs. American Educational Research Journal, 53(2), 227-262. http://doi.org/10.3102/0002831216629207

Schunk, D. H. (2012). Learning theories: An educational perspective. Boston, MA: Pearson Education.

Tinto, V. (1997). Classrooms as communities: Exploring the educational character of student persistence. The Journal of Higher Education, 68(6), 599-623.

Traxler, A. L. (2015). Community structure in introductory physics course networks. In Churukian, Jones, \& Ding (Eds.), 2015 PERC Proceedings (pp. 331-334). College Park, MD: American Association of Physics Teachers. http://doi.org/10.1119/perc.2015.pr.078

Vygotsky, L. S. (1986). Thought and language (A. Kozulin, Trans.). Cambridge, MA: The Massachusetts Institute of Technology.

Williams, E., Brewe, E., Zwolak, J., \& Dou, R. (2015). Understanding centrality: Investigating student outcomes within a classroom social network. In Proceedings of the 2015 Physics Education Research Conference (pp. 14). College Park, MD.

Yang, Y., Nainabasti, B., Brookes, D. T., \& Brewe, E. (2014). A study of informal learning communities: A tale of two physics courses. In Engelhardt, Churukian, \& Jones (Eds.), 2014 PERC Proceedings (pp. 283-286). Minneapolis, MN: American Association of Physics Teachers. http://doi.org/10.1119/perc.2014.pr.067

Zwolak, J. P., Dou, R., Williams, E. A., \& Brewe, E. (2017). Students' network integration as a predictor of persistence in introductory physics courses. Physical Review Physics Education Research, 13(1), 1-14. http://doi.org/10.1103/PhysRevPhysEducRes.13.010113 


\section{CHAPTER 5 CONCLUSIONS}

\subsection{Summary}

During my first year as a graduate student I extended past results of the work done by the physics education research (PER) group at FIU to show that despite significant differences in students' peer-to-peer connections, both students in lecture-based and active learning physics courses exhibited positive associations between their network centrality and their physics self-efficacy (Dou \& Brewe, 2014). Here commenced my examination of academic interactions that take place in active learning physics courses, and equally important, my understanding of social network analysis (SNA) as a tool to unravel some of the unknowns that exist surrounding peer-to-peer discourse.

The studies presented in this dissertation represent further advancements in our use of SNA in PER. While the techniques may not be new to social network analysts, they are relatively new to education researchers, particularly physics education researchers. Three major statistical applications involving SNA are present in my work: (a) linear regressions, (b) structural equation modeling, and (c) hierarchical linear modeling. Each of these presented challenging methodological obstacles, and forced me to think deeply about the interpretation of the outcomes resulting from the application of SNA. It was important to understand what network measures, like PageRank, mean in a real-world sense; oftentimes I could turn to social network analysts outside of PER to answer these questions, but in some cases I designed unique approaches. 
Given my application of SNA, this dissertation provides a new perspective about student participation in the MI introductory physics classroom. Most salient across the three papers is the prominent role of recognition ${ }^{9}$ from other students-that is to say the perspectives and judgments peers develop toward one another. This finding became evident in a variety of ways: (a) the predictive value of PageRank centrality, (b) the rise and fall in the growth rate of student centrality over the course of a semester, (c) the great amount of variance in student inDegree centrality explained by the perception of any particular student's peers, and (d) analyses showing that students' inDegree at the end of the first semester do not correlate with their inDegree at the start of the second.

To explain the main idea highlighted in the previous paragraph we must keep in mind the predictive power of centrality with regard to student selfefficacy. Overall self-efficacy was not predicted by student inDegree or outDegree. In other words, the number of interactions reported by students (i.e., outDegree) and the number of times students were reported by peers did not improve their confidence in their ability to perform physics related tasks. On the other hand, students who had higher PageRank centrality were more likely to have greater overall self-efficacy at the end of the course, even when controlling for their self-efficacy at the start of the course. A student's PageRank does not increase by reporting more peers, but rather by being reported by peers, and not just any set of peers, but popular peers as defined by the peers' inDegree. When

\footnotetext{
${ }^{9}$ Here I use recognition as the internal judgments people make about the abilities or resourcefulness of those around them, and not necessarily a judgment about the community belongingness or identity of those people.
} 
a student interacts with peers that others find as meaningful resources, particularly when those resourceful peers recognize that student as someone they had meaningful interactions with, both the student's perception of his or her content mastery and his or her overall self-efficacy was more likely to be higher at the end of the semester (see Chapter 2). It may be that mastering content and/or having high self-efficacy makes one more likely to be the subject of someone's meaningful interaction, or vice versa (this research does not answer that question), but getting that attention from others, especially academically popular others, was shown to be positively associated with students' perceptions of their personal abilities. But to get that attention in the first place required being perceived by those academically popular peers as someone who contributed to a meaningful interaction.

I found that MI students did not interact with just the peers in their immediate small group, but reached out to others outside of that group (see Chapter 4). The studies also showed students went about selectively participating in interactions in purposeful ways, since we find that the rate of those interactions is not stable but increases and decreases despite the stability of the curriculum and the learning environment (see Chapter 4). If interaction rate was random at any given moment (i.e., not purposeful) then we would see no particular patterns of growth over the course of a semester. The agency that students have in the classroom to initiate or be a part of these interactions implies that they are thinking about whom they are interacting with. This requires students making judgments about their peers that likely include a perception of 
their academic fortitude, especially in light of the phrasing of the survey question (i.e., "choose from the presented list people from your physics class that you had a meaningful interaction with").

In support of the idea that students' centrality is a factor of the perceptions their peers have of them, we can turn to some of the outcomes of the unconditional HLM models (see Chapter 4). Specifically, the results showed that the variance in student inDegree over time resides primarily (though not exclusively) on student-level factors. This highlights the uneven distribution of inDegree among students in the classroom. This uneven distribution is a result of the perception of the peers that surround students. The reason for this resides in the nature of inDegree as a passive metric - an actor or node is dependent on the behavior of others for their inDegree. On the other hand, the variance in outDegree lies primarily at the student-level, which makes sense given that this active metric depends primarily on the behavior of the student. Recent studies in the Ml environment supports this, showing that a student's outDegree at the end of semester one predicts their outDegree at the beginning of semester two if the student continues with the MI course sequence (Zwolak, Dou, Williams, \& Brewe, 2017). This aligns with outDegree being a metric more closely related with the student. A student's inDegree at the end of semester one does not predict that student's inDegree at the start of semester two, which aligns with inDegree being a metric more dependent on the perception of others ${ }^{10}$ than on the student.

\footnotetext{
10 We could reasonably assume that students at the beginning of a course have not had enough time interacting with one another to make judgments about or develop perceptions of their peers.
} 
In summary, the value of centrality as predicting self-efficacy is only available to those students whose peers recognize as valuable resources. The environment generated by Ml fosters these kinds of judgments by requiring students to present results of work to one another in both small group and large group settings. The exchanges between students before class, after class, and those unrelated to academic content likely serve as additional sources that contribute to the formation of these judgments. To be clear, these are judgments and perceptions formed by peers that may not necessarily align with pragmatic standards. The peer perceived as being an academic resource does not necessarily need to have a passing grade in the class if she or he can create that perception in other ways.

I should note that in the case of physics interest, PageRank centrality offers no direct value (see Chapter 3 ). The development of physics interest over the course of the Ml curriculum relies heavily on students' physics interest at the start of the semester. Students with already high physics interest will leave with high physics interest; the opposite is also true. This interest does not correlate with students' overall PageRank centrality. So, the academic perception that students have of their peers may only matter with regard to specific outcomes, like self-efficacy. Using this lens, it is worth examining additional outcomes. For example, student persistence as defined by passing MI semester one and enrolling in Ml semester two is positively predicted by inDegree and outDegree centrality, as well as "closeness" centrality (Zwolak et al., 2017). Varying 
measures of centrality that encompass different kinds of social interactions may differentially predict student outcomes.

\subsection{Future Directions in Active Learning Frameworks: Learning as Capital}

Early studies examining the Ml introductory physics course used "participationist" frameworks to interpret student behavior and outcomes (e.g., Brewe et al., 2010; Brewe, Kramer, \& O'Brien, 2010), but the works collected in this dissertation point to the need for either a different or expanded framework. The participationist framework worked well in that it aligned with constructivist views of learning - the same views that supported the development of MI (Brewe, 2008; Desbien, 2002). Participationists view people's attitudes about learning as fitting within one of two conceptual models referred to as the "acquisition metaphor" and the "participation metaphor" (Sfard, 1998). The acquisition metaphor encompasses traditional pedagogies of learning that view knowledge as an object that the "knowledge-holder" transfers to recipients as one might transfer a gift to a friend. In this scenario, persons acquire knowledge passively through reading or listening. On the other hand, adherers of the participationist view believe that learning occurs when learners actively participate in authentic practices ${ }^{11}$ that generate knowledge. This often requires interacting with others. Learning then results as an outcome of these interactions, and encompasses not simply the data or bits of information about a particular subject, but also skills in and even dispositions toward a subject matter. This framework has helped us

\footnotetext{
11 It is worth noting that participationists present their framework as a contrast to lecture-based conceptions of learning.
} 
interpret the findings in this dissertation, relating social integration (i.e., centrality) to learning. Yet, this framework fails to capture the cost and value of participation from the perspective of the students, as well as the barriers to participation that exist in the physical and social environment outside of the students' jurisdiction.

Student participation in active learning environments comes at a cost. Carlone's (2004) examination of high school physics students showed that students who held strong beliefs about being perceived as "good students" resisted interactive learning pedagogies. Their discomfort and unfamiliarity with the teaching approaches made them apprehensive, unsure about their ability to maintain their good student identity in an unfamiliar context. Their behavior reflected that. Similar outcomes have been measured in reformed, undergraduate physics courses (Turpen \& Finkelstein, 2010). The examinations of students in Ml described in this document insinuate that the cost may be more extensive than just discomfort. Students leave feeling less confident in their physics skills than they felt when they started the semester (see Chapter 2). They also end the semester less interested in physics overall (see Chapter 3). Both anecdotal and student interview data affirm some students' discomfort with the classroom structure, citing participation in large-group meetings and group examinations as anxiety inducing experiences. The participationist framework falls short of taking into account these costs that students perceive-consciously or unconsciously. Some may want to participate, but do not want to pay the price (e.g., exposing the vulnerabilities of their good student identity to peers, having experiences that make them feel less confident). Others may not recognize the 
advantages of participation (e.g., deeper understanding of the content; Brewe et al., 2010), while others may simply not know how to develop advantageous social networks. These scenarios are neither complete nor exhaustive, but point to the need for a more comprehensive framework that will help researchers make better sense of student participation in active learning courses.

To help bridge this gap, I suggest incorporating the capital theories described by Bourdieu (1986), in particular those of social and cultural capital. Bourdieu describes social capital as a person's ability to mobilize their social network to accomplish particular goals. This requires both a broad, expansive network, but also one whose members have their own forms of capital to help any particular member achieve their ends. Cultural capital takes on many forms and includes the norms, mannerisms, and dispositions of certain social networks that allow one access to those networks. This type of capital also includes objects such as books, instruments, pictures, and other material that grant the holder an advantage over others in a particular context.

Both social and cultural capitals play a role in the MI classroom (see Chapter 4). Because learning is specifically structured so that it occurs primarily through interactions with peers rather than the instructor, then students who have access to larger social networks of peers (i.e., social capital), as well as those whose network of peers includes those who have mastered the norms and mental dispositions required to succeed in the course (i.e., cultural capital), stand at an advantage over those that do not. These advantages help to waylay the costs of participation, and maximize its benefits. While more work needs to be 
done to better integrate these principles of capital theory into our understanding of student participation in active learning courses, some of it has already begun (e.g., Abassi et al., 2014; Siciliano, 2106).

\subsection{Directions for Future Work}

Future studies of active learning curricula should further explore the costs of student participation. One line of research could include deepening our understanding of both the specific contexts that trigger student anxiety and discomfort and the types of students more prone to experience anxiety. For example, Carlone's (2004) work showed that students with growth mindsets were more resilient to changes in the classroom structure and had more positive dispositions toward reformed styles of learning. Recognizing the kinds of students more prone to experience anxiety and resist the curriculum could help researchers find methods to mitigate those emotions and behavior. This might include something as simple as letting students know what they might experience prior to the start of the course, or better framing the role of error-making as the context for learning rather than self-valuing. Similarly, illuminating the structures in $\mathrm{Ml}$ and other active learning courses that cause anxiety would help researchers develop interventions or alternate designs of those activities that would alleviate any negative effects. Other research directions could include testing interventions related to the social structure of the classroom-a kind of social engineering. If we can better help students develop the social capital needed to succeed, we may facilitate participation and positive outcomes. This might involve developing student assessments that aid professors in assigning 
members to different student groups, or creating online tutorials that promote particular norms surrounding classroom socialization.

\subsection{Implications of This Research For the Teaching Enterprise}

The active learning environment encompasses the bulk of recommendations made by experts for the advancement of STEM education at both the K-12 and undergraduate levels (NRC, 2012, 2013). Yet, not all active learning is created equal. Its characteristics play out differently across settings and contexts. For example, a rural middle school in Utah may find its students building aluminum foil boats to better understand the principles of buoyancy, while a high school classroom in Florida might spend part of a month combing through spectrograms for a citizen science project on gravitational waves. The same applies at the university setting. A physics faculty member may ask freshmen to collaborate with neighbors to solve clicker questions, while a biology instructor encourages participation in peer-led learning groups. What these activities have in common, regardless of the grade level, activity, or subject area, is the involvement of students doing something with peers for the purpose of learning. Active learning cannot be defined by a set of curricular structures; it is a philosophy, a mindset, a completely different attitude about how people learnan attitude that places the onus for learning on the learners, as opposed to the teacher. The participationists put it this way:

...learning a subject is now conceived of as a process of becoming a member of a certain community. This entails, above all, the ability to communicate in the language of this community and act according to its 
particular norms. The norms themselves are to be negotiated in the process of consolidating the community. While the learners are newcomers and potential reformers of the practice, the teachers are the preservers of its continuity. From a lone entrepreneur, the learner turns into an integral part of a team. (Sfard, 1998, p. 6)

With this approach to learning in mind, a whole new set of issues arises. Rather than having to worry about keeping a lecture interesting so students remain awake, or remembering to repeat facts several times to help students memorize them, teachers must now keep in mind the stumbling blocks of active learning. The work represented in this document highlights some. Teachers should understand that participation in active learning requires students to make themselves vulnerable to the judgments of others, as well as requires them to seek out resourceful individuals that could help them make progress in the course. Those who struggle with those activities will find themselves struggling to learn, potentially feeling less confident in their abilities, and losing interest in the subject matter.

Teachers can battle these costs. As the facilitators of learning, as well as the shepherds of cultural capital, setting the norms by which success gets measured, educators could alleviate the anxiety or social pressures that come with participating in active learning. They can help students preempt the negative feelings they may experience; they can encourage students to welcome and initiate interactions in a non-threatening manner; they can define the rules of the classroom, which include how success will measured. What I believe is of great 
consequence, teachers can set the assessments by which students judge their progress and the progress of their peers. Assessments should align with the goals and intent of the curriculum. If assessment is about learning and not about memorizing facts within a certain period of time, then students should be allowed to resubmit work for reevaluation, for example. This will encourage students to take more social and academic risks that can lead to meaningful learning (Gee, 2003).

So much about the costs and benefits of active learning requires deeper understanding through additional research, but in short, educators should keep in mind that no approach exists without pitfalls. Active learning is not a panacea. The students themselves bring personalities and experiences that contribute to the learning environment in ways that teachers could not plan for. Indeed, the factors that make a great learning experience extend beyond simply offering students active learning activities.

\subsection{Final Remarks: Focusing on Active Learning Environments}

When presenting at conferences, getting feedback from reviewers, or speaking to other science education researchers about my work, I often get asked the same question: how do your results look compared to students in lecture-based physics classrooms? The reasons why people ask me this question hearken back to decades of school tradition and learning research. For a long time now education researchers have fought a battle against the popular behaviorist pedagogies of the past, promoting repetition, reinforcement, punishment, and recall through rote memorization (Schunk, 2012; Skinner, 
1950). Of course, other, more experiential learning strategies existed and were made popular by people like John Dewey and his proponents, but the Industrial Revolution and the culture of mass production that took hold of developed countries in the early $20^{\text {th }}$ century found its way into our schools (National Research Council [NRC], 2000). We believed that students were made up of raw materials, which given the right set of stimuli could produce armies of educated young people. And what better way to create this army of knowledgeable individuals than by pouring knowledge directly into their minds? Lecture-based teaching soon beat out the competition as the most efficient tool to transfer information from the minds of the experts to the students. We could pack auditoriums full of hundreds of students at a time, tell them all we want them to know, and they will leave knowing those things. Unfortunately, that did not play out well for most students.

The latter half of the $20^{\text {th }}$ century exponentially expanded our understanding of the mind. Piaget, Vygotsky, Bruner, Papert, and a myriad of other learning researchers made tremendous headway, revealing the intricacies of cognitive development. Yet, by this time, the machine of education had made a practically indelible mark. The fight against the behavioral tradition of education and the pragmatism of lecture-not to mention its cheap cost and low amount of effort required on the part of the expert—would not be easily won. Fortunately, for those of us in the United States entrenched in science, Russia beat our country to space with the launch of Sputnik. This put our nation on alert, pushing us to get the "best" children through careers in science, math, and engineering. 
With the advent of the National Defense Education Act of 1958, federal funding found its way into the hands of science education researchers, while at the same time psychologists were figuring out how people learn. Through a long, slow process, these events led some in our country to recognize that if we want to remain economically and technologically competitive as a nation, we cannot just push the "best" students into engineering and science careers; we need to prepare "all" students, and inspire as many as possible to pursue these fields. To do so would require moving beyond the traditional methods we used in classrooms, and offer students authentic, sociocultural, context-situated, active learning experiences (National Commission on Excellence in Education, 1983; NRC, 2000, 2010, 2011, 2012, 2013; PCAST, 2010).

Loosening the historical grip of the lecture-based teaching culture required researchers to compare active learning strategies to lecture-based approaches. Time and time again, active learning, even when broadly defined, beat out lecture-based learning on a myriad of outcomes. To list these studies would be futile, as there are literally hundreds, but many of them are referenced in the National Research Council reports cited here. For me, what put the final nail in the coffin, particularly in the realm of science, technology, engineering, and mathematics (STEM) education was Freeman et al.'s (2014) paper, which appeared in the Proceedings of the National Academy of Sciences. This metaanalysis of 225 studies clearly demonstrated that students taught using active learning strategies (e.g., group problem-solving, tutorials, clicker questions, studio course designs) outperformed students in equivalent lecture-based 
courses on concept inventories and exams. The authors concluded with a provocative remark:

If the experiments analyzed here had been conducted as randomized controlled trials of medical interventions, they may have been stopped for benefit-meaning that enrolling patients in the control condition might be discontinued because the treatment being tested was clearly more beneficial. (p. 8413)

Around the time of the publication of Freeman et al.'s (2014) paper, I was halfway through my first year of graduate school and solidifying my dissertation research direction. I made a conscious decision then to study the active learning environment sans any comparisons to lecture. In my mind, comparing active learning to lecture was akin to comparing the benefits of being vaccinated over not being vaccinated. There was no need for me to restate what hundreds of others had already made clear. Instead, it became my goal to further examine active learning in and of itself, which brings us back to the earlier question. I never purposed to compare the Modeling Instruction (MI) physics curriculum to lectured-based instruction. As mentioned in Chapter 4, some may be tempted to do this, especially in light of some of the less than positive findings, such as students' drop in physics interest and self-efficacy (see Chapters $2 \& 3$ ). Some may even suggest I should say something like, "Even though students are less interested in physics at the end of this active learning course, they are much less interested in physics at the end of a lecture-based course." But this mentality keeps us in the past. Of course active learning courses have tremendous 
advantages over traditional courses. What we need to do now is explore these new methods of teaching and learning, find their strengths and weaknesses, and continually improve them by helping educators, administrators, and policymakers adopt new mindsets about how people learn.

The three studies in this dissertation contribute to our advancements in science course development by exposing the social curriculum of classroom. Indeed, active learning environments tend to foster students interactions. The interactions are often structured in a way that will help students learn, and while research does show that students' academic performance increases as a result of these pedagogies, other outcomes may suffer (e.g., self-efficacy). In light of the findings in this volume, educators and administrators should think more purposefully about the social environment generated by these more progressive pedagogies and its effects on students (i.e., the social curriculum). We should not take for granted the norms students set with regard to their interactions, but rather scaffold these so as to maximize positive outcomes for all.

References (Chapter 5)

Abbasi, A., Wigand, R. T., \& Hossain, L. (2014). Measuring social capital through network analysis and its influence on individual performance. Library \& Information Science Research, 36(1), 66-73. http://doi.org/10.1016/j.lisr.2013.08.001

Bourdieu, P. (1986). The forms of capital. In J. Richardson (Ed.), Handbook of Research for the Sociology of Education (pp. 241-258). Wesport, CT: Greenwood. http://doi.org/10.1002/9780470755679.ch15

Brewe, E. (2008). Modeling theory applied: Modeling Instruction in introductory physics. American Journal of Physics, 76(12), 1155. http://doi.org/10.1119/1.2983148 
Brewe, E., Kramer, L. H., \& O’Brien, G. E. (2010). Changing participation through formation of student learning communities. AIP Conference Proceedings, 1289, 85-88. http://doi.org/10.1063/1.3515255

Brewe, E., Sawtelle, V., Kramer, L. H., O’Brien, G. E., Rodriguez, I., \& Pamel??, P. (2010). Toward equity through participation in Modeling Instruction in introductory university physics. Physical Review Special Topics - Physics Education Research, 6(1), 1-12. http://doi.org/10.1103/PhysRevSTPER.6.010106

Carlone, H. B. (2004). The cultural production of science in reform-based physics: Girls' access, participation, and resistance. Journal of Research in Science Teaching, 41(4), 392-414. http://doi.org/10.1002/tea.20006

Desbien, D. (2002). Modeling discourse management compared to other classroom management styles in university physics. Ph.D. dissertation, Arizona State University.

Dou, R., \& Brewe, E. (2014). Network centrality and student self-efficacy in an interactive introductory physics environment. In P. V. Engelhardt, A. D. Churukian, \& D. J. Jones. (Eds.), 2014 PERC Proceedings (pp. 67-70). Minneapolis, MN. http://doi.org/10.1119/perc.2014.pr.013

Freeman, S., Eddy, S. L., McDonough, M., Smith, M. K., Okoroafor, N., Jordt, H., \& Wenderoth, M. P. (2014). Active learning increases student performance in science, engineering, and mathematics. Proceedings of the National Academy of Sciences of the United States of America, 111(23), 8410-5. http://doi.org/10.1073/pnas.1319030111

Gee, J. P. (2003). What video games have to teach us about learning and literacy. New York, NY: Palgrave/MacMillan.

National Commission on Excellence in Education. (1983, April). A nation at risk: The imperative for educational reform. Washington, DC: U.S. Department of Education.

National Research Council. (2000). How people learn: Brain, mind, experience, and school: Expanded Edition. Washington, DC: The National Academies Press.

National Research Council. (2010). Rising above the gathering storm, revisited: Rapidly approaching category 5. Washington, DC. Retrieved from http://www.nap.edu/catalog.php?record_id=12999 
National Research Council. (2011). Expanding underrepresented minority Participation: America's science and technology talent at the crossroads. Washington, DC.

National Research Council. (2012). A framework for K-12 science education: Practices, crosscutting concepts, and core ideas. Washington, DC.

National Research Council. (2013). Adapting to a changing world: Challenges and opportunities in undergraduate physics education. Washington, DC: National Academies Press.

President's Council of Advisors on Science and Technology. (2010). Prepare and Inspire: K-12 Education in Science, Technology, Engineering, and Math (STEM) for America's Future: Executive Report. Washington, DC.

Schunk, D.H. (2012). Learning theories: An educational perspective. Boston, MA: Pearson Education.

Sfard, A. (1998). On two metaphors for learning and the dangers of choosing just one. Educational Researcher, 27(2), 4-13.

Siciliano, M. D. (2016). It's the quality not the quantity of ties that matter: Social networks and self-efficacy beliefs. American Educational Research Journal, 53(2), 227-262. http://doi.org/10.3102/0002831216629207

Skinner, B.F. 1950. Are theories of learning necessary? Psychological Review 57:193-216.

Turpen, C., \& Finkelstein, N. D. (2010). The construction of different classroom norms during Peer Instruction: Students perceive differences. Physical Review Physics Education Research, 6, 020123:1-22. http://doi.org/10.1103/PhysRevSTPER.6.020123

Zwolak, J. P., Dou, R., Williams, E. A., \& Brewe, E. (2017). Students' network integration as a predictor of persistence in introductory physics courses. Physical Review Physics Education Research, 13(1), 1-14. 
VITA

REMY DOU

Born, Havana, Cuba

B.S., Biological Sciences

Florida International

University

$2005-2011$

Science Department

Director, Miami Christian

School, Miami, Florida

$2011-2013$

Albert Einstein

Distinguished Educator

Fellow, National Science

Foundation, Arlington,

Virginia

$2013-2016$

Graduate Assistant,

Florida International

University, Miami, Florida

Postdoctoral Research

Associate, Department of

Physics, University of

Maryland, College Park

\section{PUBLICATIONS AND PRESENTATIONS}

Dou, R., Brewe, E., Potvin, G., Zwolak, J.P., \& Hazari, Z. (Under review). The risks we take: Understanding the development of interest, self-efficacy, and student networks in reformed undergraduate physics courses. Journal of Research in Science Teaching.

Zwolak, J. P., Dou, R., Williams, E. A., \& Brewe, E. (2017). Students' network integration as a predictor of persistence in introductory physics courses.

Physical Review Physics Education Research, 13(1), 1-14.

http://doi.org/10.1103/PhysRevPhysEducRes.13.010113 
Dou, R., Brewe, E., Zwolak, J. P., Potvin, G., Williams, E. A., \& Kramer, L. H. (2016). Beyond performance metrics: Examining a decrease in students' physics self-efficacy through a social networks lens. Physical Review Physics Education Research, 12(2), 020124.

http://doi.org/10.1103/PhysRevPhysEducRes.12.020124

Dou, R. (2016). Traversing STEM: Creating pathways for social justice in the United States. In 2016 SFERC: Fifteenth Annual South Florida Education Research Conference (pp. 30-38). Miami, Florida: Florida International University.

Dou, R., \& Brewe, E. (2014). Network centrality and student self-efficacy in an interactive introductory physics environment. In P. V. Engelhardt, A. D. Churukian, \& D. J. Jones. (Eds.), 2014 PERC Proceedings (pp. 67-70). Minneapolis, MN. doi:10.1119/perc.2014.pr.013

Dou, R. \& Gibbs, K. (2013). Engaging all students in the pursuit of STEM careers. School Science Review, 95(351), 106-112.

Dou, R. (August, 2013). Change is coming: the impact of the next generation science standards. SEEN Magazine. (15.2). Retrieved from http://www.seenmagazine.us/articles/article-detail/articleid/3258/change-iscoming-the-impact-of-the-next-generation-science-standards.aspx

Dou, R., Hogan, D., Kossover, M., Spuck, T., \& Young, S. (August 2013). Defusing Diffusion. The American Biology Teacher, 75(6), 391-395.

Dabney, K. P., Johnson, T. N., Hazari, Z., Dou, R., Sonnert, G., \& Sadler, P.M. (April, 2017). Elementary, Middle, and High School Out-of-School Time Science Experiences and STEM Career Interest. Paper presented at the 2017 Annual American Educational Research Association, San Antonio, TX.

Dou, R. (February, 2017). The Risks We Take, Poster presented at the 2017 American Association for the Advancement of Science Annual Conference, Boston, MA.

R. Dou. (April 16, 2016). Beyond Performance Metrics. Paper presented at the National Association for Research in Science Teaching, Baltimore Annual Conference, MD.

R. Dou. (February 13, 2016). Beyond Performance Metrics. Poster presented at the American Association for the Advancement of Science Annual Conference, Washington, DC. 